$$
\text { UNIVERSIDADE DE SÃO PAULO }
$$

HOSPITAL DE REABILITAÇÃO DE ANOMALIAS CRANIOFACIAIS

\title{
DIMENSÕES INTERNAS NASAIS DE ADULTOS COM OBSTRUÇÃO NASAL AVALIADAS POR RINOMETRIA ACÚSTICA
}

PRISCILA CAPELATO PRADO

Dissertação apresentada ao Hospital de Reabilitação de Anomalias Craniofaciais da Universidade de São Paulo para obtenção do título de MESTRE em Ciências da Reabilitação.

Área de concentração: Fissuras Orofaciais e Anomalias Relacionadas. 



$$
\text { UNIVERSIDADE DE SÃO PAULO }
$$

HOSPITAL DE REABILITAÇÃO DE ANOMALIAS CRANIOFACIAIS

\title{
DIMENSÕES INTERNAS NASAIS DE ADULTOS COM OBSTRUÇÃO NASAL AVALIADAS POR RINOMETRIA ACÚSTICA
}

\author{
PRISCILA CAPELATO PRADO
}

Orientadora: Prof $^{\mathrm{a}}{ }^{\mathrm{Dr}} \stackrel{\mathrm{a}}{ }$ Inge Elly Kiemle Trindade

Dissertação apresentada ao Hospital de Reabilitação de Anomalias Craniofaciais da Universidade de São Paulo para obtenção do título de MESTRE em Ciências da Reabilitação.

Área de concentração: Fissuras Orofaciais e Anomalias Relacionadas.

BAURU 
Rua Sílvio Marchione, 3-20

Caixa Postal: 1501

17012-9000 Bauru/SP - Brasil

(14) $3235-8000$

Prof $\stackrel{\text { a }}{\text {. Dr }}{ }^{\mathrm{a}}$. Suely Vilela - Reitora da USP

Prof. Dr. José Alberto de Souza Freitas - Superintendente do HRAC-USP

Autorizo, exclusivamente para fins acadêmicos e científicos, a reprodução total ou parcial deste trabalho.

$\overline{\text { PRISCILA CAPELATO PRADO }}$

Bauru, 16 de fevereiro de 2009

Prado, Priscila Capelato.
P882d Dimensões internas nasais de adultos com obstrução nasal avaliadas por rinometria acústica / Priscila Capelato Prado. Bauru, 2009. 101p.; il.; $30 \mathrm{~cm}$.

Dissertação (Mestrado - Área de Concentração: Fissuras Orofaciais e Anomalias relacionadas) - HRAC-USP

Orientador: Prof $\stackrel{\text { a }}{\text { Dra }}$. Inge Elly Kiemle Trindade

1. Cavidade nasal. 2. Obstrução nasal. 3. Septo nasal. 4. Turbinados 5. Rinometria acústica. 


\section{FOLHA DE APROVAÇÃO}

\section{Dissertação apresentada e defendida por \\ Priscila Capelato Prado}

e aprovada pela Comissão Julgadora em

Prof.(a) Dr.(a):

Instituição:

Prof.(a) Dr.(a):

Instituição:

Prof.(a) Dr.(a):

Instituição (Orientador):

Profa. Dra.: Inge Elly Kiemle Trindade

Presidente da Comissão de Pós-Graduação do HRAC-USP

Data do depósito da dissertação junto à CPG: 



\section{Priscila Capelato Prado}

12 de setembro de 1982

Pirajuí - SP

$2000-2003$

2002-2003

2004 até o presente

2004-2006

2006 até o presente
Nascimento

Graduação em Enfermagem e

Obstetrícia - Universidade do Sagrado

Coração (USC)

Curso de Licenciatura - Universidade do Sagrado Coração (USC)

Enfermeira da Unidade de Terapia Intensiva Adultos (UTI) do Hospital

Estadual Bauru

Especialização em Enfermagem em Terapia Intensiva (UTI) - Faculdade de Medicina de São José do Rio Preto (FAMERP)

Curso de Mestrado em Ciências da Reabilitação, Área de Concentração: Fissuras Orofaciais e Anomalias Relacionadas, Hospital de Reabilitação de Anomalias Craniofaciais (HRAC) USP 

Agradeço

A Deus, por todas as oportunidades, por ser a luz que ilumina o meu caminho, refúgio nos momentos difíceis e fonte de renovação para seguir em frente.

Ao meu querido pai Sérgio, pela minha vida, amor, dedicação contínua, nunca medindo esforços para nada.

À minha querida mãe Aparecida, mulher determinada e incansável, sempre me mostrando que a vida caminha por trilhos estreitos, mas que podemos chegar a qualquer lugar e que sabiamente me ensinou:

"O homem que decide parar até que as coisas melhorem, verificará, mais tarde, que aquele que não parou e colaborou com o tempo estará tão adiante, que jamais poderá ser alcançado"

A doce lembrança dos meus avós paternos Benedito e Palmira e avós maternos Liberato e Carmen. 

À minha orientadora

Profa. Dra. Inge Elly Kiemle Trindade

Pelo exemplo de sabedoria, profissionalismo e postura criteriosa na condução deste trabalho científico. Agradeço infinitamente por sua paciência, por seus ensinamentos, que foram presentes, que tive o privilégio de receber e por conduzir este estudo com tanta sabedoria.

Meu eterno agradecimento e profunda admiração. 

Agradeço ainda:

Ao Hospital de Reabilitação de Anomalias Craniofaciais, da Universidade de São Paulo, na pessoa de seu Superintendente Profo. Dro. José Aberto de Souza Freitas.

Ao Hospital Estadual Bauru, por ter permitido a realização desta pesquisa.

À Comissão de Pós-Graduação do HRAC, na pessoa de sua presidente Profa. . Dra . Inge Elly Kiemle Trindade.

Aos pacientes que participaram deste estudo colaborando na realização dos exames, e, também.

Aos médicos otorrinolaringologistas Dr. Sergio Henrique e Dr Norimar por terem colaborado na seleção e avaliação clínica dos pacientes.

À enfermeira Profª Dra.. Maria Justina D. B. Felippe, pelo grande incentivo.

À enfermeira e gerente Valéria Cavallieri, pela oportunidade concedida para realizar este estudo.

À Dra Ana Claudia Martins Sampaio Teixeira cuja amizade, dedicação, incentivo, partilha e orientação foram fundamentais para a conclusão deste trabalho.

Às profissionais do Laboratório de Fisiologia Drá. Renata Yamashita e Drª. Ana Paula Fukushiro pelo incentivo e contribuições.

Aos enfermeiros Cláudio e Marcela pela amizade e colaboração nas realizações dos plantões.

Às amigas pós-graduandas Bruna Araújo, Daniela Barbosa e doutoras Adriana Gomes e Trixy Niemeyer que compartilharam conversas, anseios, alegrias e que contribuíram para realização desta pesquisa. 

Às amigas Ariane, Andria, Nathaly e Márcia pela amizade e incentivo a esta pesquisa, pois "os verdadeiros amigos são a família que nos foi permitido escolher".

Ao Marcel Taga, pela colaboração no tratamento estatístico dos dados.

À Secretaria do Programa de Pós-Graduação do HRAC-USP, nas pessoas de Andréia, Maria José (Zezé) e Rogério, pelo apoio em todos os momentos em que tive dúvidas. Muito obrigado pelo carinho que vocês tem por nós.

Aos funcionários da UTI-Adultos que trabalham comigo no plantão noturno, pelo carinho e incentivo.

A todos que, direta ou indiretamente, contribuíram para a realização desta pesquisa. 

"A coisa mais feliz a se fazer é ser útil aos demais, tentando ultrapassar o maior obstáculo que é o medo,

ocupando-se da distração mais bela que é o trabalho,

seguindo pelo caminho mais rápido que é o correto,

para no final ter a maior satisfação, a de dever cumprido." 



\section{RESUMO}

Prado PC. Dimensões internas nasais de adultos com obstrução nasal avaliadas por rinometria acústica. [Dissertação]. Bauru: Hospital de Reabilitação de Anomalias Craniofaciais, Universidade de São Paulo; 2009.

Objetivo: Caracterizar a geometria nasal de adultos com obstrução nasal (ON) decorrente de desvio septal (DS) e/ou hipertrofia de conchas (HC) pela análise de áreas seccionais e volumes de segmentos específicos da cavidade nasal por rinometria acústica.

Modelo: Estudo prospectivo.

Local de Execução: Laboratório de Fisiologia, HRAC-USP e Ambulatório de Otorrinolaringologia, Hospital Estadual Bauru.

Participantes: Trinta pacientes com queixa de ON, de ambos os sexos, idade entre 18-40 anos, apresentando DS+HC ( $n=24)$, DS $(n=5)$ ou HC $(n=1)$ ao exame clínico.

Variáveis: Foram avaliadas as áreas seccionais correspondentes às três primeiras deflexões do rinograma $\left(\mathrm{AST}_{1}, \mathrm{AST}_{2}, \mathrm{AST}_{3}\right.$ ), suas respectivas distâncias em relação às narinas $\left(\mathrm{dAST}_{1}, \mathrm{dAST}_{2}, \mathrm{dAST}_{3}\right)$ e os volumes nos segmentos correspondentes a $1,0-3,2 \mathrm{~cm}\left(\mathrm{~V}_{1}\right), 3,3-6,4 \mathrm{~cm}\left(\mathrm{~V}_{2}\right)$ e $7,0-12,0 \mathrm{~cm}\left(\mathrm{~V}_{3}\right)$, antes e após a descongestão nasal (DN), utilizando um Rinômetro Acústico Eccovision. Para fins de análise, calculou-se a soma dos valores das cavidades direita e esquerda.

Resultados: Antes da DN, os valores médios $( \pm D P)$ corresponderam a $0,83 \pm 0,23 \mathrm{~cm}^{2}\left(\mathrm{AST}_{1}\right), \quad 1,66 \pm 0,52 \mathrm{~cm}^{2}\left(\mathrm{AST}_{2}\right), \quad 2,36 \pm 0,77 \mathrm{~cm}^{2}\left(\mathrm{AST}_{3}\right), \quad 2,19 \pm 0,20 \mathrm{~cm}$ $\left(\mathrm{dAST}_{1}\right), \quad 4,01 \pm 0,33 \mathrm{~cm}\left(\mathrm{dAST}_{2}\right), \quad 5,85 \pm 0,37 \mathrm{~cm}\left(\mathrm{dAST}_{3}\right), \quad 2,77 \pm 0,51 \mathrm{~cm}^{3}\left(\mathrm{~V}_{1}\right)$, $6,52 \pm 1,99 \mathrm{~cm}^{3}\left(V_{2}\right), \quad 26,00 \pm 9,62 \mathrm{~cm}^{3}\left(V_{3}\right)$. Esses valores foram significantemente menores $(p<0,05)$ que os definidos para adultos sem $O N$ no mesmo laboratório. A DN causou aumentos proporcionalmente maiores de AST e $V$ no grupo com ON, sugerindo a participação de componente funcional. Foram observados 12 casos com resultados normais, apesar da presença de DS e/ou HC.

Conclusão: Os resultados obtidos demonstraram, na maioria dos pacientes analisados, significativo comprometimento da patência nasal associado à ON decorrente de alterações estruturais.

Descritores: cavidade nasal, obstrução nasal, septo nasal, turbinados, rinometria acústica. 



\begin{abstract}
Prado PC. Internal nasal dimensions of adults with nasal obstruction assessed by acoustic rhinometry. [Dissertation]. Bauru: Hospital de Reabilitação de Anomalias Craniofaciais, Universidade de São Paulo; 2009.
\end{abstract}

Objective: To characterize the nasal geometry of adults with nasal obstruction due to septal deviation and/or turbinate hypertrophy by analyzing sectional areas and volumes of specific segments of the nasal cavity by means of acoustic rhinometry.

Design: Prospective study.

Setting: Laboratory of Physiology, HRAC-USP and Otorhinolaryngology Clinics, Hospital Estadual Bauru.

Participants: Thirty patients with nasal obstruction complaints, of both sexes, aged 18 to 40 years, presenting septal deviation+turbinate hypertrophy $(n=24)$, septal deviation only $(n=5)$ or turbinate hypertrophy only $(n=1)$ on clinical examination.

Main Outcome Measures: Sectional areas measured at the three main deflections of the rhinogram $\left(\mathrm{CSA}_{1}, \mathrm{CSA}_{2}, \mathrm{CSA}_{3}\right)$, their respective distances from the nostrils $\left(\mathrm{dCSA}_{1}, \mathrm{dCSA} \mathrm{A}_{2}, \mathrm{dCSA} \mathrm{A}_{3}\right)$ and volumes at the 1.0-3.2cm $\left(\mathrm{V}_{1}\right), 3.3-6.4 \mathrm{~cm}\left(\mathrm{~V}_{2}\right)$ and 7.0$12.0 \mathrm{~cm}\left(\mathrm{~V}_{3}\right)$ segments were evaluated, before and after nasal decongestion, by means of an Eccovision Acoustic Rhinometer. For analysis, the values from the right and left cavities were added.

Results: Before nasal decongestion, mean values $( \pm S D)$ obtained corresponded to $0.83 \pm 0.23 \mathrm{~cm}^{2}\left(\mathrm{CSA}_{1}\right), \quad 1.66 \pm 0.52 \mathrm{~cm}^{2}\left(\mathrm{CSA}_{2}\right), \quad 2.36 \pm 0.77 \mathrm{~cm}^{2}\left(\mathrm{CSA}_{3}\right), \quad 2.19 \pm 0.20 \mathrm{~cm}$ $\left(\mathrm{dCSA}_{1}\right), \quad 4.01 \pm 0.33 \mathrm{~cm}\left(\mathrm{dCSA}_{2}\right), \quad 5.85 \pm 0.37 \mathrm{~cm}\left(\mathrm{dCSA}_{3}\right), \quad 2.77 \pm 0.51 \mathrm{~cm}^{3}\left(\mathrm{~V}_{1}\right)$, $6.52 \pm 1.99 \mathrm{~cm}^{3}\left(\mathrm{~V}_{2}\right), \quad 26.00 \pm 9.62 \mathrm{~cm}^{3}\left(\mathrm{~V}_{3}\right)$. These values were significantly lower $(\mathrm{p}<0.05)$ than those set for adults without obstruction at the same laboratory. Decongestion caused CSA and V increases proportionally higher in the group with nasal obstruction, suggesting the involvement of a functional component. Twelve cases presented normal results, despite the presence of septal deviation and/or turbinate hypertrophy.

Conclusion: The results showed, in most patients analyzed, significant impairment of nasal patency associated with nasal obstruction due to structural defects.

Key words: nasal cavity, nasal obstruction, nasal septum, nasal turbinates, acoustic rhinometry 



\section{LISTA DE FIGURAS}

Figura 1 - Rinometria acústica: representação esquemática da instrumentação para a medida das dimensões internas da cavidade nasal (adaptado de Roithman e Cole 1995)

Figura 2 - Rinômetro Acústico Eccovision (HOOD Laboratories)

Figura 3 - Rinograma típico de um indivíduo sem obstrução nasal. No eixo $Y$ são representadas as áreas seccionais nasais $\left(\mathrm{em} \mathrm{cm}^{2}\right)$ e no eixo $\mathrm{X}$ as distâncias $(\mathrm{em} \mathrm{cm})$ relativamente às narinas $(0.0 \mathrm{~cm}) \ldots$

Figura 4- Rinograma típico de um paciente com obstrução nasal, mostrando os locais de medida (destacados com triângulos invertidos) das áreas de secção transversa (AST) e suas respectivas distâncias com relação às narinas (dAST), em pontos correspondentes à válvula nasal $\left(\mathrm{AST}_{1}, \mathrm{dAST}_{1}\right)$, à extremidade anterior da concha nasal inferior e/ou média $\left(\mathrm{AST}_{2}\right.$, $\mathrm{dAST}_{2}$ ) e à extremidade médio-posterior da concha nasal média $\left(\mathrm{AST}_{3}, \mathrm{dAST}_{3}\right)$

Figura 5- Rinograma típico de um paciente com obstrução nasal, mostrando os volumes nasais medidos em segmentos correspondentes à região da válvula nasal $\left(\mathrm{V}_{1}\right)$, conchas nasais $\left(\mathrm{V}_{2}\right)$ e nasofaringe $\left(\mathrm{V}_{3}\right)$ 



\section{LISTA DE QUADROS}

Quadro 1 - Valores das áreas seccionais nasais (AST), expressos em $\mathrm{cm}^{2}$, em adultos com obstrução nasal, decorrente de obstrução nasal crônica (ONC), desvio septal (DS) e/ou hipertrofia de conchas $(\mathrm{HC})$, antes e após descongestão nasal, por aplicação tópica de vasoconstritor (VC), relatados na literatura.

Quadro 2 - Valores das distâncias das áreas seccionais nasais (dAST), em relação às narinas, expressos em $\mathrm{cm}$, em adultos com obstrução nasal, decorrente de obstrução nasal crônica (ONC), desvio septal (DS) e/ou hipertrofia de conchas (HC), antes e após a descongestão nasal, por aplicação tópica de vasoconstritor (VC), relatados na literatura...............................

Quadro 3 - Valores dos volumes nasais (V), expressos em $\mathrm{cm}^{3}$, em adultos com obstrução nasal, decorrente de obstrução nasal crônica (ONC), desvio septal (DS) e/ou hipertrofia de conchas $(\mathrm{HC})$, antes e após a descongestão nasal, por aplicação tópica de vasoconstritor $(\mathrm{VC})$, relatados na literatura................. 



\section{LISTA DE TABELAS}

Tabela 1 - Valores médios ( \pm desvio padrão) das áreas de secção transversa da cavidade nasal $\left(\mathrm{AST}_{1}, \mathrm{AST}_{2}\right.$ e $\left.\mathrm{AST}_{3}\right)$ de adultos com obstrução nasal, aferidas por rinometria acústica, dos lados direito (LD) e esquerdo (LE), antes (SVC) e após (CVC) a descongestão nasal......................................................................

Tabela 2 - Valores médios ( \pm desvio padrão) das distâncias (d) correspondentes a $\mathrm{AST}_{1}, \mathrm{AST}_{2}$ e $\mathrm{AST}_{3}$, da cavidade nasal de adultos com obstrução nasal, aferidas por rinometria acústica, dos lados direito (LD) e esquerdo (LE), antes (SVC) e após (CVC) a descongestão nasal.

Tabela 3 - Valores médios ( \pm desvio padrão) dos volumes da cavidade nasal $\left(V_{1}, V_{2}\right.$ e $\left.V_{3}\right)$ de adultos com obstrução nasal, aferidas por rinometria acústica, dos lados direito (LD) e esquerdo (LE), antes (SVC) e após (CVC) a descongestão nasal.

Tabela 4 - Comparação entre as áreas seccionais nasais $\left(\mathrm{AST}_{1}, \mathrm{AST}_{2} \mathrm{e}\right.$ $\mathrm{AST}_{3}$ ) de adultos sem evidências de obstrução nasal (GC) analisados por Gomes (2004) e dos adultos com obstrução nasal (GON) analisados no presente estudo, aferidas por rinometria acústica, antes (SVC) e após (CVC) a descongestão nasal. Os dados mostrados representam a média da soma das áreas observadas do lado direito e esquerdo (SLDE).

Tabela 5 - Comparação entre as distâncias das três áreas seccionais nasais analisadas, relativamente às narinas $\left(\mathrm{dAST}_{1}, \mathrm{dAST}_{2} \mathrm{e}\right.$ $\mathrm{dAST}_{3}$ ), de adultos sem evidências de obstrução nasal (GC) analisados por Gomes (2004) e Camargo (2008) e dos adultos com obstrução nasal (GON) analisados no presente estudo, aferidas por rinometria acústica, antes (SVC) e após (CVC) a descongestão nasal. Os dados mostrados representam a média dos valores resultantes do cálculo da média das distâncias obtidas do lado direito e esquerdo (MLDE). 
Tabela 6 - Comparação entre os volumes nasais $\left(V_{1}, V_{2}\right.$ e $\left.V_{3}\right)$ de adultos sem evidências de obstrução nasal (GC), analisados por Gomes (2004) e dos adultos com obstrução nasal (GON) analisados no presente estudo, aferidos por rinometria acústica, antes (SVC) e após (SVC) a descongestão nasal. Os dados mostrados representam a média da soma dos volumes nasais observadas do lado direito e esquerdo (SLDE)................

Tabela 7 - Comparação entre as áreas seccionais nasais $\left(\mathrm{AST}_{1}, \mathrm{AST}_{2} \mathrm{e}\right.$ $\mathrm{AST}_{3}$ ) de adultos sem evidências de obstrução nasal (GC) analisados por Gomes (2004) e dos sub-grupos de adultos com obstrução nasal (GON) e AST normais e subnormais, analisados no presente estudo, aferidas por rinometria acústica, antes (SVC) e após (CVC) a descongestão nasal. Os dados mostrados representam a média da soma das áreas observadas do lado direito e esquerdo (SLDE)......................... 78 


\section{SUMÁRIO}

1 INTRODUÇÃO

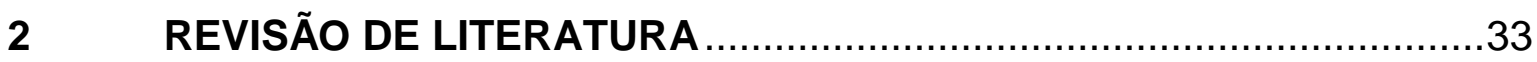

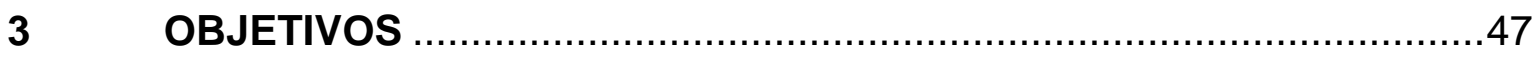

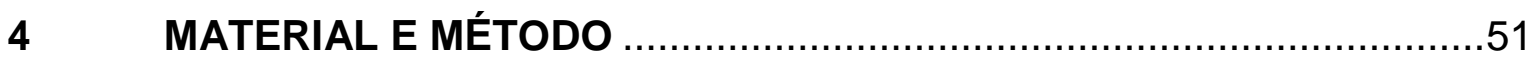

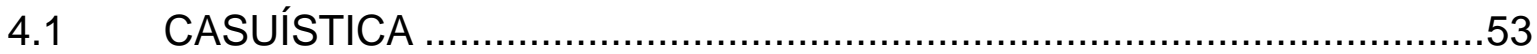

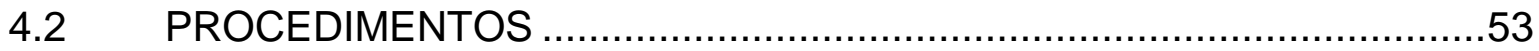

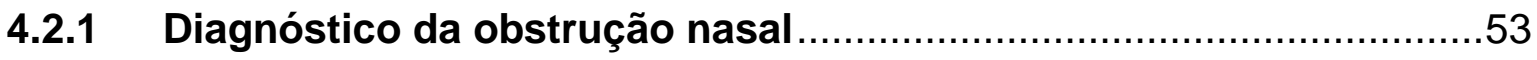

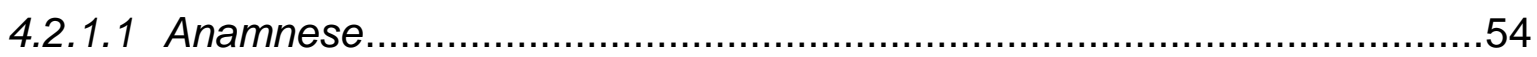

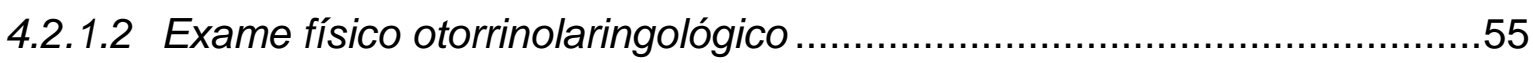

4.2.2 Avaliação das dimensões internas nasais por rinometria acústica..55

4.2.2.1 Equipamento e princípio da técnica ...................................................56

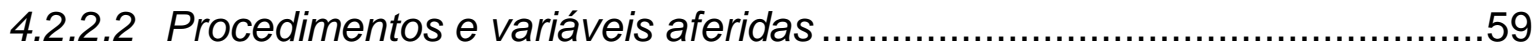

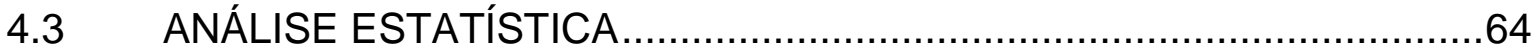

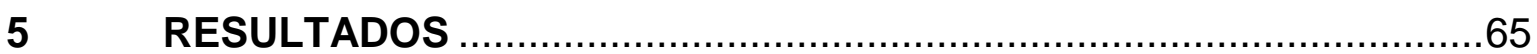

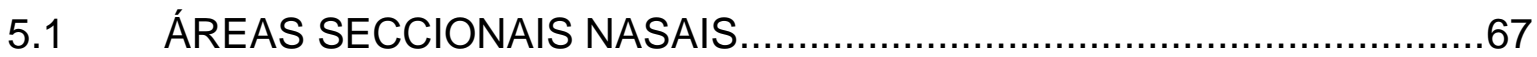

5.2 DISTÂNCIAS DAS REGIÕES ESTUDADAS RELATIVAMENTE ÀS NARINAS.. 69

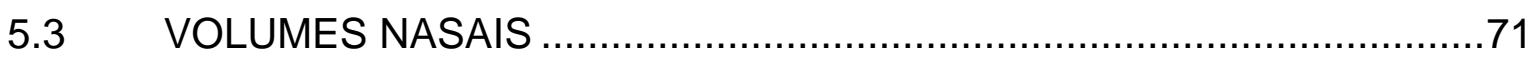

5.4 COMPARAÇÃO DOS RESULTADOS COM VALORES DE REFERÊNCIA . 71

6 DISCUSSÃO

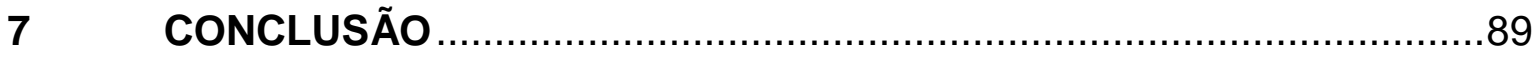

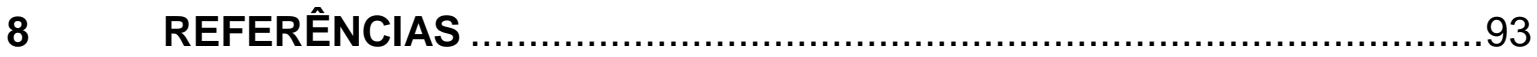

ANEXOS 

1 Introdução 



\section{INTRODUÇÃO}

As fissuras labiopalatinas são associadas a deformidades nasais características que comprometem o nariz do ponto de vista estético e funcional e que resultam da anomalia em si e das cirurgias corretivas primárias. As deformidades incluem o desvio septal e a hipertrofia das conchas nasais, que reduzem as dimensões internas da cavidade nasal, aumentam a resistência ao fluxo aéreo respiratório e produzem uma respiração oral de suplência (Wetmore 1992, Warren e Drake 1993, Trindade e Silva Filho, 2007).

Em estudo realizado no Laboratório de Fisiologia do Hospital de Reabilitação de Anomalias Craniofaciais da Universidade de São Paulo (HRAC/USP), Fukushiro e Trindade (2005) demonstraram, por meio de rinomanometria, que, em adultos, a fissura de lábio e palato bilateral já operada está associada a um maior comprometimento da patência (permeabilidade) nasal, seguida da fissura unilateral, e finalmente, da fissura de palato isolada. Em estudos subseqüentes, Bertier (2006) e Gomes (2007) confirmaram, por meio de rinometria acústica, o comprometimento estrutural causado pelas fissuras unilaterais, em adultos e crianças, respectivamente. Nenhum desses autores, entretanto, explorou suficientemente este recurso metodológico para caracterizar, em maiores detalhes, a geometria interna do nariz de indivíduos com fissura de lábio e palato. Isto porque o desenvolvimento de estudo desta natureza implica na necessidade de caracterizar, antes, o nariz normal, o que foi feito no mesmo Laboratório por Gomes (2004), e, o nariz de portadores de obstrução por desvio septal e hipertrofia de conchas não relacionada à fissura, o que é o objeto de investigação do presente estudo. 

2 Revisão de Literatura 



\section{REVISÃO DE LITERATURA}

O nariz desempenha funções vitais no organismo. Promove a filtração, o aquecimento e a umidificação do ar inspirado; representa o primeiro órgão na defesa contra alérgenos inalados; atua como órgão sensorial da olfação e caixa de ressonância na produção da fala.

A cavidade nasal representa o segmento inicial da árvore respiratória, comunicando-se com o meio ambiente através das narinas, e com a nasofaringe, através das coanas. A região mais anterior da cavidade nasal corresponde ao vestíbulo nasal, recoberto de pele. O vestíbulo se abre na válvula nasal através de um orifício chamado "ostium internum", que representa a linha de transição entre o epitélio escamoso cutâneo e a mucosa respiratória que recobre as fossas nasais. A região da válvula nasal tem como limites, lateralmente, a borda inferior da cartilagem lateral superior, medial, o septo nasal, e, inferiormente, o assoalho da fossa nasal e a cabeça da concha nasal inferior. Corresponde à porção do trato respiratório que oferece maior resistência ao fluxo aéreo, sendo, desta forma, sendo responsável por grande parte da sensação subjetiva de patência nasal (Hilberg et al 1995).

Progredindo no sentido posterior as fossas nasais, separadas por um septo osteocartilagíneo, apresentam quatro paredes: 1) uma superior ou teto 2) uma inferior ou assoalho, 3) uma medial, o próprio septo, e, 4) uma lateral, esta última formada pela justaposição de vários ossos (maxilar superior, palatino, etmóide e concha inferior). As conchas nasais ou cornetos são projeções osteomucosas, usualmente em número de três (inferior, médio e superior), podendo existir extraordinariamente uma quarta e uma quinta. Possuem uma extremidade anterior ou cabeça, uma extremidade posterior ou cauda e uma porção intermediária ou 
corpo. A concha inferior é recoberta em sua porção anterior por epitélio escamoso, seguido de epitélio transicional e, finalmente, por epitélio respiratório, do tipo pseudoestratificado, cilíndrico ciliado, ricamente entremeado por glândulas mucosas (células caliciformes e glândulas submucosas). Em sua submucosa, situa-se tecido erétil cuja fisiologia está grandemente atrelada ao sistema nervoso autônomo. Estímulos colinérgicos promovem vasodilatação dos sinusóides e acréscimo da secreção de muco, aumentando significativamente a sensação de obstrução nasal. Estímulos adrenérgicos possuem efeitos antagônicos. O teto e região das conchas superiores são recobertos por um epitélio sensorial especializado denominado "epitélio olfatório" (Hungria 2000, Navarro et al 2002, Nigro et al 2005).

Dentre as condições que mais contribuem para a obstrução anatômica nasal estão o septo desviado e as conchas nasais inferiores hipertróficas (Grützenmacher et al 2006). A obstrução nasal pode levar à respiração oral de suplência que, por sua vez, pode prejudicar o crescimento e desenvolvimento craniofacial e funções associadas ao sistema estomatognático, como a mastigação (Linder-Aronson 1979, Hairfield et al 1988, Warren et al 1992, Vig 1998). Esses fatores também têm um potencial de interferir na fisiologia respiratória, prejudicando as funções desempenhados pelo nariz, com possíveis repercussões sobre as vias aéreas inferiores, mediadas, por exemplo, pelo reflexo naso-pulmonar (Bluter 1960, Trindade et al 1992).

A avaliação da patência nasal é, usualmente, feita com base em impressões clínicas, a partir de história clínica e inspeção visual por rinoscopia e/ou nasofibroscopia. Nos últimos anos, porém, uma nova técnica tem sido cada vez mais empregada para avaliar as dimensões internas da cavidade nasal e, dessa forma, aferir de maneira mais objetiva a patência nasal; trata-se da rinometria acústica, 
introduzida por Sondhi e Gopinath (1971). A técnica foi utilizada inicialmente para avaliar as dimensões da traquéia e da árvore brônquica de cães por Jackson et al (1977), e para a medida de vias aéreas faríngeas, laríngeas e traqueais de humanos por Hoffstein et al (1984), Brown et al (1986), D'Urzo et al $(1987,1988)$ e Fredberg et al (1980). Sua introdução na prática clínica, como método de avaliação da geometria nasal, se deu com o trabalho de Hilberg et al (1989).

A técnica, também chamada rinometria por ecografia nasal por Roithmann e Cole (1995), baseia-se no princípio físico de que o som em um tubo (no caso, a cavidade nasal) é refletido frente a variações na impedância acústica causadas por variações nas dimensões internas do tubo (no caso, as constrições nasais). Em outras palavras, a rinometria acústica compreende a análise dos sons refletidos pela cavidade nasal, emitidos por uma fonte acústica e captadas por um microfone, ambos posicionados no interior do rinômetro adaptado a uma das narinas (Dalston 1992, Lai e Corey 1993 e Roithmann et al 1995). Permite medições consecutivas de áreas seccionais de diferentes segmentos da cavidade nasal, desde as narinas até as coanas e, deste modo, a identificação exata do local das diferentes constrições que contribuem para a resistência nasal, de forma rápida e não invasiva, sem a necessidade da participação ativa do paciente (Hilberg et al 1989 e Roithmann et al 1995). Além disso, também permite medir a que distância se situam às constrições relativamente às narinas e os volumes de diferentes regiões da cavidade nasal (Hilberg 2002, Bertier e Trindade 2007, Trindade et al 2007, Camargo 2008).

Hoje é amplamente reconhecida a importância da rinometria acústica como teste específico da patência nasal (Roithmann e Cole 1995, Roithmann 2005, 2007). Questões técnicas e suas aplicações clínicas foram amplamente discutidas por 
autores como Hilberg e Pedersen (2000), Parvez et al (2000), Grymer (2000), Corey (2006), Mlynsky e Beule (2007).

Valores de referência normais foram relatados por autores como Grymer et al (1989), Hilberg et al (1990), Lenders e Pirsig et al (1990), Lenders et al (1991), Grymer et al (1991), Roithmann et al (1995), Morgan et al (1995), Kesavanathan et al (1995), Roithmann et al (1997), Grymer et al (1997), Tomkinson e Eccles (1998), Corey et al (1998), Millqvist e Bende (1998), Kunkel et al (1999), Silkoff et al (1999), Ognibene et al (2001) Zancanella e Anselmo-Lima (2004), e, também, por Gomes (2004), Trindade et al (2007), Qian et al (2007), Camargo (2008), Gomes et al (2008), em projeto desenvolvido junto ao Laboratório de Fisiologia do HRAC.

Em indivíduos com obstrução de vias aéreas nasais de diferentes etiologias, valores subnormais foram observados por autores como Grymer et al (1989), Hilberg et al (1990), Lenders e Pirsig (1990), Lenders et al (1991), Grymer et al (1993), Grymer et al (1995), Fisher et al (1995), Roithmann et al (1995, 1997), Mann et al (1997), Shemen e Hamburg (1997), Gilain et al (1997), Kunkel et al (1997), Reber et al (1998), Suzcs (1998), Kemker et al (1999), Urpegui et al (1999), Sung et al (2000), Mamikoglu et al (2000, 2002), Pirilä e Tikanto (2001), Voegels et al (2002), Carlini et al (2002), Egeli (2004), Hurst et al (2006), Kjaergaard (2008), Trindade et al (2009).

Os principais achados de estudos que envolveram especificamente indivíduos portadores de alterações nasais anatômicas, mais precisamente, desvio septal e hipertrofia de conchas, não associados a outras anomalias ou deformidades significativas, em termos de áreas seccionais, distâncias das áreas seccionais em relação às narinas e volumes nasais estão resumidos nos quadros 1,2 e 3 , respectivamente, onde, também, são apresentados dados relativos ao equipamento utilizado, número de pacientes analisados, sua idade e condições nasais. 
Quadro 1 - Valores das áreas seccionais nasais (AST), expressos em $\mathrm{cm}^{2}$, em adultos com obstrução nasal, decorrente de obstrução nasal crônica (ONC), desvio septal (DS) e/ou hipertrofia de conchas (HC), antes e após descongestão nasal, por aplicação tópica de vasoconstritor (VC), relatados na literatura.

\begin{tabular}{|c|c|c|c|c|c|c|c|c|c|c|c|c|c|}
\hline \multirow[b]{2}{*}{ Autores } & \multirow[b]{2}{*}{ Ano } & \multirow{2}{*}{$\begin{array}{c}\text { Rinometria Acústica } \\
\text { (Equipamento) }\end{array}$} & \multirow[b]{2}{*}{$\mathbf{N}$} & \multirow[b]{2}{*}{$\begin{array}{l}\text { Idade } \\
\text { (anos) }\end{array}$} & \multirow[b]{2}{*}{ Condição } & \multicolumn{4}{|c|}{ Sem VC } & \multicolumn{4}{|c|}{ Com VC } \\
\hline & & & & & & ASTmin & AST1 & AST2 & AST3 & ASTmin & AST1 & AST2 & AST3 \\
\hline \multirow{4}{*}{$\begin{array}{l}\text { Grymer et } \\
\text { al }\end{array}$} & \multirow{4}{*}{1989} & \multirow{4}{*}{ NE } & $28 \mathrm{CN}$ & $15-41$ & DS anterior leve & $\begin{array}{c}0,63 \\
{[0,05]}\end{array}$ & & & & $\begin{array}{c}0,81 \\
{[0,05]}\end{array}$ & & & \\
\hline & & & $5 \mathrm{CN}$ & $15-41$ & DS anterior moderado & $\begin{array}{c}0,53 \\
{[0,15]}\end{array}$ & & & & $\begin{array}{c}0,76 \\
{[0,11]}\end{array}$ & & & \\
\hline & & & $9 \mathrm{CN}$ & $15-41$ & DS anterior grave & $\begin{array}{c}0,27 \\
{[0,05]}\end{array}$ & & & & $\begin{array}{c}0,33 \\
{[0,10]}\end{array}$ & & & \\
\hline & & & $7 \mathrm{P}$ & $15-41$ & DS anterior grave & $\begin{array}{c}1,11 \\
{[0,15]} \\
\text { soma dos lados }\end{array}$ & & & & $\begin{array}{c}1,27 \\
{[0,14]} \\
\text { soma dos lados }\end{array}$ & & & \\
\hline \multirow{4}{*}{$\begin{array}{l}\text { Grymer et } \\
\text { al }\end{array}$} & \multirow{4}{*}{1993} & \multirow{4}{*}{ NE } & \multirow{2}{*}{$\begin{array}{l}37+13 \\
P \\
\text { respectiva } \\
\text { mente }\end{array}$} & \multirow{2}{*}{$18-61$} & \multirow{2}{*}{$\mathrm{DS}$ anterior grave $+\mathrm{HC}$} & $\begin{array}{c}0,24 \\
{[0,01]} \\
\text { lado menor } \\
\end{array}$ & & & & $\begin{array}{c}0,34 \\
{[0,01]} \\
\text { lado menor } \\
\end{array}$ & & & \\
\hline & & & & & & $\begin{array}{c}0,57 \\
{[0,03]} \\
\text { lado maior } \\
\end{array}$ & & & & $\begin{array}{c}0,64 \\
{[0,03]} \\
\text { lado maior } \\
\end{array}$ & & & \\
\hline & & & \multirow{2}{*}{$\begin{array}{l}37+11 \\
P \\
\text { respectiva } \\
\text { mente }\end{array}$} & \multirow{2}{*}{$18-61$} & \multirow{2}{*}{$\begin{array}{l}\text { DS anterior menos } \\
\text { pronunciado+HC }\end{array}$} & $\begin{array}{c}0,46 \\
{[0,02]} \\
\text { lado menor } \\
\end{array}$ & & & & $\begin{array}{c}0,64 \\
{[0,03]} \\
\text { lado menor } \\
\end{array}$ & & & \\
\hline & & & & & & $\begin{array}{c}0,68 \\
{[0,03]} \\
\text { lado maior } \\
\end{array}$ & & & & $\begin{array}{c}0,81 \\
{[0,03\}} \\
\text { lado maior }\end{array}$ & & & \\
\hline $\begin{array}{l}\text { Grymer et } \\
\text { al }\end{array}$ & 1995 & NE & $45 \mathrm{P}$ & $18-74$ & $\mathrm{ONC}-\mathrm{HC}$ & $\begin{array}{c}1,07 \\
{[0,04]} \\
\text { soma dos lados } \\
\end{array}$ & & & & $\begin{array}{c}1,47 \\
{[0,05]} \\
\text { soma dos lados }\end{array}$ & & & \\
\hline \multirow{2}{*}{$\begin{array}{l}\text { Roithmann } \\
\text { et al }\end{array}$} & \multirow{2}{*}{1995} & \multirow{2}{*}{$\begin{array}{l}\text { Eccovision Hood } \\
\text { Laboratories AR-1003 }\end{array}$} & $23 \mathrm{CN}$ & $17-66$ & $\begin{array}{l}\text { DS anterior com } 50 \% \\
\text { de obstrução }\end{array}$ & $\begin{array}{c}0,27 \\
{[0,02]}\end{array}$ & & & & $\begin{array}{c}0,33 \\
{[0,02]}\end{array}$ & & & \\
\hline & & & $31 \mathrm{CN}$ & $16-49$ & $\mathrm{HC}$ & $\begin{array}{c}0,44 \\
{[0,02]}\end{array}$ & & & & $\begin{array}{c}0,61 \\
{[0,02]}\end{array}$ & & & \\
\hline Mann et al & 1997 & NE & $25 \mathrm{P}$ & $26-52$ & $\begin{array}{l}\mathrm{DS}+\mathrm{HC} \text { (unilateral } \\
\text { e/ou bilateral) }\end{array}$ & $\begin{array}{c}1,10 \\
(0,34) \\
\text { soma dos lados }\end{array}$ & & & & & & & \\
\hline
\end{tabular}


Quadro 1 - Continuação

\begin{tabular}{|c|c|c|c|c|c|c|c|c|c|c|c|c|c|}
\hline \multirow[b]{2}{*}{ Autores } & \multirow[b]{2}{*}{ Ano } & \multirow{2}{*}{$\begin{array}{c}\text { Rinometria Acústica } \\
\text { (Equipamento) }\end{array}$} & \multirow[b]{2}{*}{$\mathbf{N}$} & \multirow[b]{2}{*}{$\begin{array}{l}\text { Idade } \\
\text { (anos) }\end{array}$} & \multirow[b]{2}{*}{ Condição } & \multicolumn{4}{|c|}{ Sem VC } & \multicolumn{4}{|c|}{ Com VC } \\
\hline & & & & & & ASTmin. & AST1 & AST2 & AST3 & ASTmin. & AST1 & AST2 & AST3 \\
\hline $\begin{array}{l}\text { Shemen } \\
\text { et al }\end{array}$ & 1997 & $\begin{array}{l}\text { Eccovision Hood } \\
\text { Laboratories }\end{array}$ & $48 \mathrm{CN}$ & $\begin{array}{l}37,7 \\
\text { média }\end{array}$ & $\mathrm{DS}+\mathrm{HC}$ & 0,55 & & & & & & & \\
\hline \multirow{2}{*}{$\begin{array}{l}\text { Reber } \\
\text { et al }\end{array}$} & \multirow{2}{*}{1998} & \multirow{2}{*}{$\begin{array}{l}\text { Stimotron- AR } \\
\text { Rhinoclack } 2.0 \\
\text { Software }\end{array}$} & \multirow{2}{*}{$27 \mathrm{P}$} & \multirow{2}{*}{$\begin{array}{l}32 \\
\text { média }\end{array}$} & \multirow{2}{*}{$\mathrm{DS}+\mathrm{HC}$} & $\begin{array}{c}1,05 \\
\{0,55-1,38\} \\
\text { soma dos lados }\end{array}$ & & & & $\begin{array}{c}1,10 \\
\{0,60-1,38\} \\
\text { soma dos lados }\end{array}$ & & & \\
\hline & & & & & & $\begin{array}{c}0,47 \\
\{0,13-0,66\} \\
\text { lado menor }\end{array}$ & & & & $\begin{array}{c}0,49 \\
\{0,13-0,69\} \\
\text { lado menor }\end{array}$ & & & \\
\hline \multirow{4}{*}{$\begin{array}{l}\text { Szucs } \\
\text { et al }\end{array}$} & \multirow{4}{*}{1998} & \multirow{4}{*}{ Rhino 2000} & $8 P$ & $18-64$ & $\begin{array}{l}\text { DS anterior grave } \\
\text { (Cottle I e II) }\end{array}$ & $\begin{array}{c}0,16 \\
\{0,09-0,29\}^{*}\end{array}$ & & & & $\begin{array}{c}0,25 \\
\{0,21-0,30\}^{*}\end{array}$ & & & \\
\hline & & & $14 \mathrm{P}$ & $18-64$ & $\begin{array}{l}\text { DS anterior } \\
\text { moderado (Cottle } \\
\text { I e II) }\end{array}$ & $\begin{array}{c}0,27 \\
\{0,20-0,40\}^{*}\end{array}$ & & & & $\begin{array}{c}0,37 \\
\{0,30-0,44\}^{*}\end{array}$ & & & \\
\hline & & & $12 \mathrm{P}$ & $18-64$ & $\begin{array}{l}\text { DS médio } \\
\text { (Cottle IV) }\end{array}$ & $\begin{array}{c}0,45 \\
\{0,33-0,51\}^{*}\end{array}$ & & & & $\begin{array}{c}0,45 \\
\{0,38-0,47\}^{*}\end{array}$ & & & \\
\hline & & & $16 P$ & $18-64$ & $\begin{array}{l}\text { DS posterior } \\
\text { (Cottle V) }\end{array}$ & $\begin{array}{c}0,41 \\
\{0,31-0,51\}^{*}\end{array}$ & & & & $\begin{array}{c}0,54 \\
\{0,36-0,62\}^{*}\end{array}$ & & & \\
\hline \multirow{2}{*}{$\begin{array}{l}\text { Kemker } \\
\text { et al }\end{array}$} & \multirow{2}{*}{1999} & \multirow{2}{*}{$\begin{array}{l}\text { Eccovision Hood } \\
\text { Laboratories }\end{array}$} & \multirow{2}{*}{$14 \mathrm{P}$} & \multirow{2}{*}{$24-50$} & \multirow{2}{*}{ DS } & & & & & & $\begin{array}{c}0,58 \\
(0,21) \\
\text { lado menor } \\
\end{array}$ & $\begin{array}{c}1,63 \\
(0,39) \\
\text { lado menor } \\
\end{array}$ & $\begin{array}{c}2,41 \\
(0,51) \\
\text { lado menor }\end{array}$ \\
\hline & & & & & & & & & & & $\begin{array}{c}0,88 \\
(0,25) \\
\text { lado maior } \\
\end{array}$ & $\begin{array}{c}1,97 \\
(0,54) \\
\text { lado maior } \\
\end{array}$ & $\begin{array}{c}2,48 \\
(0,65) \\
\text { lado maior } \\
\end{array}$ \\
\hline $\begin{array}{l}\text { Urpegui } \\
\text { et al }\end{array}$ & 1999 & Rhin 2000 & $45 \mathrm{P}$ & $18-40$ & DS & & 0,39 & 0,49 & & & & & \\
\hline \multirow{2}{*}{$\begin{array}{l}\text { Sung et } \\
\text { al }\end{array}$} & \multirow{2}{*}{2000} & \multirow{2}{*}{ Rhinoklak-RK 1000} & \multirow{2}{*}{$20 P$} & \multirow{2}{*}{$\begin{array}{l}23,5 \\
\text { média }\end{array}$} & \multirow{2}{*}{ DS anterior } & $\begin{array}{c}0,46 \\
(0,13) \\
\text { lado menor } \\
\end{array}$ & & & & & & & \\
\hline & & & & & & $\begin{array}{c}0,78 \\
(0,17) \\
\text { lado maior }\end{array}$ & & & & & & & \\
\hline
\end{tabular}

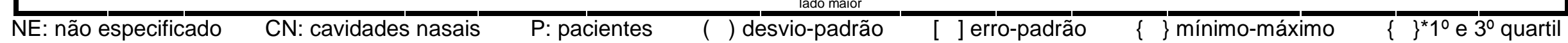


Quadro 2 - Valores das distâncias das áreas seccionais nasais (dAST), em relação às narinas, expressos em cm, em adultos com obstrução nasal, decorrente de obstrução nasal crônica (ONC), desvio septal (DS) e/ou hipertrofia de conchas (HC), antes e após a descongestão nasal, por aplicação tópica de vasoconstritor (VC), relatados na literatura.

\begin{tabular}{|c|c|c|c|c|c|c|c|c|c|c|c|c|c|}
\hline \multirow[b]{2}{*}{ Autores } & \multirow[b]{2}{*}{ Ano } & \multirow{2}{*}{$\begin{array}{c}\text { Rinometria Acústica } \\
\text { (Equipamento) }\end{array}$} & \multirow[b]{2}{*}{$\mathbf{N}$} & \multirow[b]{2}{*}{ Idade (anos) } & \multirow[b]{2}{*}{ Condição } & \multicolumn{4}{|c|}{ Sem VC } & \multicolumn{4}{|c|}{ Com VC } \\
\hline & & & & & & dASTmin & $\mathrm{dAST}_{1}$ & $\mathrm{dAST}_{2}$ & $\mathrm{dAST}_{3}$ & dASTmin. & dAST $_{1}$ & $\mathrm{dAST}_{2}$ & $\mathrm{dAST}_{3}$ \\
\hline \multirow{3}{*}{$\begin{array}{l}\text { Grymer et } \\
\text { al }\end{array}$} & \multirow{3}{*}{1989} & \multirow{3}{*}{ NE } & $28 \mathrm{CN}$ & $15-41$ & DS anterior leve & $\begin{array}{l}2,28 \\
{[0,19]}\end{array}$ & & & & $\begin{array}{c}1,98 \\
{[0,19]}\end{array}$ & & & \\
\hline & & & $5 \mathrm{CN}$ & $15-41$ & $\begin{array}{l}\text { DS anterior } \\
\text { moderado }\end{array}$ & $\begin{array}{l}2,20 \\
{[0,32]}\end{array}$ & & & & $\begin{array}{c}1,90 \\
{[0,43]}\end{array}$ & & & \\
\hline & & & $9 \mathrm{CN}$ & $15-41$ & DS anterior grave & $\begin{array}{l}2,65 \\
{[0,16]}\end{array}$ & & & & $\begin{array}{l}2,68 \\
{[0,15]}\end{array}$ & & & \\
\hline \multirow{2}{*}{$\begin{array}{l}\text { Roithmann } \\
\text { et al }\end{array}$} & \multirow{2}{*}{1995} & \multirow{2}{*}{$\begin{array}{l}\text { Eccovision Hood } \\
\text { Laboratories AR-1003 }\end{array}$} & $23 \mathrm{CN}$ & $17-66$ & $\begin{array}{l}\text { DS anterior com } \\
50 \% \text { de obstrução }\end{array}$ & $\begin{array}{l}2,75 \\
{[0,13]}\end{array}$ & & & & $\begin{array}{l}2,75 \\
{[0,15]}\end{array}$ & & & \\
\hline & & & $31 \mathrm{CN}$ & $16-49$ & $\mathrm{HC}$ & $\begin{array}{c}3,29 \\
{[0,17]}\end{array}$ & & & & $\begin{array}{c}2,12 \\
{[0,02]}\end{array}$ & & & \\
\hline \multirow{4}{*}{$\begin{array}{l}\text { Szucs et } \\
\text { al }\end{array}$} & \multirow{4}{*}{1998} & \multirow{4}{*}{ Rhino 2000} & $8 \mathrm{P}$ & $18-64$ & $\begin{array}{l}\text { DS anterior grave } \\
\text { (Cottle I e II) }\end{array}$ & $\begin{array}{c}2,19 \\
\{1,96-2,27\}^{\star}\end{array}$ & & & & $\begin{array}{c}2,17 \\
\{2,00-2,31\}^{*}\end{array}$ & & & \\
\hline & & & $14 \mathrm{P}$ & $18-64$ & $\begin{array}{l}\text { DS anterior } \\
\text { moderado (Cottle I } \\
\text { e II) }\end{array}$ & $\begin{array}{c}2,14 \\
\{2,00-2,20\}^{*}\end{array}$ & & & & $\begin{array}{c}2,07 \\
\{1,88-2,24\}^{*}\end{array}$ & & & \\
\hline & & & $12 \mathrm{P}$ & $18-64$ & $\begin{array}{l}\text { DS médio } \\
\text { (Cottle IV) }\end{array}$ & $\begin{array}{c}2,12 \\
\{1,96-2,16\}^{*}\end{array}$ & & & & $\begin{array}{c}1,88 \\
\{0,52-2,12\}^{*}\end{array}$ & & & \\
\hline & & & $16 P$ & $18-64$ & $\begin{array}{l}\text { DS posterior } \\
\text { (Cottle V) }\end{array}$ & $\begin{array}{c}2,11 \\
\{2,02-2,23\}^{*}\end{array}$ & & & & $\begin{array}{c}2,00 \\
\{1,79-2,16\}^{*}\end{array}$ & & & \\
\hline
\end{tabular}


Quadro 3 - Valores dos volumes nasais (V), expressos em $\mathrm{cm}^{3}$, em adultos com obstrução nasal, decorrente de obstrução nasal crônica (ONC), desvio septal (DS) e/ou hipertrofia de conchas (HC), antes e após a descongestão nasal, por aplicação tópica de vasoconstritor (VC), relatados na literatura.

\begin{tabular}{|c|c|c|c|c|c|c|c|c|}
\hline & & Rinometria Acústica & & & & & Sem VC & Com VC \\
\hline Autores & Ano & (Equipamento) & $\mathbf{N}$ & $\begin{array}{l}\text { Idade } \\
\text { (anos) }\end{array}$ & Condição & $\begin{array}{l}\text { Segmento } \\
\text { Avaliado }\end{array}$ & V & V \\
\hline Grymer et al & 1989 & NE & $9 P$ & $15-41$ & $\begin{array}{l}\text { obstrução nasal desde } \\
\text { infância }\end{array}$ & narinas $-7 \mathrm{~cm}$ & $\begin{array}{l}22,93 \\
{[1,69]}\end{array}$ & \\
\hline \multirow[t]{2}{*}{ Grymer et al } & \multirow[t]{2}{*}{1993} & \multirow[t]{2}{*}{ NE } & $\begin{array}{l}37+13 \mathrm{P} \\
\text { respectivamente }\end{array}$ & $18-61$ & $\mathrm{DS}$ anterior grave $+\mathrm{HC}$ & narinas $-7 \mathrm{~cm}$ & $\begin{array}{c}\begin{array}{c}8,02 \\
{[0,46]} \\
\text { lado menor }\end{array} \\
11,06 \\
{[0,40]} \\
\text { lado maior }\end{array}$ & $\begin{array}{c}\begin{array}{c}11,15 \\
{[0,43]} \\
\text { lado menor }\end{array} \\
14,07 \\
{[0,47]} \\
\text { lado maior }\end{array}$ \\
\hline & & & $\begin{array}{l}37+11 \mathrm{P} \\
\text { respectivamente }\end{array}$ & $18-61$ & $\begin{array}{l}\text { DS anterior menos } \\
\text { pronunciado+HC }\end{array}$ & narinas $-7 \mathrm{~cm}$ & 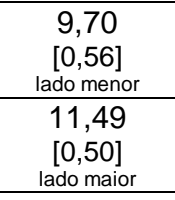 & $\begin{array}{c}\begin{array}{c}13,51 \\
{[0,47]} \\
\text { lado menor }\end{array} \\
14,58 \\
{[0,44]} \\
\text { lado maior } \\
\end{array}$ \\
\hline \multirow{2}{*}{ Roithmann et al } & \multirow{2}{*}{1995} & \multirow{2}{*}{$\begin{array}{l}\text { Eccovision Hood } \\
\text { Laboratories AR-1003 }\end{array}$} & $23 \mathrm{CN}$ & $17-66$ & $\begin{array}{l}\text { DS anterior com } 50 \% \\
\text { de obstrução }\end{array}$ & $0-8 \mathrm{~cm}$ & $\begin{array}{c}7,80 \\
{[0,58]}\end{array}$ & $\begin{array}{l}10,78 \\
{[0,70]}\end{array}$ \\
\hline & & & $31 \mathrm{CN}$ & $16-49$ & $\mathrm{HC}$ & $0-8 \mathrm{~cm}$ & $\begin{array}{c}7,56 \\
{[0,30]}\end{array}$ & $\begin{array}{l}13,91 \\
{[0,50]}\end{array}$ \\
\hline Shemen et al & 1997 & $\begin{array}{l}\text { Eccovision Hood } \\
\text { Laboratories }\end{array}$ & $48 \mathrm{CN}$ & $\begin{array}{l}37,7 \\
\text { média }\end{array}$ & $\mathrm{DS}+\mathrm{HC}$ & NE & $\begin{array}{c}8,32 \\
\text { volume total }\end{array}$ & \\
\hline \multirow{4}{*}{ Szucs et al } & \multirow{4}{*}{1998} & \multirow{4}{*}{ Rhino 2000} & $8 P$ & $18-64$ & $\begin{array}{l}\text { DS anterior grave } \\
\text { (Cottle I e II) }\end{array}$ & $0-2,5 \mathrm{~cm}$ & $\begin{array}{c}1,40 \\
\{1,07-1,79\}^{\star}\end{array}$ & $\begin{array}{c}1,52 \\
\{1,44-1,75\}^{*} \\
\end{array}$ \\
\hline & & & $14 \mathrm{P}$ & $18-64$ & $\begin{array}{l}\text { DS anterior moderado } \\
\text { (Cottle I e II) }\end{array}$ & $0-2,5 \mathrm{~cm}$ & $\begin{array}{c}1,50 \\
\{1,28-2,02\}^{*}\end{array}$ & $\begin{array}{c}1,53 \\
\{1,46-2,26\}^{*}\end{array}$ \\
\hline & & & $12 \mathrm{P}$ & $18-64$ & $\begin{array}{l}\text { DS médio } \\
\text { (Cottle IV) }\end{array}$ & $4,5-8 \mathrm{~cm}$ & $\begin{array}{c}1,87 \\
\{1,46-2,20\}^{*}\end{array}$ & $\begin{array}{c}3,20 \\
\{2,38-3,62\}^{*}\end{array}$ \\
\hline & & & $16 P$ & $18-64$ & $\begin{array}{l}\text { DS posterior } \\
\text { (Cottle V) }\end{array}$ & $4,5-8 \mathrm{~cm}$ & $\begin{array}{c}4,80 \\
\{4,46-5,23\}^{*}\end{array}$ & $\begin{array}{c}7,02 \\
\{5,70-8,80\}^{*}\end{array}$ \\
\hline
\end{tabular}

NE: não especificado CN: cavidades nasais P:pacientes ( ) desvio-padrão [ ] erro-padrão $\left\{\right.$ \} mínimo-máximo \{\}$^{*} 1^{\circ}$ e $3^{\circ}$ quartil 
Quadro 3 - Continuação

\begin{tabular}{|c|c|c|c|c|c|c|c|c|}
\hline & & Rinometria Acústica & & & & & Sem VC & Com VC \\
\hline Autores & Ano & (Equipamento) & $\mathbf{N}$ & Idade (anos) & Condição & $\begin{array}{c}\text { Segmento } \\
\text { Avaliado }\end{array}$ & V & $\mathbf{V}$ \\
\hline \multirow[t]{2}{*}{ Reber et al } & \multirow[t]{2}{*}{1998} & \multirow{2}{*}{$\begin{array}{l}\text { Stimotron- AR } \\
\text { Rhinoclack } 2.0 \text { Software }\end{array}$} & \multirow[t]{2}{*}{$27 \mathrm{P}$} & \multirow{2}{*}{$\begin{array}{l}32 \\
\text { média }\end{array}$} & \multirow[t]{2}{*}{$\mathrm{DS}+\mathrm{HC}$} & narinas-7cm & $\begin{array}{c}34,30 \\
\{14,30-82,51\} \\
\text { volume total }\end{array}$ & $\begin{array}{c}42,38 \\
\{21,48-80,78\} \\
\text { volume total }\end{array}$ \\
\hline & & & & & & narinas $-7 \mathrm{~cm}$ & $\begin{array}{c}12,94 \\
\{4,56-28,93\} \\
\text { lado menor }\end{array}$ & $\begin{array}{c}16,22 \\
\{4,97-28,10\} \\
\text { lado menor }\end{array}$ \\
\hline \multirow{2}{*}{$\begin{array}{l}\text { Kemker et } \\
\text { al }\end{array}$} & \multirow{2}{*}{1999} & \multirow{2}{*}{$\begin{array}{l}\text { Eccovision Hood } \\
\text { Laboratories }\end{array}$} & \multirow{2}{*}{$14 \mathrm{P}$} & \multirow{2}{*}{$24-50$} & \multirow[t]{2}{*}{ DS } & $0-6 \mathrm{~cm}$ & & $\begin{array}{c}8,67 \\
(1,31) \\
\text { lado menor }\end{array}$ \\
\hline & & & & & & $0-6 \mathrm{~cm}$ & & $\begin{array}{c}10,27 \\
(2,17) \\
\text { lado maior }\end{array}$ \\
\hline \multirow{2}{*}{$\begin{array}{l}\text { Urpegui et } \\
\text { al }\end{array}$} & \multirow{2}{*}{1999} & \multirow{2}{*}{ Rhin 2000} & \multirow{2}{*}{$45 \mathrm{P}}$. & \multirow{2}{*}{$18-40$} & \multirow{2}{*}{ DS } & $0-3,2 \mathrm{~cm}$ & 1,74 & \\
\hline & & & & & & $3,2-6,4 \mathrm{~cm}$ & 3,18 & \\
\hline \multirow{2}{*}{ Sung et al } & \multirow{2}{*}{2000} & \multirow{2}{*}{ Rhinoklak-RK 1000} & \multirow{2}{*}{$20 P$} & \multirow{2}{*}{$\begin{array}{l}23,5 \\
\text { média }\end{array}$} & \multirow{2}{*}{ DS anterior } & narinas $-7 \mathrm{~cm}$ & $\begin{array}{c}12,66 \\
(2,87) \\
\text { lado menor }\end{array}$ & \\
\hline & & & & & & narinas $-7 \mathrm{~cm}$ & $\begin{array}{c}13,28 \\
(2,37) \\
\text { lado maior }\end{array}$ & \\
\hline
\end{tabular}
NE: não especificado
$\mathrm{CN}$ : cavidades nasais
P: pacientes
( ) desvio-padrão
[ ] erro-padrão
\{ \} mínimo-máximo 
Pioneiros no uso da rinometria acústica em pacientes com obstrução nasal de origem estrutural, Grymer e seus colaboradores (1989), analisaram 21 pacientes adultos com diferentes graus de desvio septal, de leve a grave, estudando as áreas seccionais, respectivas distâncias, e, volumes nasais, além de acompanhar os efeitos da septoplastia. Nas avaliações pré-operatórias, os autores demonstraram que, comparativamente a um grupo controle, pacientes com deformidades leves ou moderadas apresentavam áreas seccionais mínimas na mesma faixa de grandeza $\left(0,53 \mathrm{~cm}^{2}\right.$ a $0,63 \mathrm{~cm}^{2}$, em média), localizadas à mesma distância em relação à narina (2,20 a 2,28cm, em média). Já o grupo com obstrução grave diferiu dos demais, apresentando áreas significativamente menores, da ordem de 0,27cm², em média, mas situadas a uma distância equivalente da narina $(2,60 \mathrm{~cm})$, verificaram, ainda, que as áreas seccionais mínimas aumentavam com a descongestão nasal e que se deslocavam anteriormente nos grupo controle e com obstrução leve e moderada. Estas e outras observações comprovaram a importância da rinometria acústica para a caracterização da geometria nasal e permitiram antecipar as aplicações da técnica para o diagnóstico da obstrução nasal. Por outro lado, mais recentemente, Trindade et al (2009) concluíram um estudo no Laboratório de Fisiologia do HRAC/USP no qual foram determinadas as áreas seccionais e volumes nasais de adultos com fissura de lábio e palato unilateral reparada, e, além disso, também acompanharam os efeitos da correção cirúrgica das deformidades nasais. Do lado da fissura, antes da cirurgia, foram observados valores que se mostraram significativamente menores que os valores de referência publicados pelo Laboratório (Gomes 2004, Trindade et al. 2007 e Gomes et al 2008). Verificaram, ainda, que a rinosseptoplastia levou a um aumento persistente da patência nasal em grande parcela de pacientes, traduzida por um aumento significante da área de secção transversa e do volume do segmento 
correspondente à válvula nasal do lado da fissura. Esses achados demonstraram ser bons indicadores do sucesso das cirurgias corretivas, em termos funcionais, e vieram a reforçar a importância do uso de métodos objetivos, particularmente a rinometria acústica, para acompanhar a qualidade de procedimentos que tem efeito potencial de inferir com a morfo-fisiologia da cavidade nasal.

Com base nas observações da literatura, e como parte de um estudo mais abrangente, em andamento em nosso laboratório, que visa caracterizar a geometria das vias aéreas nasais de indivíduos com fissura labiopalatina, pretendeu-se com o presente estudo, contribuir para a caracterização do efeito obstrutivo de alterações estruturais não relacionadas à fissura, lançando mão dos recursos metodológicos trazidos pela rinometria acústica. 

3 Objetivos 



\section{OBJETIVOS}

O presente trabalho teve por objetivo determinar, por meio da rinometria acústica, as dimensões internas nasais de adultos com obstrução nasal decorrente de desvio septal e/ou hipertrofia de conchas.

Para tanto, foram analisadas as áreas seccionais, e respectivas distâncias em relação às narinas, e os volumes de segmentos específicos da cavidade nasal, comparativamente aos respectivos valores de referência, determinados em indivíduos sem evidências de obstrução nasal, em estudo anterior realizado por Gomes (2004). 

4 Material e Método 



\section{MATERIAL E MÉTODO}

\subsection{CASUÍSTICA}

Foram analisados 30 adultos de cor branca ou parda*, com idade entre 18 a 40 anos, sendo 16 do sexo feminino e 14 do sexo masculino, selecionados entre os pacientes em atendimento regular no ambulatório do Hospital Estadual de Bauru (HEB), que apresentavam obstrução nasal como queixa principal. A seleção ficou a cargo dos Médicos Otorrinolaringologistas Dr. Sergio Henrique Kiemle Trindade e Dr. Norimar Hernandes Dias da Equipe de Otorrinolaringologia do HEB.

Uma vez atendidos os critérios de inclusão, detalhados no item 4.2.1, os pacientes receberam esclarecimentos da pesquisadora responsável (PCP) sobre os objetivos e forma de execução da pesquisa. Após concordância, assinaram o Termo de Consentimento Livre e Esclarecido (anexo1) e foram encaminhados ao HRAC para serem submetidos à rinometria acústica.

O projeto recebeu aprovação do Comitê de Ética em Pesquisa do HRAC/USP, sob o protocolo no 381/2006-SVAPEPE-CEP (anexo 2) e da Comissão de Pesquisa Científica do HEB sob o protocolo no HEB-CC-097/06 (anexo 3).

\subsection{PROCEDIMENTOS}

\subsubsection{Diagnóstico da obstrução nasal}

O diagnóstico da obstrução nasal foi feito com base no conjunto de dados aferidos em anamnese e exame clínico realizados segundo protocolo elaborado para este fim (anexo 4).

\footnotetext{
*Segundo nomenclatura IBGE, 2000

Brasil. Ministério do Planejamento, Orçamento e Gestão. Instituto Brasileiro de Geografia e Estatística IBGE - Censo Demográfico 2000. Rio de Janeiro: Ministério do Planejamento, Orçamento e Gestão; 2000.
} 
Foram incluídos no estudo pacientes que apresentavam queixa de obstrução nasal confirmada pela identificação de desvio septal e/ou hipertrofia de conchas nasais inferiores ao exame físico. Foram excluídos da pesquisa, pacientes com obstrução de outras etiologias, como hipertrofia de tonsilas faríngeas, pólipo nasal, neoplasia e/ou processo infeccioso agudo, bem como pacientes com outras lesões detectadas na rinoscopia anterior, com cirurgia nasal prévia, ou qualquer outra condição que impedia a realização de todas as etapas do estudo. Pacientes que faziam uso de medicação nasal de qualquer tipo eram solicitados a interromper 0 tratamento durante 5 a 7 dias para a realização da rinometria acústica; exceção foi feita a um paciente que permaneceu apenas 24 horas sem a medicação.

\subsubsection{Anamnese}

O protocolo de avaliação consistia, primeiramente, de anamnese dirigida, na qual foram levantados os seguintes parâmetros:

1) tempo e duração das queixas obstrutivas;

2) lado da obstrução nasal: direito, esquerdo, bilateral ou em báscula;

3) freqüência da obstrução nasal: fixa, intermitente, diária, semanal;

4) sintomas de rinite: espirros, prurido, rinorréia, prurido otológico, faríngeo ou ocular;

5) sintomas faríngeos: gotejamento posterior, desconforto, pigarro ou dor;

6) sintomas nasossinusais: cefaléia, crostas nasais;

7) sintomas otológicos: plenitude auricular, estalidos, zumbidos ou vertigens;

8) antecedentes nasais: tratamentos prévios (medicamentos, cirurgias otorrinolaringológicas); 
9) doenças associadas e hábitos: asma, bronquite, doença pulmonar obstrutiva crônica, hipertensão arterial sistêmica, tabagismo e outras.

Os principais achados da anamnese dos 30 pacientes incluídos no estudo são mostrados no anexo 5 .

\subsubsection{Exame físico otorrinolaringológico}

A seguir, o paciente era submetido a exame físico otorrinolaringológico geral, no qual, com auxílio de foco de luz e espelho frontal, era realizada a rinoscopia anterior e posterior. Otoscopia e exame do segmento cervical eram realizados para pesquisa de lesões associadas.

No exame da cavidade nasal foram avaliadas as características da mucosa e das secreções nasais, o grau e tipo de desvio septal e a presença de hipertrofia das conchas nasais inferiores. Os desvios septais foram classificados em esquerdo ou direito de acordo com a predominância da lateralidade do desvio. Foram classificados como anteriores, os desvios cartilaginosos ou ósseo-cartilaginosos que se situavam até a região de transição entre cartilagem quadrangular e septo ósseo, e, como posteriores, os predominantemente de vômer. Foi feita, ainda, a graduação da intensidade do desvio septal e hipertrofia de conchas em: grau 1 (obstrução em até $25 \%$ da luz da cavidade nasal), grau 2 (entre 25 e 50\%), grau 3 (entre 50 e $75 \%$ ) e grau 4 ( $75 \%$ ou mais).

Os principais achados do exame físico otorrinolaringológico realizados nos 30 pacientes incluídos no estudo são mostrados no anexo 6.

\subsubsection{Avaliação das dimensões internas nasais por rinometria acústica}

Concluídas as etapas 4.2.1.1 e 4.2.1.2 e caracterizada a obstrução, os pacientes eram encaminhados para a realização da rinometria acústica. 


\subsubsection{Equipamento e princípio da técnica}

Para a avaliação rinométrica foi utilizado o sistema Eccovision Acoustic Rhinometer (HOOD Laboratories). O equipamento consiste de uma fonte sonora (altofalante) montada na porção distal de um tubo de $24 \mathrm{~cm}$ que tem na sua porção proximal um microfone de registro. A configuração do sistema é mostrada nas figuras 1 e 2 .

A rinometria acústica avalia a geometria da cavidade nasal pela análise de ondas sonoras refletidas (ecos) que emergem da cavidade nasal em resposta a uma onda sonora incidente. $\mathrm{O}$ exame é realizado da seguinte forma: um adaptador de silicone conectado à porção proximal do rinômetro é encostado em uma das narinas. O examinador segura firmemente o tubo em paralelo ao dorso do nariz. Uma onda sonora é gerada pelo alto-falante, que se propaga pelo tubo e entra na cavidade nasal. Variações da área de secção transversa, ou seja, quaisquer constrições que diminuam a luz da cavidade, causam a reflexão da onda sonora de volta para o tubo. Os sinais de pressão sonora sensibilizam o microfone, são amplificados, digitalizados e analisados com um software específico de um microcomputador conectado ao sistema.

A área de secção transversa nasal é calculada a partir da intensidade do eco. A distância da constrição é calculada com base na velocidade da onda e o tempo de chegada do eco. Os dados são convertidos em função área-distância na forma de um gráfico chamado de rinograma, que é mostrado na tela do computador. No gráfico, a área $\left(\mathrm{cm}^{2}\right)$ é representada em escala semilogarítmica no eixo y e a distância $(\mathrm{cm})$ no eixo $x$. O sistema faz medições em rápida sucessão (aproximadamente a cada 0,5 segundo) e permite medidas de toda a cavidade nasal, dos lados direito e esquerdo independentemente. Um rinograma de um indivíduo normal é mostrado na figura 3. 


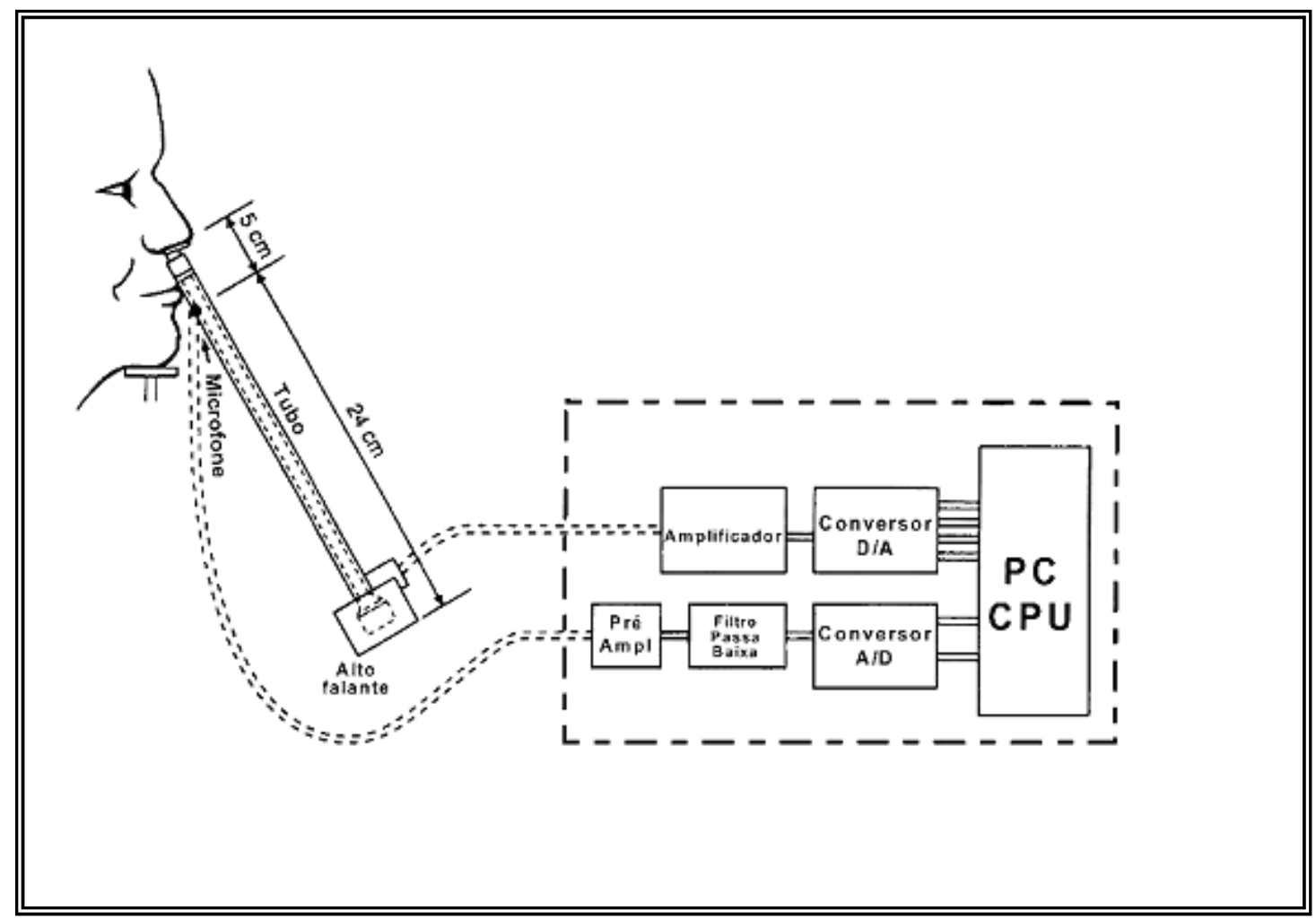

Figura 1 - Rinometria acústica: representação esquemática da instrumentação para a medida das dimensões internas da cavidade nasal (adaptado de Roithman e Cole 1995). 


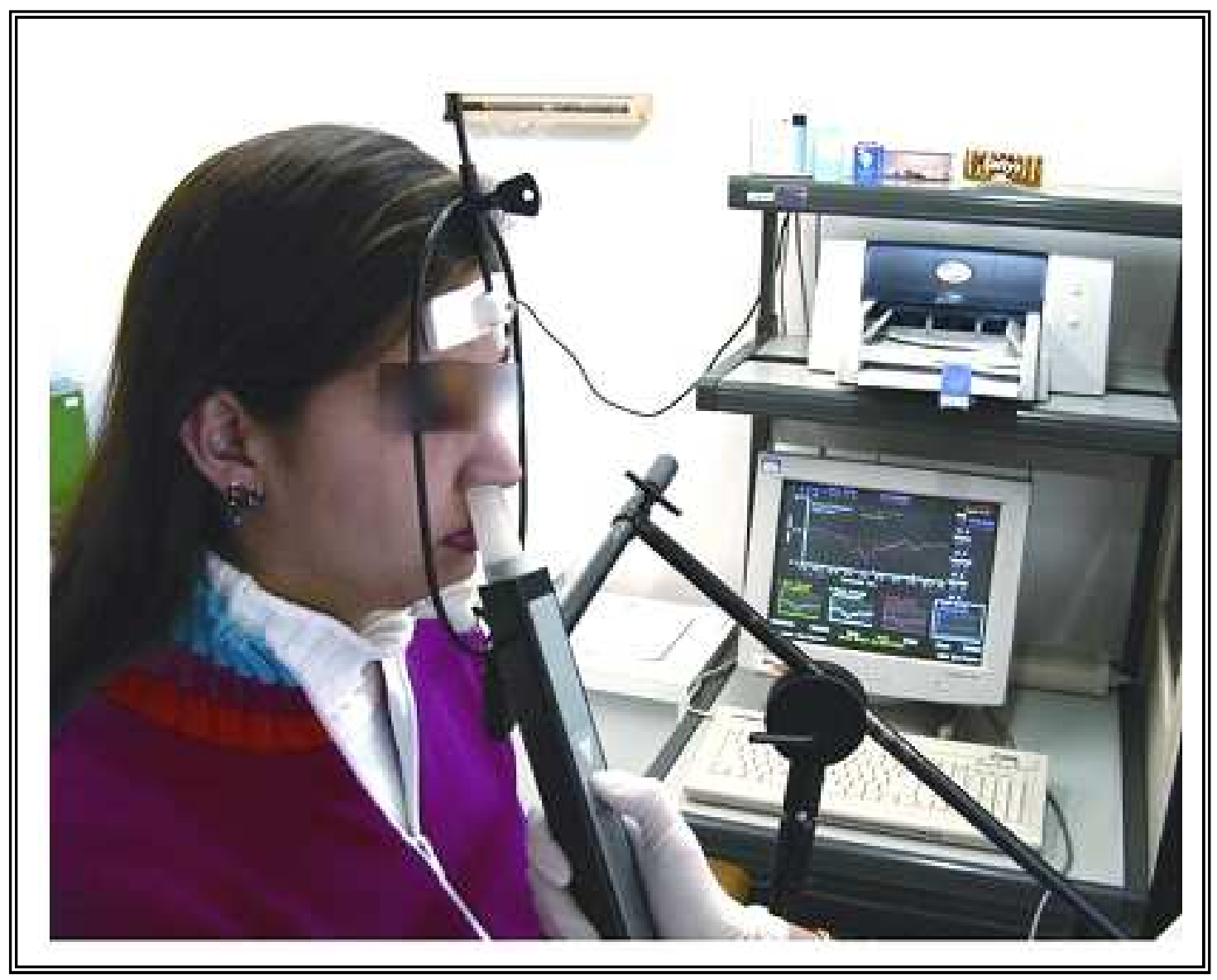

Figura 2 - Rinômetro Acústico Eccovision (HOOD Laboratories). 


\subsubsection{Procedimentos e variáveis aferidas.}

No presente estudo, três curvas foram coletadas para cada cavidade nasal, sendo descartadas aquelas que apresentaram artefatos óbvios. Os valores considerados para análise representam a média dessas três medidas tecnicamente aceitáveis, as quais foram feitas antes e 10 minutos após instilação de 5 gotas de um vasoconstritor nasal (cloridrato de xilometazolina a 0,1\%o) em cada narina, após higiene nasal, estando a cabeça do indivíduo reclinada para trás. A descongestão nasal teve por objetivo minimizar o efeito funcional (tecido mole-mucosa) e aferir basicamente o aspecto estrutural (ósseo-cartilaginoso) da cavidade em análise.

Para evitar possíveis erros nas medidas, durante a execução do exame, foram tomados os seguintes cuidados, de modo a garantir boa reprodutibilidade:

1. O equipamento foi calibrado no início de cada período do dia, segundo instrução do fabricante;

2. O exame foi realizado com o paciente na posição sentada, estando o queixo e a testa apoiados em uma armação especialmente desenvolvida para este fim, de modo a manter a cabeça estável durante o exame (figura 4);

3. O tubo foi posicionado de forma a não provocar deformação da narina e, por conseqüência, da válvula nasal;

4. O exame foi realizado durante a suspensão voluntária da respiração nasal, ao final de uma expiração, sendo o paciente orientado a permanecer com a boca fechada, sem deglutir ou movimentar a língua no momento da aquisição dos dados, o que não superou 10 segundos, de modo a evitar interferências nas medidas e na qualidade dos rinogramas; 


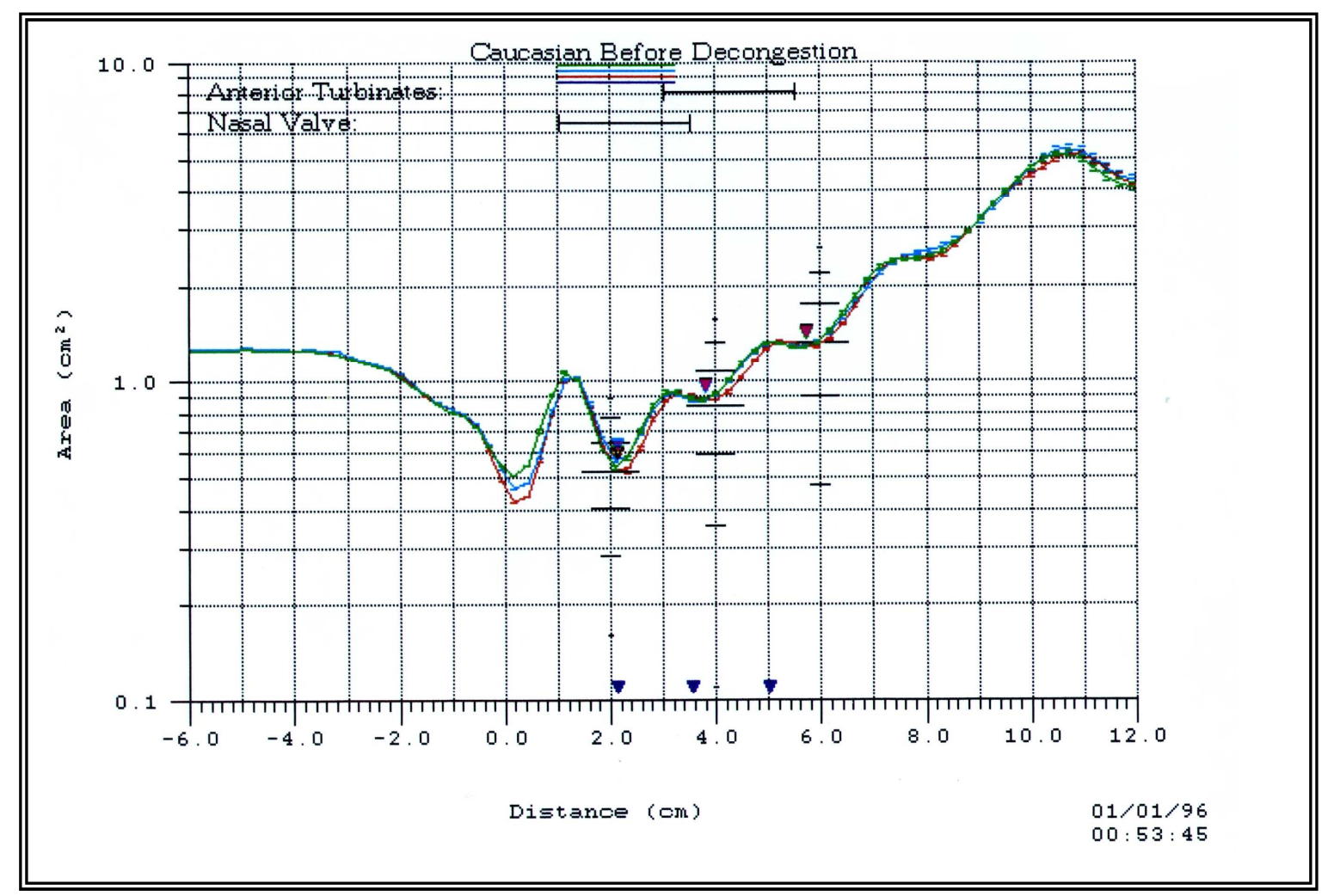

Figura 3 - Rinograma típico de um indivíduo sem obstrução nasal. No eixo $Y$ são representadas as áreas seccionais nasais $\left(e m \mathrm{~cm}^{2}\right)$ e no eixo $X$ as distâncias $(\mathrm{em} \mathrm{cm})$ relativamente às narinas $(0.0 \mathrm{~cm})$. 


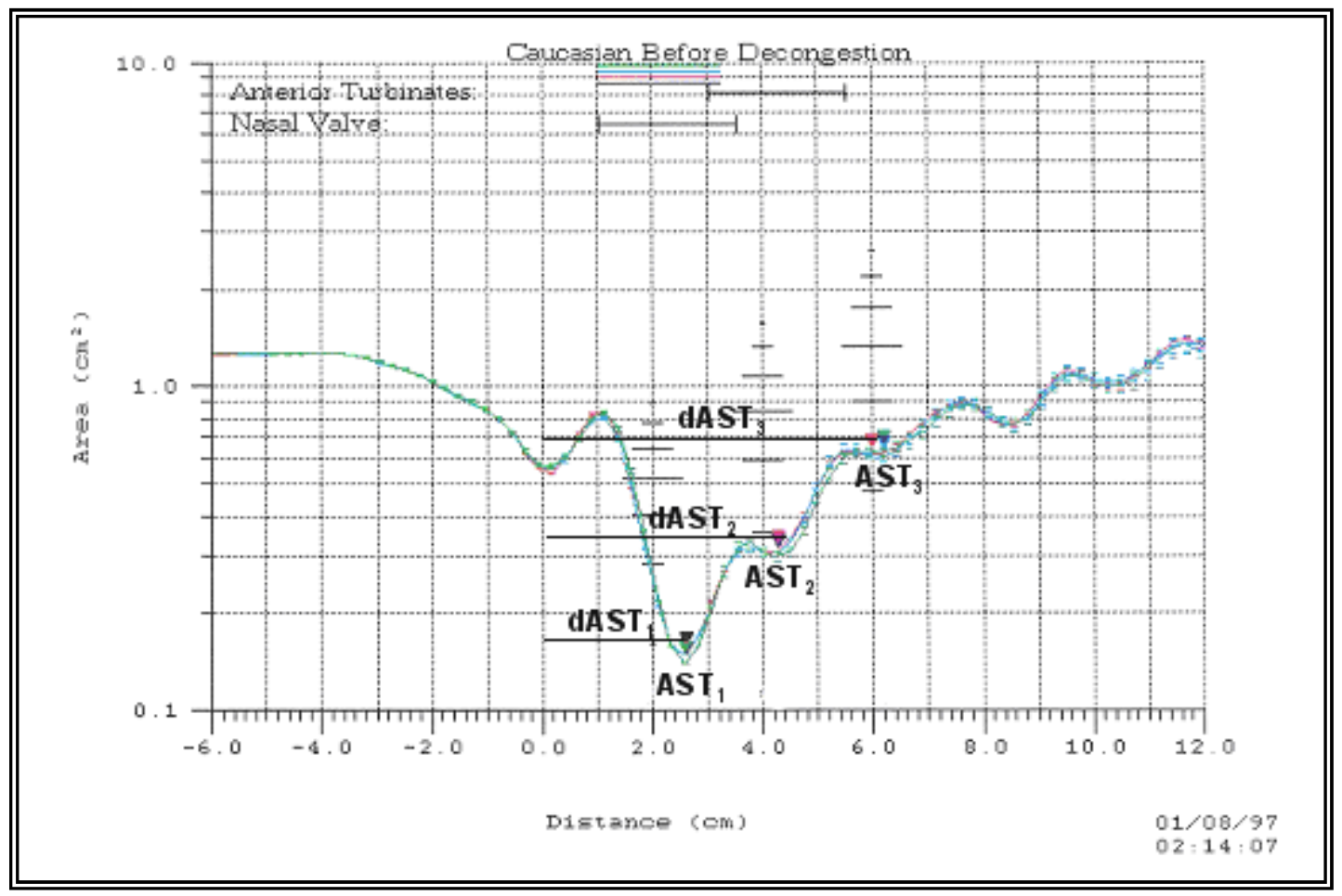

Figura 4 - Rinograma típico de um paciente com obstrução nasal, mostrando os locais de medida (destacados com triângulos invertidos) das áreas de secção transversa (AST) e suas respectivas distâncias com relação às narinas (dAST), em pontos correspondentes à válvula nasal $\left(\mathrm{AST}_{1}\right.$, $\mathrm{dAST}_{1}$ ), à extremidade anterior da concha nasal inferior e/ou média $\left(\mathrm{AST}_{2}, \mathrm{dAST}_{2}\right)$ e à extremidade médio-posterior da concha nasal média $\left(\mathrm{AST}_{3}, \mathrm{dAST}_{3}\right)$. 
5. As medidas foram realizadas sempre na mesma sala, em ambiente com temperatura relativamente estável (entre 22 e $26^{\circ} \mathrm{C}$ ) e nível de ruído controlado (inferior à $60 \mathrm{~dB}$ ), após um período de adaptação do paciente às condições ambientais de cerca de 30 minutos.

6. O vedamento entre o adaptador e a cavidade nasal foi feito utilizando gel neutro para eletrocardiograma com o objetivo de evitar perda sonora.

A partir do gráfico área-distância (figura 4) foram calculadas as áreas de secção transversa nasais (AST), em $\mathrm{cm}^{2}$, e suas distâncias em relação às narinas (dAST), em cm, na $2^{a}$ deflexão da curva: correspondente à área da válvula nasal $\left(\mathrm{AST}_{1}\right.$ e $\left.\mathrm{dAST}_{1}\right)$, na $3^{\text {a }}$ deflexão $\left(\mathrm{AST}_{2}\right.$ e $\left.\mathrm{dAST}_{2}\right)$ : correspondente à extremidade anterior da concha nasal inferior e/ou média e na $4^{\underline{a}}$ deflexão $\left(\mathrm{AST}_{3}\right.$ e $\mathrm{dAST}_{3}$ ): correspondente à extremidade médio-posterior da concha nasal média (Corey 2006). A primeira deflexão observada no rinograma, correspondente à região da narina, não foi considerada. Por esta razão, considerou-se as três deflexões acima descritas como $1^{\underline{a}}, 2^{a}$ e $3^{\underline{a}}$, respectivamente.

A partir da integração da curva área-distância, foram, também, determinadas as seguintes variáveis: $V_{1}=$ segmento situado entre 10 e $32 \mathrm{~mm}$ em relação à narina, correspondente à região da válvula nasal, $V_{2}=$ segmento situado entre 33 e 64 mm, correspondente à região das conchas nasais, e, $V_{3}=$ segmento situado entre $70 \mathrm{e}$ $120 \mathrm{~mm}$, correspondente à região da nasofaringe, $\mathrm{em}^{\mathrm{cm}^{3}}$, conforme feito por Antilla et al 1997 (figura 5). 


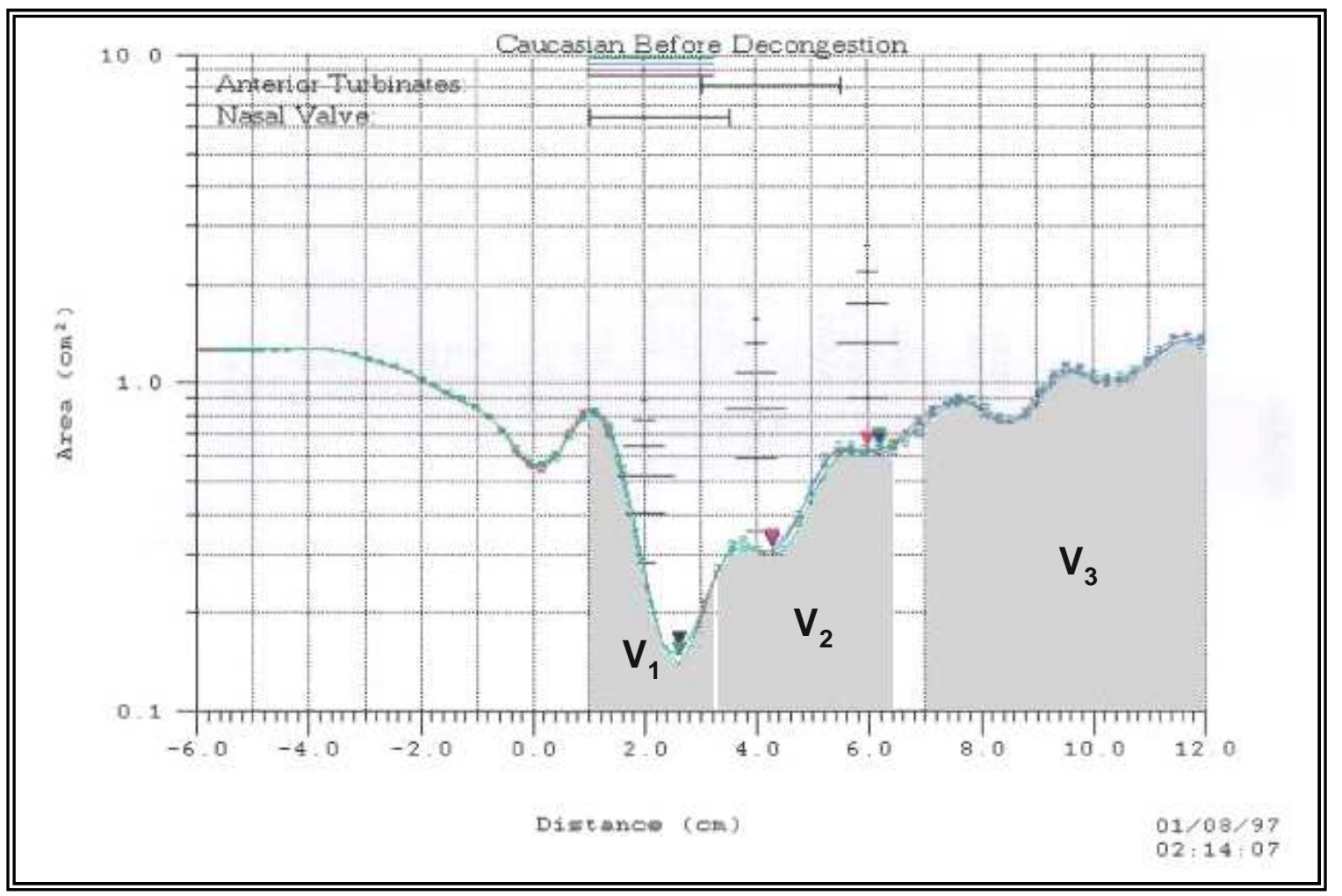

Figura 5 - Rinograma típico de um paciente com obstrução nasal, mostrando os locais de medida (áreas sob a curva) dos volumes correspondentes à região da válvula nasal $\left(\mathrm{V}_{1}\right)$, conchas nasais $\left(\mathrm{V}_{2}\right)$ e nasofaringe $\left(\mathrm{V}_{3}\right)$, segundo Antila et al 1997. 


\subsection{ANÁLISE ESTATÍSTICA}

As variáveis aferidas na rinometria acústica são expressas como média \pm desvio-padrão. Para analisar a significância das diferenças entre amostras independentes (grupo com obstrução nasal x grupo sem obstrução nasal) foi utilizado o teste "t" de Student. Para analisar a significância das diferenças entre as amostras relacionadas (antes e após o uso do descongestionante, e, lado direito e esquerdo da cavidade nasal) foi utilizado o teste "t" de Student para as amostras pareadas. Foram aceitos como significantes os valores de $p<0,05$. Para fins de comparação, foram utilizados os valores das áreas seccionais, de suas distâncias em relação às narinas, e, dos volumes nasais observados em adultos sem evidências de obstrução nasal, de faixa etária equivalente, analisados no Laboratório de Fisiologia HRAC/USP (Gomes 2004, Trindade et al 2007, Gomes et al 2008, Camargo 2008). Para a identificação de valores rinométricos indicativos de obstrução nasal, calculou-se, a partir desses valores de referência, o limite inferior de normalidade, subtraindo dois desvios-padrão à média relatada (Snedecor e Cochran, 1980). 
5 Resultados 



\section{RESULTADOS}

Os resultados obtidos nos 30 indivíduos com obstrução nasal analisados encontram-se nas tabelas 1 a 7 . Vinte e quatro pacientes apresentavam desvio de septo associado à hipertrofia de conchas nasais inferiores, 5 apresentavam desvio de septo isolado e 1 apresentou hipertrofia de conchas nasais inferiores isolada. Foram analisados 14 indivíduos do sexo masculino e 16 do sexo feminino, os quais foram reunidos em um só grupo, visto que na condição basal, ou seja, antes da descongestão nasal, não foram constatadas diferenças estatisticamente significantes entre os dois sub-grupos. Os principais achados da anamnese e do exame clínico, que levaram ao diagnóstico de obstrução nasal, são apresentados nos anexos 5 e 6, respectivamente.

\section{1 ÁREAS SECCIONAIS NASAIS}

$\mathrm{Na}$ tabela 1 encontram-se os valores médios das áreas de secção transversa nasal das três regiões estudadas $\left(\mathrm{AST}_{1}, \mathrm{AST}_{2}\right.$ e $\left.\mathrm{AST}_{3}\right)$, acompanhados dos respectivos desvios-padrão, observados nos 30 indivíduos com obstrução nasal analisados, antes e após a aplicação tópica do vasoconstritor nasal.

Observou-se que as médias de $\mathrm{AST}_{1}, \mathrm{AST}_{2}$ e $\mathrm{AST}_{3}$ do lado direito (LD) corresponderam a $0,45 \pm 0,19 \mathrm{~cm}^{2}, 0,80 \pm 0,36 \mathrm{~cm}^{2}$ e $1,13 \pm 0,53 \mathrm{~cm}^{2}$, respectivamente.

Do lado esquerdo (LE) corresponderam a $0,37 \pm 0,15 \mathrm{~cm}^{2}, \quad 0,87 \pm 0,40 \mathrm{~cm}^{2}$ e $1,22 \pm 0,51 \mathrm{~cm}^{2}$, respectivamente. Não se constatou diferença estatisticamente significante entre LD e LE, mas, com o intuito de eliminar uma eventual interferência do ciclo nasal nas medidas unilaterais, calculou-se a média da soma dos valores obtidos do LD e LE (SLDE) que corresponderam a $0,83 \pm 0,23 \mathrm{~cm}^{2}, 1,66 \pm 0,52 \mathrm{~cm}^{2} \mathrm{e}$ $2,36 \pm 0,77 \mathrm{~cm}^{2}$, respectivamente, antes da descongestão nasal. 
Tabela 1 - Valores médios ( \pm desvio padrão) das áreas de secção transversa da cavidade nasal ( $\mathrm{AST}_{1}, \mathrm{AST}_{2}$ e $\mathrm{AST}_{3}$ ) de adultos com obstrução nasal, aferidas por rinometria acústica, dos lados direito (LD) e esquerdo (LE), antes (SVC) e após (CVC) a descongestão nasal.

\begin{tabular}{|c|c|c|c|c|}
\hline CONDIÇÃO & LADO & $\begin{array}{l}\mathrm{AST}_{1} \\
\left(\mathrm{~cm}^{2}\right)\end{array}$ & $\begin{array}{l}\mathrm{AST}_{2} \\
\left(\mathrm{~cm}^{2}\right)\end{array}$ & $\begin{array}{l}\mathrm{AST}_{3} \\
\left(\mathrm{~cm}^{2}\right)\end{array}$ \\
\hline \multirow{3}{*}{ SVC } & $\begin{array}{l}\text { LD } \\
(n=30)\end{array}$ & $0,45 \pm 0,19$ & $0,80 \pm 0,36$ & $1,13 \pm 0,53$ \\
\hline & $\underset{(n=30)}{\mathrm{LE}}$ & $0,37 \pm 0,15$ & $0,87 \pm 0,40$ & $1,22 \pm 0,51$ \\
\hline & $\begin{array}{l}\text { SLDE } \\
(\mathrm{n}=30)\end{array}$ & $0,83 \pm 0,23$ & $1,66 \pm 0,52$ & $2,36 \pm 0,77$ \\
\hline \multirow{3}{*}{ CVC } & $\begin{array}{l}\text { LD } \\
(\mathrm{n}=30)\end{array}$ & $0,53 \pm 0,19^{S}$ & $1,21 \pm 0,34^{S}$ & $1,71 \pm 0,54^{S}$ \\
\hline & $\begin{array}{c}\mathrm{LE} \\
(\mathrm{n}=30)\end{array}$ & $0,45 \pm 0,15^{\mathrm{S}}$ & $1,42 \pm 0,42^{S^{*}}$ & $1,93 \pm 0,42^{S^{*}}$ \\
\hline & $\begin{array}{c}\text { SLDE } \\
(n=30)\end{array}$ & $0,97 \pm 0,20^{S}$ & $2,63 \pm 0,57^{S}$ & $3,64 \pm 0,76^{s}$ \\
\hline
\end{tabular}

SLDE = soma dos valores individuais obtidos do lado $D$ e lado $E$

$s_{p}<0,05$ diferença estatisticamente significante (sem versus com vasoconstritor)

${ }^{*} \mathrm{p}<0,05$ diferença estatisticamente significante (LD versus $L E$ ) 
Após a descongestão, as áreas unilaterais e bilaterais observadas nos três segmentos foram significativamente maiores $(p=000)$. Neste caso, foram observadas diferenças estatisticamente significantes entre LD e LE nos dois segmentos mais posteriores $\mathrm{AST}_{2}$ e $\mathrm{AST}_{3}(\mathrm{p}=0,02$ e $\mathrm{p}=0,05)$. Vale ressaltar que, no presente estudo, o vasoconstritor foi utilizado com o propósito de minimizar o efeito da "mucosa" sobre as medidas e comparações realizadas.

\subsection{DISTÂNCIAS DAS REGIÕES ESTUDADAS RELATIVAMENTE ÀS NARINAS}

Na tabela 2 encontram-se os valores médios das distâncias, relativamente às narinas, dos três segmentos estudados ( $\mathrm{dAST}_{1}, \mathrm{dAST}_{2}$ e $\left.\mathrm{dAST}_{3}\right)$, acompanhados dos respectivos desvios-padrão, observados nos 30 indivíduos com obstrução nasal, antes e após a aplicação tópica do vasoconstritor.

Observou-se que as médias da $\mathrm{dAST}_{1}, \mathrm{dAST}_{2}$ e dAST 3 do lado direito (LD) corresponderam a $2,14 \pm 0,17 \mathrm{~cm}, 4,00 \pm 0,33 \mathrm{~cm}$ e $5,83 \pm 0,36 \mathrm{~cm}$, respectivamente. Do lado esquerdo (LE) corresponderam a 2,24 $\pm 0,23 \mathrm{~cm}, 4,04 \pm 0,32 \mathrm{~cm}$ e $5,88 \pm 0,37 \mathrm{~cm}$, respectivamente. Diferença estatisticamente significante entre os lados foi constatada apenas para a distância correspondente a $\mathrm{AST}_{1}$ que se mostrou significativamente maior no LE.

Após a descongestão, alteração estatisticamente significante foi observada no LE nas distâncias correspondentes a $\mathrm{AST}_{1}$, que diminuíu, e $\mathrm{AST}_{3}$, que aumentou. Nesta condição, não foram constatadas diferenças entre LD e LE. 
Tabela 2 - Valores médios ( \pm desvio padrão) das distâncias (d) correspondentes a $\mathrm{AST}_{1}, \mathrm{AST}_{2}$ e $\mathrm{AST}_{3}$, da cavidade nasal de adultos com obstrução nasal, aferidas por rinometria acústica, dos lados direito (LD) e esquerdo (LE), antes (SVC) e após (CVC) a descongestão nasal.

\begin{tabular}{|c|c|c|c|c|}
\hline CONDIÇÃO & LADO & $\begin{array}{c}\mathrm{dAST}_{1} \\
(\mathrm{~cm})\end{array}$ & $\begin{array}{c}\mathrm{dAST}_{2} \\
(\mathrm{~cm})\end{array}$ & $\begin{array}{c}\mathrm{dAST}_{3} \\
(\mathrm{~cm})\end{array}$ \\
\hline \multirow{2}{*}{ SVC } & $\begin{array}{l}\text { LD } \\
(\mathrm{n}=30)\end{array}$ & $2,14 \pm 0,17$ & $4,00 \pm 0,33$ & $5,83 \pm 0,36$ \\
\hline & $\underset{(n=30)}{L}$ & $2,24 \pm 0,23^{*}$ & $4,04 \pm 0,32$ & $5,88 \pm 0,37$ \\
\hline \multirow[t]{2}{*}{ CVC } & $\begin{array}{l}\text { LD } \\
(n=30)\end{array}$ & $2,10 \pm 0,34$ & $4,00 \pm 0,42$ & $5,94 \pm 0,51$ \\
\hline & $\begin{array}{c}\text { LE } \\
(\mathrm{n}=30)\end{array}$ & $2,11 \pm 0,18^{S}$ & $4,04 \pm 0,32$ & $5,99 \pm 0,47^{s}$ \\
\hline
\end{tabular}

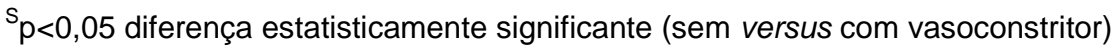

${ }^{*} \mathrm{p}<0,05$ diferença estatisticamente significante (LD versus LE) 


\subsection{VOLUMES NASAIS}

$\mathrm{Na}$ tabela 3 encontram-se os valores médios dos volumes nasais das três regiões estudadas $\left(V_{1}, V_{2}\right.$ e $\left.V_{3}\right)$, acompanhados dos respectivos desvios-padrão, observados nos 30 indivíduos com obstrução nasal analisados, antes e após a aplicação tópica do vasoconstritor nasal.

Observou-se que as médias de $V_{1}, V_{2}$ e $V_{3}$ do lado direito (LD) corresponderam a $1,46 \pm 0,41 \mathrm{~cm}^{3}, 3,17 \pm 1,38 \mathrm{~cm}^{3}$ e $13,19 \pm 5,78 \mathrm{~cm}^{3}$, respectivamente. Do lado esquerdo (LE) corresponderam a $1,31 \pm 0,37 \mathrm{~cm}^{3}, 3,35 \pm 1,44 \mathrm{~cm}^{3}$ e $12,81 \pm 5,32 \mathrm{~cm}^{3}$, respectivamente. Não se constatou diferença estatisticamente significante entre LD e LE, mas, como já mencionado, com o intuito de eliminar uma eventual interferência do ciclo nasal nas medidas unilaterais, calculou-se a soma dos valores obtidos do LD e LE (SLDE) que corresponderam a $2,77 \pm 0,51 \mathrm{~cm}^{3}$, $6,52 \pm 1,99 \mathrm{~cm}^{3}$ e $26,00 \pm 9,62 \mathrm{~cm}^{3}$, respectivamente, antes da descongestão nasal.

Após a descongestão, as áreas unilaterais e bilaterais observadas nos três segmentos foram significativamente maiores $(p=0,00)$ e, também neste caso, não foram constatadas diferenças estatisticamente significantes entre LD e LE.

\subsection{COMPARAÇÃO DOS RESULTADOS COM VALORES DE REFERÊNCIA}

Os resultados obtidos nos 30 pacientes analisados no presente estudo são, a seguir, comparados com os valores de referência obtidos em adultos sem evidências de obstrução nasal por Gomes (2004), que avaliou 30 indivíduos caucasianos, com idade entre 18 a 30 anos, sendo 14 do sexo masculino e 16 do sexo feminino. 
Tabela 3 - Valores médios ( \pm desvio padrão) dos volumes da cavidade nasal $\left(\mathrm{V}_{1}, \mathrm{~V}_{2}\right.$ e $\mathrm{V}_{3}$ ) de adultos com obstrução nasal, aferidas por rinometria acústica, dos lados direito (LD) e esquerdo (LE), antes (SVC) e após (CVC) a descongestão nasal.

\begin{tabular}{|c|c|c|c|c|}
\hline CONDIÇÃO & LADO & $\begin{array}{c}V_{1} \\
\left(\mathrm{~cm}^{3}\right)\end{array}$ & $\begin{array}{c}V_{2} \\
\left(\mathrm{~cm}^{3}\right)\end{array}$ & $\begin{array}{c}V_{3} \\
\left(\mathrm{~cm}^{3}\right)\end{array}$ \\
\hline \multirow{3}{*}{ SVC } & $\underset{(\mathrm{n}=30)}{\text { LD }}$ & $1,46 \pm 0,41$ & $3,17 \pm 1,38$ & $13,19 \pm 5,78$ \\
\hline & $\begin{array}{c}\mathrm{LE} \\
(\mathrm{n}=30)\end{array}$ & $1,31 \pm 0,37$ & $3,35 \pm 1,44$ & $12,81 \pm 5,32$ \\
\hline & $\begin{array}{c}\text { SLDE } \\
(\mathrm{n}=30)\end{array}$ & $2,77 \pm 0,51$ & $6,52 \pm 1,99$ & $26,00 \pm 9,62$ \\
\hline \multirow{3}{*}{ CVC } & $\begin{array}{l}\text { LD } \\
(\mathrm{n}=30)\end{array}$ & $1,70 \pm 0,39^{s}$ & $4,80 \pm 1,34^{\mathrm{S}}$ & $17,58 \pm 5,63^{s}$ \\
\hline & $\begin{array}{c}\mathrm{LE} \\
(\mathrm{n}=30)\end{array}$ & $1,56 \pm 0,43^{S}$ & $5,32 \pm 1,18^{S}$ & $18,99 \pm 4,27^{S}$ \\
\hline & $\begin{array}{c}\text { SLDE } \\
(n=30)\end{array}$ & $3,26 \pm 0,46^{s}$ & $10,12 \pm 1,80^{s}$ & $36,58 \pm 8,66^{s}$ \\
\hline
\end{tabular}

SLDE = soma dos valores individuais obtidos do lado $D$ e lado $E$

$s_{p<0,05}$ diferença estatisticamente significante (sem versus com vasoconstritor) 
$\mathrm{Na}$ tabela 4 são apresentadas as áreas seccionais médias (resultantes da soma dos valores aferidos dos lados direito e esquerdo: SLDE) do grupo controle (GC) e do grupo com obstrução nasal (GON). Comparando os resultados dos dois grupos, antes da descongestão nasal, verificou-se que os valores de GON foram significativamente menores nos três segmentos analisados. Após a descongestão, a diferença foi estatisticamente significante apenas para $\mathrm{AST}_{1}$. Nota-se que no GC o número de pacientes estudados foi inferior ao total analisado $(\mathrm{n}<30)$ para as variáveis $\mathrm{AST}_{2}$ e $\mathrm{AST}_{3}$ por não ter sido possível à identificação das deflexões correspondentes (Gomes 2004), o que não ocorreu no GON. A tabela 4 mostra, ainda, que no GC, a variação percentual dos valores médios de $\mathrm{AST}_{1}, \mathrm{AST}_{2}$ e $\mathrm{AST}_{3}$ após o uso do vasoconstritor correspondeu a $+5 \%,+45 \%$ e $+39 \%$, respectivamente, enquanto que no GON, a variação foi de maior magnitude, correspondendo a $+17 \%$, $+58 \%$ e $+54 \%$, respectivamente.

Na tabela 5 são apresentados os valores médios das distâncias, relativamente às narinas, dos três segmentos estudados (dAST $1, \mathrm{dAST}_{2}$ e dAST ${ }_{3}$ ) obtidos do lado direito e esquerdo nos dois grupos. Antes da descongestão nasal, observou-se que as médias de $\mathrm{dAST}_{1}$ e $\mathrm{dAST}_{2}$ foram significativamente maiores no GON. Após a descongestão, a diferença foi estatisticamente significante apenas para dAST 2 .

$\mathrm{Na}$ tabela 6 são apresentados os volumes médios (resultantes da soma dos valores aferidos do lado direito e esquerdo: SLDE) dos dois grupos. Antes e após a descongestão nasal, foram observados valores significativamente menores no GON em todos as regiões analisadas. No GC, a variação percentual dos valores médios de $V_{1}, V_{2}$ e $V_{3}$ após o uso do vasoconstritor correspondeu a $+8 \%,+39 \%$ e $+29 \%$, respectivamente. No GON, a variação foi de maior magnitude correspondendo $\mathrm{a}+18 \%,+55 \%$ e $+41 \%$, respectivamente. 
Tabela 4 - Comparação entre as áreas seccionais nasais $\left(\mathrm{AST}_{1}, \mathrm{AST}_{2}\right.$ e $\left.\mathrm{AST}_{3}\right)$ de adultos sem evidências de obstrução nasal (GC) analisados por Gomes (2004) e dos adultos com obstrução nasal (GON) analisados no presente estudo, aferidas por rinometria acústica, antes (SVC) e após (CVC) a descongestão nasal. Os dados mostrados representam a média da soma das áreas observadas do lado direito e esquerdo (SLDE).

\begin{tabular}{|c|c|c|c|c|c|}
\hline CONDIÇÃO & GRUPO & LADO & $\begin{array}{l}\mathrm{AST}_{1} \\
\left(\mathrm{~cm}^{2}\right) \\
\end{array}$ & $\begin{array}{l}\mathrm{AST}_{2} \\
\left(\mathrm{~cm}^{2}\right) \\
\end{array}$ & $\begin{array}{l}\mathrm{AST}_{3} \\
\left(\mathrm{~cm}^{2}\right) \\
\end{array}$ \\
\hline \multirow{3}{*}{ SVC } & $\begin{array}{c}\mathrm{GC} \\
(\mathrm{n}=30)\end{array}$ & SLDE & $1,08 \pm 0,21$ & $\begin{array}{c}1,95 \pm 0,35 \\
(n=26)\end{array}$ & $\begin{array}{c}2,85 \pm 0,51 \\
(n=26)\end{array}$ \\
\hline & & & & & \\
\hline & $\begin{array}{l}\text { GON } \\
(n=30)\end{array}$ & SLDE & $0,83 \pm 0,23^{S}$ & $1,66 \pm 0,52^{S}$ & $2,36 \pm 0,77^{s}$ \\
\hline \multirow{2}{*}{ CVC } & $\begin{array}{c}\mathrm{GC} \\
(\mathrm{n}=30)\end{array}$ & SLDE & $1,13 \pm 0,17$ & $\begin{array}{c}2,83 \pm 0,40 \\
(n=13)\end{array}$ & $\begin{array}{c}3,97 \pm 0,70 \\
(n=15)\end{array}$ \\
\hline & $\begin{array}{l}\text { GON } \\
(n=30)\end{array}$ & SLDE & $\begin{array}{c}0,97 \pm 0,20^{\mathrm{S}} \\
{[+17 \%]}\end{array}$ & $\begin{array}{c}2,63 \pm 0,57 \\
{[+58 \%]}\end{array}$ & $\begin{array}{c}3,64 \pm 0,76 \\
{[+54 \%]}\end{array}$ \\
\hline
\end{tabular}

[ ] média da variação percentual pós-descongestão (SVC versus CVC)

$s_{p<0,05}$ diferença estatisticamente significante (GC versus $G O N$ ) 
Tabela 5 - Comparação entre as distâncias das três áreas seccionais nasais analisadas, relativamente às narinas ( $\mathrm{dAST}_{1}, \mathrm{dAST}_{2}$ e $\left.\mathrm{dAST}_{3}\right)$, de adultos sem evidências de obstrução nasal (GC) analisados por Gomes (2004) e Camargo (2008) e dos adultos com obstrução nasal (GON) analisados no presente estudo, aferidas por rinometria acústica, antes (SVC) e após (CVC) a descongestão nasal. Os dados mostrados representam a média dos valores resultantes do cálculo da média das distâncias obtidas do lado direito e esquerdo (MLDE).

\begin{tabular}{|c|c|c|c|c|c|}
\hline CONDIÇÃO & GRUPO & LADO & $\begin{array}{c}\mathrm{dAST}_{1} \\
(\mathrm{~cm})\end{array}$ & $\begin{array}{c}\mathrm{dAST}_{2} \\
(\mathrm{~cm})\end{array}$ & $\begin{array}{c}\mathrm{dAST}_{3} \\
(\mathrm{~cm})\end{array}$ \\
\hline \multirow{2}{*}{ SVC } & $\underset{(n=30)}{G C}$ & MLDE & $2,12 \pm 0,19$ & $3,82 \pm 0,34$ & $5,74 \pm 0,41$ \\
\hline & $\begin{array}{l}\text { GON } \\
(n=30)\end{array}$ & MLDE & $2,19 \pm 0,20^{s}$ & $4,01 \pm 0,33^{S}$ & $5,85 \pm 0,37$ \\
\hline \multirow{2}{*}{ CVC } & $\underset{(n=30)}{G C}$ & MLDE & $2,04 \pm 0,17$ & $3,89 \pm 0,35$ & $5,85 \pm 0,51$ \\
\hline & $\begin{array}{l}\text { GON } \\
(n=30)\end{array}$ & MLDE & $2,10 \pm 0,26$ & $4,02 \pm 0,37^{\mathrm{S}}$ & $5,96 \pm 0,49$ \\
\hline
\end{tabular}

$s_{p<0,05}$ diferença estatisticamente significante (GC versus $\left.G O N\right)$ 
Tabela 6 - Comparação entre os volumes nasais $\left(V_{1}, V_{2}\right.$ e $\left.V_{3}\right)$ de adultos sem evidências de obstrução nasal (GC), analisados por Gomes (2004) e dos adultos com obstrução nasal (GON) analisados no presente estudo, aferidos por rinometria acústica, antes (SVC) e após (SVC) a descongestão nasal. Os dados mostrados representam a média da soma dos volumes nasais observadas do lado direito e esquerdo (SLDE).

\begin{tabular}{|c|c|c|c|c|c|}
\hline CONDIÇÃO & GRUPO & LADO & $\begin{array}{r}V_{1} \\
\left(\mathrm{~cm}^{3}\right) \\
\end{array}$ & $\begin{array}{r}V_{2} \\
\left(\mathrm{~cm}^{3}\right) \\
\end{array}$ & $\begin{array}{c}V_{3} \\
\left(\mathrm{~cm}^{3}\right) \\
\end{array}$ \\
\hline \multirow{2}{*}{ SVC } & $\underset{(n=30)}{G C}$ & SLDE & $3,37 \pm 0,50$ & $7,95 \pm 1,22$ & $35,34 \pm 7,13$ \\
\hline & $\begin{array}{l}\text { GON } \\
(n=30)\end{array}$ & SLDE & $2,77 \pm 0,51^{s}$ & $6,52 \pm 1,99^{S}$ & $26,00 \pm 9,62^{5}$ \\
\hline \multirow[t]{2}{*}{ CVC } & $\begin{array}{c}\mathrm{GC} \\
(\mathrm{n}=30)\end{array}$ & SLDE & $\begin{array}{c}3,65 \pm 0,42 \\
{[+8 \%]}\end{array}$ & $\begin{array}{c}11,06 \pm 1,70 \\
{[+39 \%]}\end{array}$ & $\begin{array}{c}45,41 \pm 8,06 \\
{[+29 \%]}\end{array}$ \\
\hline & $\begin{array}{l}\text { GON } \\
(n=30)\end{array}$ & SLDE & $\begin{array}{c}3,26 \pm 0,46^{\mathrm{S}} \\
{[+18 \%]}\end{array}$ & $\begin{array}{c}10,12 \pm 1,80^{\mathrm{S}} \\
{[+55 \%]}\end{array}$ & $\begin{array}{c}36,58 \pm 8,66^{5} \\
{[+41 \%]}\end{array}$ \\
\hline
\end{tabular}


Da comparação dos resultados individuais com os limites de normalidade calculados a partir dos dados de Gomes (2004) complementada pela observação dos rinogramas, mostrados no anexo 8 , verificou-se que 18 pacientes do grupo analisado apresentaram áreas seccionais subnormais (menores que limite inferior de normalidade) em um ou mais dos segmentos analisados (AST $1, \mathrm{AST}_{2}$ e $\mathrm{AST}_{3}$ ); os demais $(n=12)$ apresentaram valores acima do limite inferior de normalidade. Os rinogramas dos pacientes com AST subnormais estão assinalados com asterisco no anexo 8.

Para melhor interpretação desses achados, o grupo total foi dividido em dois sub-grupos e as médias das áreas seccionais individuais foram recalculadas e novamente comparadas com os valores médios de referência de Gomes (2004), conforme mostra a tabela 7. Assim procedendo, constatou-se que as médias do subgrupo "GON com AST individuais normais"” foram significativamente menores que as do GC apenas para AST 1. Já no sub-grupo "GON com AST individuais subnormais", as diferenças entre as médias foram estatisticamente significantes nos três segmentos analisados, relativamente ao GC e ao sub-grupo "GON com AST individuais normais".

$\mathrm{Na}$ tabela 7 observa-se, ainda, que o sub-grupo "GON com AST individuais subnormais", a variação percentual dos valores médios de $\mathrm{AST}_{1}, \mathrm{AST}_{2}$ e $\mathrm{AST}_{3}$, foi de maior magnitude $(+27 \%,+82 \%$ e $+74 \%$, respectivamente) que a observada no subgrupo GON com AST individuais normais $(+6 \%,+32 \%$ e $+33 \%$, respectivamente), esta última comparável àquela observada no GC. 
Tabela 7 - Comparação entre as áreas seccionais nasais $\left(\mathrm{AST}_{1}, \mathrm{AST}_{2}\right.$ e $\left.\mathrm{AST}_{3}\right)$ de adultos sem evidências de obstrução nasal (GC) analisados por Gomes (2004) e dos sub-grupos de adultos com obstrução nasal (GON) e AST normais e subnormais, analisados no presente estudo, aferidas por rinometria acústica, antes (SVC) e após (CVC) a descongestão nasal. Os dados mostrados representam a média da soma das áreas observadas do lado direito e esquerdo (SLDE).

\begin{tabular}{|c|c|c|c|c|c|}
\hline \multirow[b]{2}{*}{ CONDIÇÃO } & \multirow[b]{2}{*}{ GRUPOS } & \multirow[b]{2}{*}{$\begin{array}{c}\text { SUB- } \\
\text { GRUPOS } \\
\end{array}$} & \multicolumn{3}{|c|}{ SLDE } \\
\hline & & & $\begin{array}{l}\mathrm{AST}_{1} \\
\left(\mathrm{~cm}^{2}\right) \\
\end{array}$ & $\begin{array}{l}\mathrm{AST}_{2} \\
\left(\mathrm{~cm}^{2}\right) \\
\end{array}$ & $\begin{array}{l}\mathrm{AST}_{3} \\
\left(\mathrm{~cm}^{2}\right) \\
\end{array}$ \\
\hline \multirow{3}{*}{ SVC } & GC & - & $\begin{array}{c}1,08 \pm 0,21 \\
(n=30)\end{array}$ & $\begin{array}{c}1,95 \pm 0,35 \\
(\mathrm{n}=26)\end{array}$ & $\begin{array}{c}2,85 \pm 0,51 \\
(n=26)\end{array}$ \\
\hline & \multirow{2}{*}{ GON } & $\begin{array}{c}\text { AST } \\
\text { normal } \\
(\mathrm{n}=12)\end{array}$ & $0,96 \pm 0,19^{S}$ & $2,02 \pm 0,41$ & $2,83 \pm 0,46$ \\
\hline & & $\begin{array}{c}\text { AST } \\
\underset{(n=18)}{\text { subnormal }}\end{array}$ & $0,74 \pm 0,21^{\mathrm{SH}}$ & $1,43 \pm 0,46^{\text {S\# }}$ & $2,04 \pm 0,77^{\text {S\# }}$ \\
\hline \multirow{3}{*}{ CVC } & GC & - & $\begin{array}{c}1,13 \pm 0,17 \\
(n=30) \\
{[5 \%]}\end{array}$ & $\begin{array}{c}2,83 \pm 0,40 \\
(n=13) \\
{[45 \%]}\end{array}$ & $\begin{array}{c}3,97 \pm 0,70 \\
(n=15) \\
{[39 \%]}\end{array}$ \\
\hline & \multirow{2}{*}{ GON } & $\begin{array}{c}\text { AST } \\
\text { normal } \\
(\mathrm{n}=12)\end{array}$ & $\begin{array}{c}1,02 \pm 0,18^{\mathrm{S}} \\
{[+6 \%]}\end{array}$ & $\begin{array}{c}2,67 \pm 0,40 \\
{[+32 \%]}\end{array}$ & $\begin{array}{c}3,76 \pm 0,41 \\
{[+33 \%]}\end{array}$ \\
\hline & & $\begin{array}{c}\text { AST } \\
\text { subnormal } \\
(n=18)\end{array}$ & $\begin{array}{c}0,94 \pm 0,21^{\mathrm{s}} \\
{[+27 \%]}\end{array}$ & $\begin{array}{c}2,61 \pm 0,67 \\
{[+82 \%]}\end{array}$ & $\begin{array}{c}3,56 \pm 0,92^{\mathrm{S}} \\
{[+74 \%]}\end{array}$ \\
\hline
\end{tabular}

${ }^{s} \mathrm{p}<0,05$ diferença estatisticamente significante (GC versus $\mathrm{GON}$ )

$\# p<0,05$ diferença estatisticamente significante (GON AST normal versus GON ASTsubnormal) 



\section{DISCUSSÃO}

Em adultos, o nariz representa a porção mais estreitada das vias aéreas, de modo que pequenas alterações da geometria nasal podem resultar em alterações substanciais da patência nasal. Fatores que contribuem para a geometria da cavidade nasal incluem sua estrutura anatômica, o grau de ingurgitamento da circulação venosa que perpassa a mucosa respiratória, e o grau de edema, hiperplasia e/ou hipertrofia dessa mesma mucosa (Gosepath et al 2000).

A obstrução nasal é uma queixa comum entre portadores de desordens que afetam a geometria nasal como desvio septal, hipertrofia de conchas, pólipos nasais, rinite alérgica, vasomotora ou medicamentosa, sinusite crônica, e outras doenças inflamatórias. Essas condições podem ocorrer isoladamente ou de forma combinada, como é mais comum (Corey 2006). É o caso do desvio septal que, com freqüência, está associado à hipertrofia de concha. Sabe-se, inclusive, a partir de observações clínicas e estudos feitos em modelos, que, ao longo do tempo, o desvio septal pode levar a uma hipertrofia compensatória da concha contralateral ao desvio, condição conhecida como corneto vicariante (Illum 1997, Grützenmacher et al 2006).

Os estudos feitos em modelos que reproduzem, de maneira simplificada, a anatomia da cavidade nasal têm sido úteis para descrever os efeitos fisiológicos do desvio septal e as diferenças relacionadas à localização da obstrução. Grützenmacher et al (2006), por exemplo, demonstraram que durante a inspiração, em função do estreitamento causado pela convexidade do septo desviado, ocorre maior fricção das partículas de ar entre si e contra as paredes laterais do nariz causando um aumento da resistência ao fluxo. Adicionalmente, o espaço morto criado por detrás do estreitamento gera uma região de turbulência, até mesmo em 
fluxos baixos, que acaba por aumentar ainda mais a resistência ao fluxo aéreo. Como nas regiões mais posteriores o diâmetro é maior, o desarranjo do fluxo é menor. Inversamente, na região da válvula, o segmento de menor área seccional, qualquer obstrução resulta em comprometimento proporcionalmente maior. Isto explica porque desvios da parte anterior do nariz causam queixas com mais freqüência que nas partes mais posteriores. Grützenmacher et al (2006) também descreve as modalidades de fluxo no lado oposto ao da obstrução. Nos desvios anteriores, o fluxo de ar inspiratório depois de passar pela válvula nasal se desloca de forma laminar ao longo da concavidade criada pelo desvio, para depois seguir em direção à região posterior de forma turbilhonar. Nos desvios das porções média ou posterior, o fluxo percorre a cavidade nasal de forma laminar e paralela à parede lateral para só depois da constrição muda de regime. O novo espaço morto formado predispõe à formação de crostas e, principalmente nos desvios mais posteriores, leva ao alargamento da concha nasal ou à intumescência do septo. Curiosamente, este mecanismo compensatório, ao reduzir o espaço morto, termina por normalizar o regime de fluxo nessa cavidade nasal contralateral ao desvio, que se torna, então, assintomático. Isto reforça a constatação de que os desvios anteriores, onde esse mecanismo inexiste, são mais sintomáticos.

$\mathrm{Na}$ amostra de 30 adultos analisados no presente estudo, a maioria $(n=24)$ apresentava desvio de septo associado à hipertrofia de conchas nasais inferiores. Apenas 5 apresentavam desvio de septo isolado e 1 hipertrofia de conchas nasais inferiores isolada.

Pretendeu-se, nessa amostra de pacientes com obstrução nasal, caracterizar a geometria nasal por meio da rinometria acústica. Na análise global dos resultados, ficou comprovado que o grupo de pacientes estudados apresentava 
redução significativa das dimensões internas nasais, compatível com o diagnóstico clínico realizado pelos otorrinolaringologistas.

Como já mencionado, a rinometria acústica é a técnica que examina a geometria nasal com base na análise de um sinal acústico incidente, refletido pelas constrições encontradas no seu trajeto até a nasofaringe. No presente estudo, em condições basais, ou seja, sem o uso de vasoconstritor, três deflexões foram identificadas nos rinogramas gerados, a semelhança do que se verificou anteriormente em adultos e crianças normais (Gomes 2004, 2007). Foi possível constatar que o segmento mais estreitado, ou seja, a área de secção transversa mínima (ASTm), em 26 dos 30 casos analisados, estava localizada na parte anterior da cavidade nasal, a uma distância de até $3 \mathrm{~cm}$ das narinas, como descrito por Clement e Gordts (2005) em artigo publicado pelo Comitê de Padronização de Avaliação Objetiva da Via Aérea Nasal. Nestes 26 casos, portanto, a AST 1 e ASTm eram equivalentes. Essa primeira deflexão do rinograma, correspondente à válvula nasal, e identificada na literatura européia como I-notch em referência a Isthmus nasi, se deslocava no sentido anterior sob efeito da descongestão, como observado no estudo original de Grymer et al (1989). Identificou-se, também, em todos os rinogramas outra deflexão, situada à frente da deflexão que chamamos de primeira, correspondente à narina. Por se tratar apenas de um marco de referência (posição 0.0), foi desconsiderada nesta análise.

A segunda deflexão $\left(\mathrm{AST}_{2}\right)$, por sua vez, corresponde à área de secção transversa da cabeça da concha nasal média e/ou inferior, é identificada como Cnotch em referência a Concha. Esta medida não apresentou resposta à decongestão. Vale ressaltar que, em indivíduos normais, a ASTm não necessariamente corresponde à válvula. Segundo Clement e Gordts (2005), em 
alguns casos podem corresponder à $\mathrm{AST}_{2}$, ou seja, à cabeça da concha nasal média e/ou inferior. A comparação da localização da ASTm antes e após a descongestão em um mesmo indivíduo, é útil para definir a estrutura envolvida; isto porque, com a descongestão, o deslocamento anterior da ASTm é mais pronunciado quando corresponde à cabeça da concha nasal média e/ou inferior.

Verificou-se, ainda, a presença de uma terceira deflexão $\left(\mathrm{AST}_{3}\right)$, de origem menos clara e de identificação mais difícil no rinograma, supostamente correspondente à cauda da concha nasal média Clement e Gordts (2005). Esta apresentava tendência a se deslocar mais posteriormente, sob efeito da descongestão. A acuidade das medidas feitas com a rinometria acústica na porção posterior da cavidade nasal tem sido questionada pela possível interferência imposta por fatores como: 1) presença de obstruções significativas situadas anteriormente à nasofaringe, que subestimariam as medidas (Cakmak et al 2005), 2) reflexão acústica do som para a cavidade nasal contralateral ou para os seios paranasais, verificada em estudos feitos em modelos ou in vivo, que superestimariam as medidas (Cakmak et al 2005), 3) movimentos palatinos voluntários ou involuntários, 4) esforço respiratório, (Hilberg et al 1990, Kunkel e Hochbahn 1994, Fisher et al 1995, Kunkel et al 1999, Clement e Gordts 2005). Há que se lembrar, contudo, que alterações de resistência nas porções mais posteriores da cavidade nasal afetam menos a sensação de patência nasal (Zambetti 2004) e que a obstrução nasal está geralmente localizada na porção mais anterior (Hilberg e Pedersen 2000), como se demonstrou na população presentemente estudada.

Analisando, mais detalhadamente, os resultados obtidos, e comparando-os a dados normativos, foi possível constatar que as áreas seccionais médias dos três segmentos nasais analisados - válvula $\left(\mathrm{AST}_{1}\right)$, porção anterior $\left(\mathrm{AST}_{2}\right)$ e porção 
posterior das conchas nasais $\left(\mathrm{AST}_{3}\right)$ mostraram-se significantemente menores que áreas de referência definidas por Gomes (2004) em adultos sem evidências de obstrução nasal. Naquele estudo, utilizando igual metodologia, foram observadas, em 60 cavidades nasais, áreas seccionais médias de 0,54, 0,98 e 1,42 $\mathrm{cm}^{2}$, respectivamente, ao passo que, no presente estudo, do lado direito, corresponderam a $0,45,0,80$ e $1,13 \mathrm{~cm}^{2}$ do lado direito, respectivamente, e, do lado esquerdo, a 0,37, 0,87 e $1,22 \mathrm{~cm}^{2}$, respectivamente. Todos esses valores foram significativamente menores que os observados nos indivíduos normais, o que se repetiu na análise dos volumes das três regiões nasais analisadas - válvula $\left(\mathrm{V}_{1}\right)$, conchas $\left(\mathrm{V}_{2}\right)$ e nasofaringe $\left(V_{3}\right)$, na qual se observou, médias de $1,68,3,98$ e $18,93 \mathrm{~cm}^{3}$, nos indivíduos normais, e valores de 1,46, 3,17 e 13,19cm ${ }^{3}$, do lado direito, e 1,31, 3,35 e $12,81 \mathrm{~cm}^{3}$, do lado esquerdo, nos indivíduos com obstrução, respectivamente. Estes valores são similares aos relatados por diferentes autores (quadros 1 e 3). No entanto, a comparação deve ser feita com cautela, porque inúmeras variáveis não controladas entre os diversos estudos influenciam as dimensões internas nasais, tais como grau de obstrução, idade, sexo, postura, raça, temperatura ambiente, ruídos externos, respiração entre outras (Roithmann e Cole 1995, Morgan 1995, Fisher et al 1995, Tomkinson e Eccles 1996, Hilberg e Pedersen 2000, Parvez et al 2000). É certo, portanto, que o comprometimento atingia se não a todos, ao menos, a maioria dos pacientes analisados, o que se comprovou na análise individual dos dados. Ressalte-se que embora não pareçam diferenças substanciais, trata-se aqui de medidas quadráticas e cúbicas, o que significa que variações aparentemente pequenas podem representar, em verdade, modificações de grandeza suficiente para alterar a patência nasal. 
Após a aplicação tópica de vasoconstritor nasal, procedimento usado de rotina na avaliação rinométrica para minimizar a interferência da mucosa sobre as medidas e aferir o aspecto esquelético, os valores médios aumentaram todos como observado também para adultos normais (Gomes 2004). Outro dado a destacar é que $\mathrm{o}$ aumento percentual das áreas seccionais e volumes médios após a descongestão nasal, ou seja, a resposta ao vasoconstritor, foi claramente maior no grupo com obstrução comparado ao observado por Gomes (2004) em normais, indicando a presença de um componente funcional na origem dos sintomas obstrutivos dos pacientes analisados, em adição às alterações esqueléticas observadas ao exame otorrinolaringológico. Sintomas compatíveis com obstrução de origem funcional foram, de fato, constatados na anamnese em alguns deles.

Vale lembrar que, ainda que não se tenha observado diferenças entre os lados, optou-se, no presente estudo, por analisar os valores resultantes da soma dos lados, com a finalidade de evitar as possíveis diferenças relacionadas ao ciclo nasal. Trata-se de um fenômeno fisiológico episódico que se caracteriza por ciclos alternados de congestão e descongestão da mucosa que afetam reciprocamente as duas cavidades nasais, levando a fases de repouso de baixo fluxo e fases de trabalho de alto fluxo (Cole 1993, Mlynski 2006).

Com relação às distâncias das três principais constrições identificadas no rinograma (dAST $1, d A T_{2}, d A S T_{3}$ ), Camargo (2008) observou, nos adultos analisados por Gomes (2004), valores médios de 2,12, 3,82, 5,74cm, respectivamente. No grupo com obstrução observou-se, do lado direito, médias de $2,14,4,00$ e 5,83cm, respectivamente, e, do lado esquerdo, 2,24, 4,04 e 5,88, respectivamente, ou seja, valores maiores, particularmente para dAST1 e dAST2. Diferenças entre lados, quando constatadas, não pareceram de significado clínico. 
Os resultados obtidos sugerem que a obstrução pode ter causado um certo deslocamento das principais constrições do trato nasal no sentido posterior, ao menos em parte dos casos, comportamento também observado após eliminada a participação da mucosa com a descongestão nasal.

No conjunto, esses achados comprovam a presença de significativo comprometimento da patência nasal associado à obstrução nasal por desvio septal e hipertrofia de conchas nasais. Contudo, segundo Clement e Gordts (2005), para fins diagnósticos a melhor maneira de se avaliar os resultados da rinometria acústica é analisar a curva rinométrica como um todo, ao invés de valores absolutos derivados da curva. Disto se depreende, também, que a análise do comportamento médio de uma amostra de pacientes, como feito até aqui, mostra tendências, mas não pode, para fins clínicos, substituir a análise individual dos casos. Estudo subseqüente deverá ser conduzido com esse propósito, e, assim, investigar as correlações entre queixas, achados clínicos e achado rinométricos.

Apenas a título de especulação, como uma primeira aproximação do problema, procedeu-se à análise comparativa dos rinogramas obtidos. Isto levou à observação de que 12 pacientes apresentavam curvas aparentemente normais (curva W-ascendente, conforme nomenclatura usada por Cakmak et al 2005), ou seja, com áreas seccionais dentro dos limites normais, determinados a partir dos dados de Gomes (2004), apesar dos achados clínicos apontarem para a presença de alterações estruturais. Ressalte-se que, se fosse adotado o limite de normalidade de $0,40 \mathrm{~cm}^{2}$ proposto por Grymer et al (1993), o número de pacientes com valores normais, ainda assim, se situariam em 6 (seis). Dividindo, então, o grupo total em dois sub-grupos, e analisando, mais uma vez as médias, constatou-se que aquele com áreas subnormais (curva W-descendente) diferia do grupo controle em todos os 
segmentos analisados, enquanto o grupo de 12 pacientes com áreas individuais paradoxalmente normais diferia do grupo controle apenas em $\mathrm{AST}_{1}$, o que pode significar uma tendência a pequenos estreitamentos circunscritos à região da válvula e, explicar a sensação subjetiva de obstrução nasal experimentada por estes pacientes, dada a natureza resistiva desse segmento. Estudos nesse sentido são, portanto, necessários, visto que a sensação subjetiva de obstrução nasal não é meramente uma questão de área seccional ou, mesmo, de relação entre fluxos laminar e turbulento, como bem assinalaram Clement e Gordts (2005). Observou-se, ainda, que, enquanto no sub-grupo com valores subnormais a resposta ao vasoconstritor se mostrou nitidamente aumentada em relação à observada em normais, nos 12 pacientes com valores normais a resposta se mostrou diminuída comparável a dos normais. Assim sendo, há que se investigar se esse comportamento não estaria relacionado a alterações na regulação autonômica da mucosa nasal, o que denotaria uma mucosa nasal doente, não reativa a estímulos adrenérgicos (Ciprandi et al 2008).

Em suma, face às demandas por uma medicina baseada em evidências, a presente investigação demonstra que a rinometria acústica pode contribuir decisivamente para a análise objetiva da obstrução da via aérea nasal, complementando os dados aferidos na clínica otorrinolaringológica. Neste aspecto, o estudo pôde também contribuir para a sistematização de um protocolo de avaliação clínica, útil para fins de documentação e pesquisa. 

7 Conclusões 


\section{CONCLUSÕES}

$\mathrm{Na}$ presente investigação, os resultados obtidos com o uso da rinometria acústica mostraram que adultos com obstrução nasal por desvio septal e/ou hipertrofia de conchas nasais inferiores, comparativamente a adultos sem evidências de obstrução, estudados por Gomes (2004), apresentaram, em média:

1) Áreas seccionais dos três segmentos nasais analisados - válvula, porção anterior e porção posterior das conchas nasais - significantemente menores, sendo que após a descongestão nasal, a diferença foi significativa apenas na região da válvula nasal.

2) Distâncias em relação às narinas significantemente aumentadas dos dois segmentos mais anteriores analisados, sendo que após a descongestão nasal, a diferença foi significativa apenas para a porção anterior da conchas.

3) Volumes nasais das três regiões nasais analisadas - válvula, conchas e nasofaringe - significantemente menores, antes e após a descongestão nasal.

4) Aumento proporcionalmente maior das áreas seccionais e dos volumes nasais com a descongestão nasal, demonstrando a existência de um componente funcional na obstrução apresentada pelos pacientes analisados.

Esses achados traduzem a presença de significativo comprometimento da patência nasal associado à obstrução nasal por desvio septal e hipertrofia de conchas nasais. Ressalte-se, contudo, que um sub-grupo de pacientes com resultados rinométricos normais foi identificado entre os pacientes analisados, apesar dos achados clínicos apontarem para a presença de alterações estruturais, o que deverá ser objeto de estudo subseqüente no Laboratório de Fisiologia do HRAC/USP. 

8 Referências 



\section{REFERÊNCIAS}

Antila J, Sipilä J, Tshushima Y, Pólo O, Laurikainen E, Suonpää. The effect of laseruvulopalatopharyngoplasty on the nasal and nasopharyngeal volume measured with acoustic rhinometry. Acta Otolaryngol Suppl 1997; 529:202-5.

Bertier CE. Efeitos da rinoseptoplastia sobre as dimensões internas nasais e ressonância da fala em indivíduos com fissura de lábio e palato unilateral reparada: análise por rinometria acústica e nasometria [tese]. Bauru: Universidade de São Paulo; 2006.

Bertier CE, Trindade IEK. Deformidades nasais: avaliação e tratamento cirúrgico. In: Trindade IEK, Silva Filho OG. Fissuras Labiopalatinas: uma abordagem interdisciplinar. São Paulo: Santos; 2007. p. 87-07

Butler J. The work of breathing through the nose. Clin Sci 1960; 19:55-62.

Brasil. Ministério do Planejamento, Orçamento e Gestão. Instituto Brasileiro de Geografia e Estatística - IBGE - Censo Demográfico 2000. Rio de Janeiro: Ministério do Planejamento, Orçamento e Gestão; 2000.

Brown IG, Zamel N, Hoffstein V. Pharyngeal cross-sectional area in normal men and women. J Appl Physiol 1986; 61:890-5.

Cakmak O, Tarhan E, Coskun M, Cankurtaran M, Çelik H. Acoustic rhinometry: accuracy and ability to detect changes in passage area at different locations in the nasal cavity. Annals of Otology, Rhinology \& Laryngology 2005; 114:949-957.

Camargo TF. Distância da válvula nasal de adultos com e sem fissura labiopalatina estimada por rinometria acústica [monografia]. Bauru: Universidade de São Paulo; 2008.

Carlini D, Ouriques DM, Weckx LLM, Fujitaet RR. Modified method of acoustic rhinometry. Acta Otolaryngol 2002; 122:298-301.

Ciprandi G, Cirillo I, Pistorio A, Grutta SL. Relationship between rhinitis duration and worsening of nasal function. Otolaryngol Head and Neck Surgery 2008; 138:725-29.

Clement PAR, Gordts F. Consensus report on acoustic rhinometry and rhinomanometry. Rhinology 2005; 43:169-179.

Cole P. The respiratory role of the upper airways: a selective clinical and pathophysiological review 1993. St Louis: Mosby Year Book. 158p.

Corey JP. Acoustic rhinometry: should we be using it? Otolaryngol Head Neck Surg 2006, 14:29-34. 
Corey JP, Gungor A, Nelson R, Liu X, Fredberg J. Normative standards for nasal cross-sectional areas by race as measured by acoustic rhinometry. Otolaryngol Head Neck Surg 1998; 119:389-93.

D'Urzo AD, Lawson VG, Vassal KP, Rebuck AS, Slutsky AS, Hoffstein V. Airway area by acoustic response measurements and computerized tomography. Am Rev Respir Dis 1987; 135:392-5.

D'Urzo AD, Rubinstein I, Lawson VG, Vassal KP, Rebuck AS, Slutsky AS et al. Comparison of glottic areas measured by acoustic reflection vs. Computerized tomography. J Appl Physiol 1988; 64:367-70.

Dalston RM. Acoustic assessment of the nasal airway. Cleft Palate Craniofac J 1992; 29:520-6

Egeli E, Demirci L, Yazýcý B, Harputluoglu U. Evaluation of the inferior turbinate in patients with deviated nasal septum by using computed tomography. Laryngoscope 2004; 114:113-16.

Fisher EW, Palmer CR, Daly NJ, Lund VJ. Acoustic rhinometry in the pre-operative assessment of adenoidectomy candidates. Acta Otolaryngol 1995; 115:815-22.

Fredberg JJ, Wohl ME, Glass GM, Dorkin HL. Airway area by acoustic reflectionsmeasured at the mouth. J Appl Physiol 1980, 48:749-58.

Fukushiro AP, Trindade IEK. Nasal airway dimensions of adults with cleft lip and palate: differences among cleft types. Cleft Palate Craniofac J 2005; 42:396-402

Gilain L, Coste A, Ricolf F, Dahan E, Marliac D, Peynegre R et al. Nasal cavity geometry measured by acoustic rhinometry and computed tomography. Arch Otolaryngol Head Neck Surg 1997; 123:401-5.

Gomes AOC. Dimensões nasais e nasofaríngeas de indivíduos sem evidencias de obstrução nasal avaliadas por rinometria acústica no repouso e na fala [dissertação]. Bauru: Universidade de São Paulo; 2004.

Gomes AOC. Dimensões internas nasais de crianças com fissura de lábio e palato unilateral aferidas por rinometria acústica [tese]. Bauru: Universidade de São Paulo, 2007.

Gomes AOC, Sampaio-Teixeira ACM, Trindade SHK, Trindade IEK. Áreas seccionais nasais de adultos sadios aferidas por rinometria acústica. Rev. Bras. de Otorrinolaringologia 2008, 74:746-54.

Gosepath J, Belafsky P, Kaldenbach T, Rolfe KW, Mann WJ, Amedee R. The use of acoustic rhinometry in predicting outcomes after sinosal surgery. Am Journal of Rhinology 2000; 14: 97-100.

Grymer LF. Clinical applications of acoustic rhinometry. Supplement 2000, 16:35-43. 
Grymer LF, Hilberg O, Elbrond O, Pedersen OF. Acoustic rhinometry: evaluation of the cavity nasal with septal deviations, before and after septoplasty. Laryngoscope 1989; 99:1180-7.

Grymer LF, Hilberg O, Pedersen OF. Rasmussen TR. Acoustic rhinometry: values from adults with subjective normal nasal patency. Rhinology 1991; 29:35-47.

Grymer LF, Hilberg O, Pedersen OF. Prediction of nasal obstruction basead on clinical examination and acoustic rhinometry. Rhinology 1997; 35:53-7.

Grymer LF, Illum P, Hilberg O. Septoplasty and compensatory inferior turbinate hypertrophy: a randomized study evaluated by acoustic rhinometry. The Journal of Laryngology and Otology 1993, 107:413-17.

Grymer LF, Illum P, Hilberg O. Bilateral inferior turbinoplasty in chronic nasal obstruction. Rhinology 1995; 34:50-3.

Grützenmacher S, Robinson DM, Gräfe K, Lang C, Mlynski G. First Findings concerning airflow in noses with septal deviation and compensatory turbinate hypertrophy - a model study. ORL 2006; 68:199-205.

Hairfield WM, Warren DW, Seaton DL. Prevalence of mouthbreathing in cleft lip and palate. Cleft Palate J 1988; 25:135-8.

Hilberg O. Objective measurement of nasal airway dimensions using acoustic rhinometry: methodological and clinical aspects. Allergy 2002; 57:5-39.

Hilberg O, Grymer LF, Pedersen O. Spontaneous variations in congestion of the nasal mucosa. Ann Allergy Asthma Immunol. 1995; 74:516-21.

Hilberg O, Grymer LF, Pedersen O, Elbrond O. Turbinate hypertrophy: evaluation of the nasal cavity by acoustic rhinometry. Arch Otolaryngol Head Neck Surg 1990; 116:283-9.

Hilberg O, Jackson AC, Swift DL, Pedersen OF. Acoustic rhinometry: evaluation of nasal cavity geometry by acoustic geometry by acoustic reflection. J Appl Physiol 1989; 66:295-3003.

Hilberg O, Pedersen OF. Acoustic rhinometry: recommendations for technical specifications and standard operating procedures. Rhinol Suppl 2000; 16:3-17.

Hoffstein V, Zamel N, Philipson EA. Lung volume dependence of pharyngeal crosssectional area in patients with obstructive sleep apnea. Am Rev Respir Dis 1984; 130:178-8.

Hungria $H$, Doenças das fossas nasais e cavidades paranasais. In: Hungria $H$. Otorrinolaringologia. 8 ed. Rio de Janeiro: Guanabara Koogan S/A.; 2000. 
Hurst JR, Kuchai R, Michael P, Perera WR, Wilkinson TMA, Wedzicha JA. Nasal symptoms, airway obstruction and disease severity in chronic obstructive pulmonary disease. Clin Physiol Funct Imaging 2006; 25:270-4.

Illum P. Septoplasty and compensatory inferior turbinate hypertrophy: long-term results after randomized turbinoplasty. Eur Otorhinolaryngol 1997; 254:89-92.

Jackson AC, Butler JP, Millet EJ, Hoppin Junior FG, Dawson SV. Airway geometry by analysis of acoustic pulse response measurements. J Appl Physiol 1977; 43:523-36.

Kemker B, Liu X, Gungor A, Moinuddin R, Corey JP. Effect of nasal surgery on the nasal cavity as determined by acoustic rhinometry. Otolaryngol Head Neck Surg 1999; 121:567-71.

Kesavanathan J, Swift DL, Bascom R. Nasal pressure-volume relationship determined with acoustic rhinometry. J Appl Physiol 1995; 79:547-53.

Kjaergaard T, CvancarovaM, Steinsvag SK. Does nasal obstruction mean that the nose is obstructed? Laryngoscope 2008; 118:1476-80.

Kunkel M, Hochban W. Acoustic rhinometry: a new diagnostic procedureexperimental and clinical experience. Int J Oral Maxillofac Surg 1994; 23:409-12.

Kunkel M, Wahlmann U, Wagner W. Nasal airway in cleft-palate patients: acoustic rhinometric data. J Cranio-Max Fac Surg 1997; 25:270-4.

Kunkel M, Wahlmann U, Wagner W. Acoustic airway profiles in unilateral cleft palate patients. Cleft Palate Craniofac J 1999; 36:434-40.

Lai VWS, Corey JP. The objective assessment of nasal patency. Ear Nose Throat $J$ 1993; 72:395-400.

Lenders $\mathrm{H}$, Pirsig W. Diagnostic value of acoustic rhinometry: patients with allergic and vasomotor rhinitis compared with normal controls. Rhinology 1990; 28:5-16.

Lenders H, Schaefer J, Pirsig W. Turbinate hipertrophy in habitual snorers and patients with obstrutive sleep apnea: findings of acoustic rhinometry. Laryngoscope $1991 ; 101: 614-8$.

Linder-Aronson S. Naso-respiratory function and craniofacial growth. In: McNamara Junior JA, editor. Naso-respiratory function and craniofacial growth. Ann Arbor: Center for Human Growth and Development; 1979. p.121-47.

Mamikoglu B, Houser SM, Akbar INGB, Corey JP. Acoustic rhinometry and computed tomography scans for the diagnosis of nasal septal deviation, with clinical correlation. Otolaryngol Head Neck Surg 2000; 123:61-8.

Mamikoglu B, Houser SM, Corey JP. An interpretation method for objective assessment of nasal congestion with acoustic rhinometry. Laringoscope 2002; 112:926-9. 
Mann WJ, Riechelmann H, Hinni ML. Acoustic rhinometry - predictive value in septal and turbinate surgery. Adv Otorhinolaryngol 1997; 51:61-7.

Millqvist E, Bende M. Reference values for acoustic rhinometry in subjects without nasal symptoms. Am J Rhinol 1998; 12:341-3.

Mlynski G. Surgery of the nasal sptum. Seminars in plastic surgery. 2006; 22:223-29.

Mlynski G, Beule A. Diagnostik der respiratorischen funktion der nase. HNO 2007, 56:81-99.

Morgan NJ, MacGregor FB, Birchall MA, Lund VJ, Sittampalam Y. Racial differences in nasal fossa dimensions determined by acoustic rhinometry. Rhinology 1995; 33: 224-8.

Navarro JAC, Navarro PL, Navarro ML. Anatomia da cavidade nasal e seios paranasais. In: Campos $\mathrm{CAH}$, Costa HOO. Tratado de Otorrinolaringologia. São Paulo: Roca. 2002. 47, 591-609.

Nigro CEN, Nigro JFA, Voegels RL, Mion O, Mello Jr JF. Acoustic rhinometry: anatomic correlation of the first two notches found in the nasal echogram. Rev Bras Otorrinolaringol (Engl Ed). 2005 Mar-Apr; 71(2):149-54.

Ognibene NE, Merrick MA, Ingersoll CD. Intra and intercession reability of acoustic rhinometry in measuring nasal cross-sectional area. Ear Nose Throat J 2001; 80:53640.

Parvez L, Erasala G, Noronha A. Novel techniques standartization tools to enhance reliability of acoustic rhinometry measurements. Rhinol Suppl 2000; 16:18-28.

Pirilä T, Tikanto J. Unilateral and bilateral effects of nasal septum surgery demonstrated with acoustic rhinometry, rhinomanometry, and subjective assessment. Am J Rhinol 2001; 15:127-33.

Qian W, Chen W, Chen JM, Haight J. Acoustic rhinometry in preschool children. Otolaringol Head Neck Surg 2007; 137:39-42.

Reber M, Rahm F, Monnier PH. The role of acoustic rhinometry in the pre and postoperative evaluation of surgery for nasal obstruction. Rhinology 1998; 36:184-7.

Roithmann R. Testes específicos da permeabilidade nasal [editorial]. Rev. Bras. Otorrinolaringologia 2007; 73(1):2.

Roithmann R, Cole P. Objective assessment of nasal patency: why, when, how? Rev Bras Otorrinolaringologia 1995; 61:104-9.

Roithmann R, Cole P, Chapnik J, Shpirerl, Hoffstein V, Zamel N. Acoustic rhinometry in the evaluation of nasal obstruction. Laryngoscope 1995; 105:275-81. 
Roithmann R, Chapnik J, Zamel N, Barreto SM, Cole P. Acoustic rhinometry assessment of the nasal valve. Am J Rhinol 1997; 11:379-85.

Roithmann R, Demeneghi P, Faggiano R, Cury A. Efeitos da alteração de postura sobre a permeabilidade nasal. Rev Bras Otorrinolaringologia 2005; 71:478-84.

Shemen L, Hamburg R. Preoperative and postoperative nasal septal surgery assessment with acoustic rhinometry. Otolaryngol Head Neck Surg 1997; 117:33842.

Silkoff PE, Chakravorty S, Chapnik J, Cole P, Zamel N. Reproducibility of acoustic rhinometry and rhinomanometry in normal subjects. Am J Rhinol 1999; 13:131-5

Snedecor GW, Cochran WG. Statistical methods. 7th edn. lowa State University Press: Ames, 1980. 39-63.

Sondhi MM, Gopinath B. Determination of vocal tract shape from impulse response at the lips. J Acoust Soc Am 1971; 49:1867-73.

Sung YW, Lee MH, Kim IJ, Lim DW, Rha KS, Park Cl. Nasal cycle in patients with septal deviation: evalution by acoutic rhinometry. American Journal of Rhinology 2000; 14:171-4.

Szücs E, Peter AR, Clememt MD. Acoustic rhinometry and rhinomanometry in the evaluation of nasal patency of patients with nasal septal deviation. American Journal of Rhinology 1998; 12:345-51.

Tomkinson A, Eccles R. Acoustic rhinometry: an explanation of some common artefacts associated with nasal descongestion. Clin Otolaryngol 1998; 23:20-6.

Trindade IEK, Bertier CE ; Sampaio-Teixeira.ACM. Objective assessment of internal nasal dimensions and speech resonance in individuals with repaired unilateral cleft lip and palate following rhinoseptoplasty.. Journal of Craniofacial Surgery. In press 2009.

Trindade IEK, Gomes AOC, Sampaio-Teixeira ACM, Trindade SHK. Volumes nasais de adultos aferidos por rinometria acústica. Rev. Bras.Otorrinolaringologia 2007, 73: 32-39.

Trindade IEK, Manço JC, Trindade Junior AS. Pulmonary function of individuals with congenital cleft palate. Cleft Palate Craniofac J 1992; 29:429-34.

Trindade IEK, Silva Filho OG. Fissuras Labiopalatinas: uma abordagem interdisciplinar. São Paulo: Santos; 2007. 337p.

Urpegui AM, Vallés H, Millan J, Royo J. Eváluacion mediante rinometría acústica de los resultados quirúrgicos en pacientes intevenidos de septoplastia. Acta Otorrilaring Esp 1999; 50:34-9. 
Vig KWL. Nasal obstruction and facial growth: the strength of evidence for clinical assumptions. Am J Orthod Dentofacial Orthop 1998; 113:603-11.

Voegels RL, Goto EY, Lessa MM, Romano, FR, Neves MC, Tavares R, et al. Avaliação pré e pós-operatória por rinometria acústica de pacientes submetidos à cirurgia de septo nasal e conchas inferiores. Arq Otorrionolaryngol 2002; 6:169-72

Warren DW, Drake AF. Cleft nose: form and function. Clin Plast Surg 1993; 20:76979.

Warren DW, Drake A, Davis JU. Nasal airway in breathing and speech. Cleft Palate Craniofac J 1992; 29:511-9.

Wetmore RF. Importance of maintaining normal function in the cleft palate patient. Cleft Palate Craniofac J 1992; 29:498-506.

Zambetti G, Filiaci F, Romeo R, Soldo P, Filiaci F. Assessment of Cottle's areas through the application of a mathemtical model deriving from acoustic rhinometry and rhinomanometric data. Clinical Otolaryngology 2005; 128-134.

Zancanella E, Anselmo-Lima WT. Uso da rinometria acústica como método diagnóstico. Rev Bras Otorrinolaringologia 2004; 70(4):500-3. 

ANEXOS 

Anexo 1

Termo de Consentimento Livre e Esclarecido 



\section{ANEXO 1 - TERMO DE CONSENTIMENTO LIVRE E ESCLARECIDO}

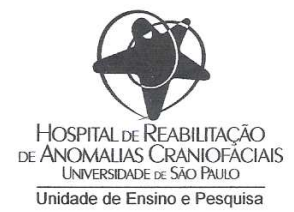

TERMO DE CONSENTIMENTO LIVRE E ESCLARECIDO

Pelo presente instrumento que atende às exigências legais, o Sr. (a) , portador da cédula de identidade *responsável pelo paciente

após leitura minuciosa deste documento, devidamente explicado pelos profissionais em seus mínimos detalhes, ciente dos serviços e procedimentos aos quais será submetido, não restando quaisquer dúvidas a respeito do lido e explicado, firma seu CONSENTIMENTO LIVRE E ESCLARECIDO concordando em participar da pesquisa: "Dimensões internas nasais de indivíduos com obstrução nasal avaliadas por Rinometria Acústica", realizada por: Priscila Capelato Prado (COREN-SP 0124740), sob orientação da Drª: Inge Elly Kiemle Trindade (CRBM 1-2081), que tem por objetivo avaliar o funcionamento do nariz de pacientes que apresentam o nariz obstruído.

No Hospital Estadual Bauru (HEB) você será avaliado pelos médicos do Serviço de Otorrinolaringologia que farão perguntas sobre o estado de sua saúde e exames de rotina daquele serviço, tais como a rinoscopia (anterior e posterior). Na rinoscopia anterior a narina será aberta delicadamente, com um espéculo nasal (instrumento que permite alargar a cavidade nasal para a realização do exame) junto com uma iluminação adequada; na rinoscopia posterior, o médico segurará sua língua com uma gaze e será introduzido um pequeno instrumento com um espelho redondo na ponta, até a região próxima a "campainha" e você será solicitado a respirar pelo nariz. Ambos exames são necessários para investigar o tipo e o grau da obstrução nasal que você apresenta.

Se for comprovado que seu nariz tem desvio de septo e hipertrofia dos cornetos, convidamos você a comparecer no LABORATÓRIO DE FISIOLOGIA do HOSPITAL DE REABILITAÇÃO DE ANOMALIAS CRANIOFACIAIS - HRAC (CENTRINHO) para ser submetido a um exame chamado "rinometria acústica" que permite determinar áreas e volumes de diferentes partes da cavidade nasal. Durante o exame, o paciente fica sentado com o queixo apoiado em um suporte, um tubo do equipamento é encostado na narina e um som é lançado no nariz e recolhido, depois, como um eco. Isto permite que sejam feitas as medições do tamanho do nariz no computador. O exame não causa dor, apenas um desconforto mínimo.

Rua Silvio Marchione, $\mathrm{n}^{\circ} 3-20$ - Bauru/SP - Brasi Caixa postal 1501 - Cep $17.012-900$
Tel. 551432358421 - Fax. 551432358162 e-mail: anag@usp.br 


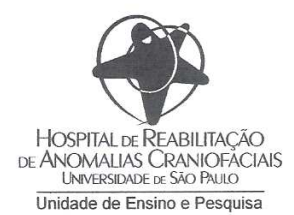

Na divulgação dos dados da pesquisa a sua identidade será mantida em sigilo. Qualquer dúvida poderá ser por nós esclarecida pessoalmente ou pelo telefone (14) 3235-8137.

"Caso o sujeito da pesquisa queira apresentar reclamações em relação a sua participação na pesquisa, poderá entrar em contado com o Comitê de Ética em Pesquisa em Seres Humanos do HRAC/USP, no endereço Rua Silvio Marchione 3-20 na Unidade de Ensino e Pesquisa ou pelo telefone (14) 3235-8421".

Fica claro que o sujeito da pesquisa ou seu representante legal, pode a qualquer momento retirar seu CONSENTIMENTO LIVRE E ESCLARECIDO e deixar de participar desta pesquisa e ciente de que todas as informações prestadas tornaram-se confidenciais e guardadas por força de sigilo profissional (Art. 35 do Código de Ética dos Profissionais de Enfermagem).

Por estarem de acordo assinam o presente termo.

Bauru-SP, de de

\section{* A SER PREENCHIDO, SE O SUJEITO DA PESQUISA NÃO FOR O PACIENTE.}

Nome do Pesquisador Responsável: PRISCILA CAPELATO PRADO

Endereço do Pesquisador Responsável (Rua, No): Praça Rui Barbosa, $\mathrm{n}^{\circ} 2-68$ - Apto. 113

Cidade: Bauru

Telefone: (14) 3222-4291

Estado: São Paulo

CEP: $17010-200$

Endereço Institucional (Rua, $\mathrm{N}^{\circ}$ ): Rua Silvio Marchione, $\mathrm{n}^{\circ}$ 3-20

Cidade: Bauru

Estado: São Paulo

Telefone: (14) 3235-8421
Ramal: 8137 
Anexo 2

Parecer do Comitê de Ética em Pesquisa do Hospital de Reabilitação de Anomalias Craniofaciais da Universidade de São Paulo 



\section{ANEXO 2 - PARECER DO COMITÊ DE ÉTICA EM PESQUISA DO HOSPITAL DE REABILITAÇÃO DE ANOMALIAS CRANIOFACIAIS DA UNIVERSIDADE DE SÃO PAULO}

Ofício $n^{\circ} 381 / 2006-S V A P E P E-C E P$

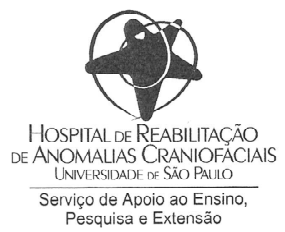

Bauru, 05 de dezembro de 2006.

Prezado(a) Senhor(a)

O projeto de pesquisa encaminhado a cste Comitê de Ética em Pesquisa em Seres Humanos, denominado "Dimensões internas nasais de indivíduos com ohstrução nasal avaliadas por rinometria acústica.", de autoria de PRISCILA CAPELATO PRADO desenvolvido sob sua orientação, foi enviado ao relator para avaliação.

Na reunião de 29/11/2006 o parecer do relator, aprovando o projeto, foi aceito pelo Comitê, considerando que não existem infrações éticas pendentes para início da pesquisa. Solicitamos a V.S a gentileza de comunicar o parecer à pesquisadora e anexar o presente ofício ao projeto, pois o mesmo será necessário para futura publicação do trabalho.

A pesquisadora fica responsável pela entrega no Serviço de Apoio ao Ensino, Pesquisa e Extensão dos relatórios semestrais, bem como comunicar ao CEP todas as alterações que possam ocorrer no projeto.

Informamos que após o recebimento do trabalho concluído, este Comitê enviará o parecer final para publicação.

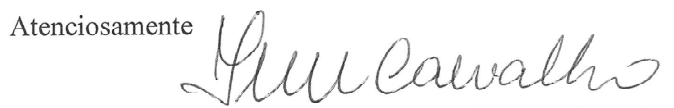

PROFA. DRA. IZABEL MARIA MARCHI DE CARVALHO

Vice-Coordenadora, em exercício, do Comitê de Ética em Pesquisa em Seres Humanos do HRAC-USP

Ilmo(a) $\operatorname{Sr}(a)$

Dra. Inge Elly Kiemle Trindade

Fisiologia - HRAC/USP

Rua Silvio Marchione, 3-20 Bauru SP Brasi Caixa Postal 1501 CEP 17.012-900 Tel. 551432358421 Fax: 551432347818
E-mail: anag@usp.br 

Anexo 3

Parecer da Comissão de Pesquisa do Hospital Estadual Bauru 

ANEXO 3 - PARECER DA COMISSÃO DE PESQUISA DO HOSPITAL ESTADUAL BAURU (HEB)

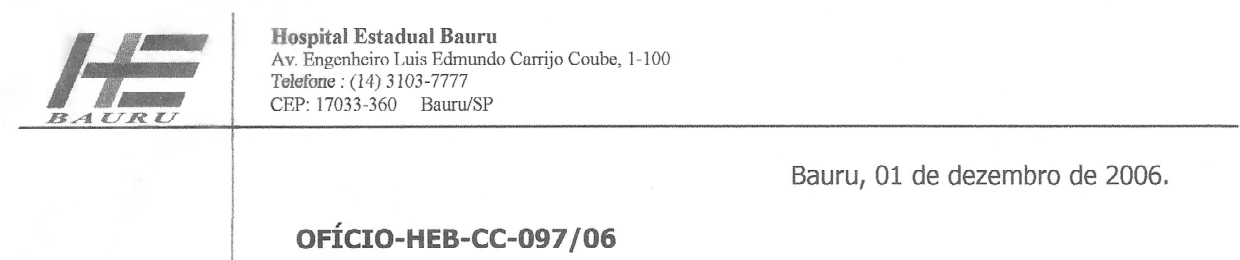

Ref.: Projeto de Pesquisa: "Dimensões Internas Nasais de Indivíduos com Obstrução Nasal Avaliadas por Rinometria Acústica"

Prezada Sra,

Informamos que a Comissão Científica deu parecer favorável quanto a realização de sua pesquisa citada acima.

Solicitamos que ao término de sua pesquisa, encaminhe cópia do relatório final, para que possamos arquivar em seu processo.

Quaisquer dúvidas, favor entrar em contato através do ramal 3366.

Profo Dr Ulisses-Frederibue Junior

Presidente Comissão Científica

IIma. Sra

Priscila Capelato Prado 

Anexo 4

Ficha de Anamnese e Exame Clínico 



\section{ANEXO 4 - FICHA DE ANAMNESE E EXAME CLÍNICO}

HOSPITAL DE REABILITAÇÃO DE ANOMALIAS CRANIOFACIAIS HOSPITAL ESTADUAL BAURU

\section{IDENTIFICAÇÃO}

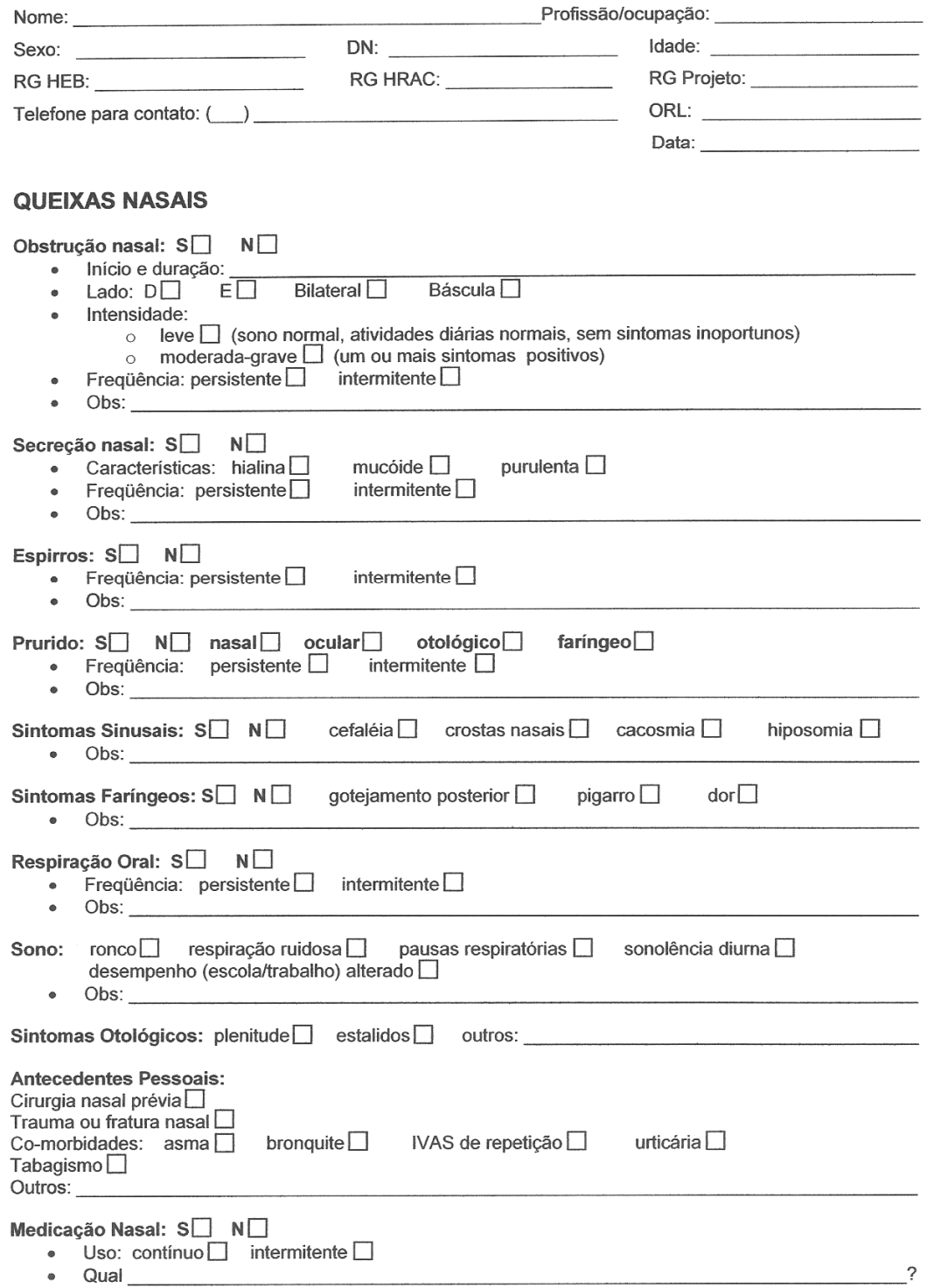




\section{EXAME FÍSICO OTORRINOLARINGOLÓGICO}

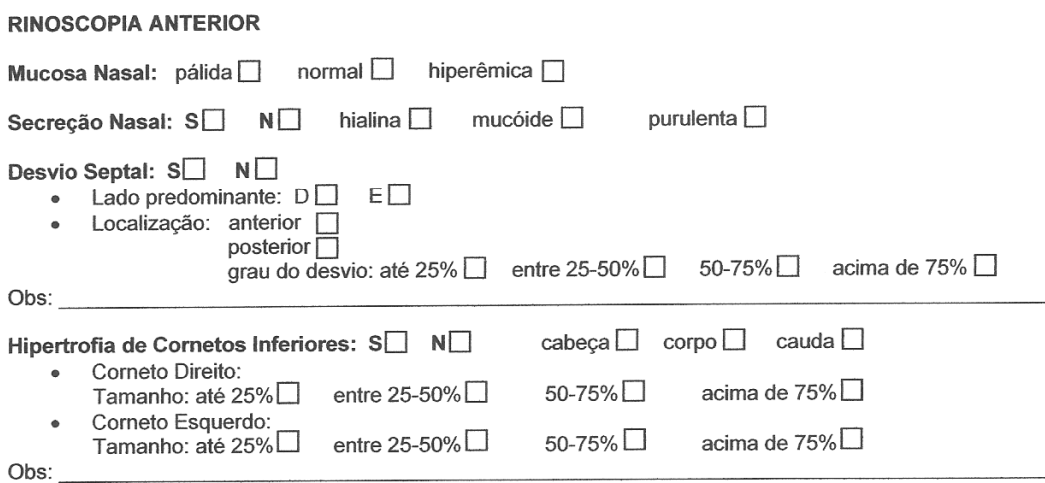

\section{RINOSCOPIA POSTERIOR}

Visualização: adequada $\square$ inadequada $\square$ Obs:

Presença de Adenóide: $\mathrm{S} \square \quad \mathrm{N} \square$

- Grau de obstrução da nasofaringe: até $25 \% \square \quad$ entre $25-50 \% \square \quad 50-75 \% \square \quad$ acima de $75 \% \square$ Cauda do Corneto Inferior Visível: $\mathrm{S} \square \mathrm{N} \square$

- Grau de obstrução da nasofaringe: até $25 \% \square \quad$ entre $25-50 \% \square \quad 50-75 \% \square \quad$ acima de $75 \% \square$

Secreção na Nasofaringe: $S \square \quad N \square \quad$ hialina $\square \quad$ mucóide $\square \quad$ purulenta $\square$

APÓS VASOCONSTRIÇÃO

10 minutos após instilação de 5 gotas de cloridrato de xilometazolina a 1\% - OTRIVINA®

Grau de retração do corneto inferior: até $25 \% \square \quad$ entre $25-50 \% \square \quad 50-75 \% \square \quad$ acima de $75 \% \square$

Outros achados:

Paciente incluído no Projeto: $\mathrm{S} \square \mathrm{N} \square$

Obs:

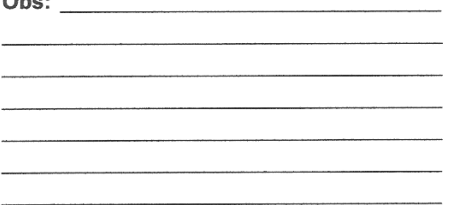

FATORES DE INCLUSAO

Adultos brancos ou pardos (18 a 40 anos)

Obstrução nasal por desvio de septo e/ou hipertrofia de cometos inferiores

FATORES DE EXCLUSĀO

Cirurgia nasal prévia

Hipertrofia de tonsilas faringeas

Pólipo

Neoplasia

Processo infeccioso agudo 
Anexo 5

Observações Clínicas Individuais - Anamnese/Queixas $\mathcal{N a s a i s ~}$ 

ANEXO 5 - OBSERVAÇÕES CLÍNICAS INDIVIDUAIS - ANAMNESE/QUEIXAS NASAIS

\begin{tabular}{|c|c|c|c|c|c|c|c|c|c|c|c|c|}
\hline PAC & ON & SEC & ESP & PRU & SINT SIN & SINT FAR & RESP OR & DRS & CN & TRAUMA & CO MORB & MED \\
\hline 1 & B-mg & $\mathrm{N}$ & $\mathrm{N}$ & $\mathrm{N}$ & S & $\mathrm{N}$ & $\mathrm{Sp}$ & $\mathrm{S}$ & $\mathrm{N}$ & $\mathrm{N}$ & $\mathrm{N}$ & $\mathrm{N}$ \\
\hline 2 & Bpmg & Sp & Sp & S- & - & S & Sp & $\mathrm{S}$ & $\mathrm{N}$ & $\mathrm{N}$ & $\mathrm{S}$ & $\mathrm{Si}$ \\
\hline 3 & Bimg & $\mathrm{N}$ & $\mathrm{N}$ & $\mathrm{N}$ & $\mathrm{N}$ & S & $\mathrm{N}$ & $\mathrm{N}$ & $\mathrm{N}$ & $\mathrm{N}$ & $\mathrm{N}$ & $\mathrm{N}$ \\
\hline 4 & Epmg & Sp & $\mathrm{N}$ & $\mathrm{N}$ & S & S & Si & S & $\mathrm{N}$ & $\mathrm{N}$ & $\mathrm{N}$ & $\mathrm{N}$ \\
\hline 5 & BBSpmg & $\mathrm{N}$ & $\mathrm{N}$ & $\mathrm{N}$ & $\mathrm{N}$ & $\mathrm{N}$ & $\mathrm{Si}$ & $\mathrm{S}$ & $\mathrm{N}$ & $\mathrm{N}$ & $\mathrm{N}$ & $\mathrm{N}$ \\
\hline 6 & Bpmg & $\mathrm{Si}$ & $\mathrm{N}$ & $\mathrm{N}$ & $S$ & $\mathrm{~S}$ & Sp & $S$ & $\mathrm{~N}$ & $\mathrm{~N}$ & $\mathrm{~N}$ & $\mathrm{~N}$ \\
\hline 7 & Bpmg & $\mathrm{N}$ & $\mathrm{Si}$ & $\mathrm{Si}$ & $\mathrm{N}$ & $\mathrm{N}$ & $\mathrm{Si}$ & S & $\mathrm{N}$ & $\mathrm{N}$ & $\mathrm{N}$ & Sc \\
\hline 8 & Bpmg & $\mathrm{Si}$ & $\mathrm{N}$ & $\mathrm{N}$ & S & $\mathrm{S}$ & Si & $\mathrm{S}$ & $\mathrm{N}$ & $\mathrm{N}$ & $\mathrm{N}$ & Sc \\
\hline 9 & BSpl & $\mathrm{N}$ & $\mathrm{N}$ & $\mathrm{N}$ & S & $\mathrm{N}$ & Sp & $\mathrm{S}$ & $\mathrm{N}$ & $\mathrm{N}$ & $\mathrm{N}$ & Sc \\
\hline 10 & BSpmg & $\mathrm{Si}$ & $\mathrm{Si}$ & $\mathrm{Si}$ & $S$ & $S$ & $\mathrm{Si}$ & $S$ & $\mathrm{~N}$ & $\mathrm{~N}$ & $S$ & Sc \\
\hline 11 & Bpmg & S- & Sp & Sp & S & S & Sp & $S$ & $\mathrm{~N}$ & $\mathrm{~N}$ & $\mathrm{~N}$ & $\mathrm{~N}$ \\
\hline 12 & Dpmg & Sp & Sp & Sp & $\mathrm{S}$ & $\mathrm{N}$ & $\mathrm{Si}$ & $\mathrm{N}$ & $\mathrm{N}$ & $\mathrm{N}$ & $\mathrm{N}$ & $\mathrm{N}$ \\
\hline 13 & BSpmg & $\mathrm{Si}$ & $\mathrm{Si}$ & $\mathrm{Si}$ & $S$ & $S$ & Sp & $S$ & $\mathrm{~N}$ & $\mathrm{~N}$ & $\mathrm{~N}$ & Si \\
\hline 14 & Bpmg & $\mathrm{N}$ & $\mathrm{N}$ & $\mathrm{N}$ & $\mathrm{N}$ & $\mathrm{N}$ & $\mathrm{N}$ & S & $\mathrm{N}$ & $\mathrm{N}$ & S & $\mathrm{N}$ \\
\hline 15 & Dimg & $\mathrm{Si}$ & $\mathrm{N}$ & $\mathrm{N}$ & $S$ & $S$ & $\mathrm{Si}$ & $S$ & $\mathrm{~N}$ & $\mathrm{~N}$ & $\mathrm{~N}$ & $\mathrm{Si}$ \\
\hline 16 & Dpmg & $\mathrm{N}$ & $\mathrm{Si}$ & Sp & S & $S$ & Si & S & $\mathrm{N}$ & $\mathrm{N}$ & $\mathrm{N}$ & $\mathrm{Si}$ \\
\hline 17 & B-I & $\mathrm{Si}$ & $\mathrm{Si}$ & $\mathrm{N}$ & $\mathrm{N}$ & $\mathrm{N}$ & $\mathrm{N}$ & S & $\mathrm{N}$ & $\mathrm{N}$ & $\mathrm{N}$ & Sc \\
\hline 18 & Bpmg & $\mathrm{N}$ & Sp & S- & $S$ & $\mathrm{~S}$ & Sp & $S$ & $\mathrm{~N}$ & $\mathrm{~N}$ & $\mathrm{~N}$ & Sc \\
\hline 19 & Bpmg & Sp & Sp & S- & S & $\mathrm{N}$ & Sp & $\mathrm{S}$ & $\mathrm{N}$ & $\mathrm{N}$ & S & $\mathrm{N}$ \\
\hline 20 & Bimg & Si & Si & $\mathrm{Si}$ & $S$ & $S$ & $\mathrm{~N}$ & $\mathrm{~N}$ & $\mathrm{~N}$ & $\mathrm{~N}$ & $\mathrm{~N}$ & Sc \\
\hline 21 & Bpmg & S- & Sp & S- & S & S & Sp & S & $\mathrm{N}$ & $\mathrm{N}$ & $\mathrm{N}$ & $\mathrm{N}$ \\
\hline 22 & Bpmg & $\mathrm{Si}$ & $\mathrm{Si}$ & Sp & $\mathrm{N}$ & $S$ & Sp & $S$ & $\mathrm{~N}$ & $\mathrm{~N}$ & $\mathrm{~N}$ & $\mathrm{Si}$ \\
\hline 23 & EBSpmg & $\mathrm{N}$ & Sp & Sp & S & S & $\mathrm{Si}$ & $S$ & $\mathrm{~N}$ & $\mathrm{~N}$ & $\mathrm{~N}$ & $\mathrm{Si}$ \\
\hline 24 & EBS-mg & $\mathrm{Si}$ & S- & SS- & $\mathrm{N}$ & $\mathrm{N}$ & $\mathrm{Si}$ & $\mathrm{S}$ & $\mathrm{N}$ & $\mathrm{N}$ & $\mathrm{N}$ & $\mathrm{N}$ \\
\hline 25 & Bil & $\mathrm{Si}$ & $\mathrm{Si}$ & $\mathrm{Si}$ & $\mathrm{N}$ & $\mathrm{N}$ & $\mathrm{Si}$ & $S$ & $\mathrm{~N}$ & $\mathrm{~N}$ & $\mathrm{~N}$ & $\mathrm{Si}$ \\
\hline 26 & BBSpmg & S- & $\mathrm{Si}$ & $\mathrm{Si}$ & $S$ & $S$ & Sp & S & $\mathrm{N}$ & $\mathrm{N}$ & $\mathrm{N}$ & $\mathrm{N}$ \\
\hline 27 & Bpmg & $\mathrm{N}$ & $\mathrm{Si}$ & Sp & S & S & Sp & S & $\mathrm{N}$ & $\mathrm{N}$ & $\mathrm{N}$ & $\mathrm{N}$ \\
\hline 28 & Bpmg & $\mathrm{N}$ & $\mathrm{N}$ & S- & $\mathrm{N}$ & $S$ & Si & $\mathrm{N}$ & $\mathrm{N}$ & $\mathrm{N}$ & $\mathrm{N}$ & $\mathrm{N}$ \\
\hline 29 & Bmg- & $\mathrm{N}$ & $\mathrm{Si}$ & $\mathrm{Si}$ & $\mathrm{N}$ & $\mathrm{N}$ & Si & S & $\mathrm{N}$ & $\mathrm{N}$ & S & Sc \\
\hline 30 & Bpmg & $\mathrm{N}$ & $\mathrm{Si}$ & $\mathrm{Si}$ & $\mathrm{N}$ & $S$ & $\mathrm{~N}$ & $\mathrm{~N}$ & $\mathrm{~N}$ & $\mathrm{~N}$ & $\mathrm{~N}$ & $\mathrm{~N}$ \\
\hline
\end{tabular}

PAC: paciente, ON: obstrução nasal, SEC: secreção nasal, ESP: espirro, PRU: prurido, SINT SIN: sintomas sinusais, SINT FAR: sintomas faríngeos, RESP OR: respiração oral, DRS: queixas respiratórios no sono,CN: cirurgia nasal prévia, CO MORB: co-morbidade, MED: medicação.

S: sim, N: não, -: informação não disponível; D: direito, E: esquerdo, B: bilateral, BS: báscula, p: persistente, i: intermitente, I: leve, mg: moderada-grave, c: contínuo. 

Anexo 6

Observações Clínicas Individuais - Exame Físico Otorrinolaringológico 

ANEXO 6 - OBSERVAÇÕES CLÍNICAS INDIVIDUAIS - EXAME FÍSICO OTORRINOLARINGOLÓGICO

\begin{tabular}{|c|c|c|c|c|c|c|c|c|}
\hline PAC & MUC & SEC & DESV SEP & HIPER CONC INF & ADEN & CONC INF VIS & SEC NF & VC \\
\hline 1 & $p$ & $\mathrm{~N}$ & Da25-50\% & DE25\% & $\mathrm{N}$ & $\mathrm{N}$ & $\mathrm{N}$ & $25 \%$ \\
\hline 2 & $p$ & Shl & Ea25\% & $E->75 \%$ & $\mathrm{~N}$ & $25-50 \%$ & Shl & $25 \%$ \\
\hline 3 & $\mathrm{~h}$ & $\mathrm{~N}$ & Da50-75\% & E- $50-75 \%$ & $\mathrm{~N}$ & $25-50 \%$ & $\mathrm{~N}$ & $25-50 \%$ \\
\hline 4 & $\mathrm{n}$ & $\mathrm{N}$ & Ep50-75\% & DEcaco25\% & $\mathrm{N}$ & - & - & $25-50 \%$ \\
\hline 5 & $p$ & $\mathrm{~N}$ & Ea50-75\% & DE-25\% & $\mathrm{N}$ & $25 \%$ & $\mathrm{Sm}$ & $25 \%$ \\
\hline 6 & $\mathrm{~h}$ & $\mathrm{~N}$ & Eap50-75\% & DEcocau25-50\% & $\mathrm{N}$ & $25-50 \%$ & $\mathrm{~N}$ & $25 \%$ \\
\hline 7 & $\mathrm{~h}$ & Spr & Dp25-50\% & DEcacocau50-75\% & $\mathrm{N}$ & $50-75 \%$ & Spr & $25-50 \%$ \\
\hline 8 & $\mathrm{~h}$ & $\mathrm{~N}$ & Ep50-75\% & Dcaco25-50\% & - & - & - & $25 \%$ \\
\hline 9 & $n$ & $\mathrm{~N}$ & Ea25-50\% & DE-50-75\%/25-50\% & $\mathrm{N}$ & $25-50 \%$ & $\mathrm{~N}$ & $25-50 \%$ \\
\hline 10 & $p$ & Shl & Dap50-75\% & $D-25 \%$ & $\mathrm{~N}$ & $25 \%$ & $\mathrm{~N}$ & $25-50 \%$ \\
\hline 11 & $n$ & $\mathrm{~N}$ & $\mathrm{Ea}>75 \%$ & D25-50\% & $\mathrm{N}$ & $\mathrm{N}$ & $\mathrm{N}$ & $25 \%$ \\
\hline 12 & $\mathrm{~h}$ & $\mathrm{~N}$ & $\mathrm{~N}$ & DE-25-50\% & $\mathrm{N}$ & - & $\mathrm{N}$ & $25-50 \%$ \\
\hline 13 & $p$ & Shl & $\mathrm{Da}>75 \%$ & DEcaco $>75 \%$ & $\mathrm{~N}$ & - & Shl & $25 \%$ \\
\hline 14 & $\mathrm{~h}$ & $\mathrm{~N}$ & Da25-50\% & $\mathrm{N}$ & - & - & - & $25 \%$ \\
\hline 15 & $n$ & $\mathrm{~N}$ & Da25-50\% & $\mathrm{N}$ & $\mathrm{N}$ & $\mathrm{N}$ & $\mathrm{N}$ & $25 \%$ \\
\hline 16 & p & $\mathrm{N}$ & Dp25-50\% & DEcaco25\% & $\mathrm{N}$ & $25 \%$ & $\mathrm{~N}$ & $25 \%$ \\
\hline 17 & $p$ & $\mathrm{~N}$ & Da50-75\% & DE-25-50\% & $\mathrm{N}$ & - & $\mathrm{N}$ & $25 \%$ \\
\hline 18 & $p$ & $\mathrm{~N}$ & Ep50-75\% & DEcocau25-50\% & $\mathrm{N}$ & E25-50\%/D50-75\% & $\mathrm{N}$ & $25-50 \%$ \\
\hline 19 & $p$ & Shl & Da50-75\% & DEcacocau25\%/50-75\% & $\mathrm{N}$ & $25-50 \%$ & Shl & $25-50 \%$ \\
\hline 20 & p & Shl & Da25-50\% & DEca25\% & $\mathrm{N}$ & $25 \%$ & Shl & $25-50 \%$ \\
\hline 21 & b & Shl & Ea25\% & Dcacocau25-50\% & $\mathrm{N}$ & $50-75 \%$ & Shl & $>75 \%$ \\
\hline 22 & $p$ & $\mathrm{~N}$ & Da25\% & DEcaco $25-50 \%$ & - & $\mathrm{N}$ & - & $25-50 \%$ \\
\hline 23 & p & $\mathrm{N}$ & Ep $>75 \%$ & $D-25-50 \%$ & $\mathrm{~N}$ & $\mathrm{~N}$ & $\mathrm{~N}$ & $25-50 \%$ \\
\hline 24 & $p$ & Shl & $\mathrm{Ea}>75 \%$ & DEcaco25-50\% & $\mathrm{N}$ & $\mathrm{N}$ & Shl & - \\
\hline 25 & p & Shl & Ea50-75\% & Dcaco25-50\% & - & $\mathrm{N}$ & $\mathrm{N}$ & - \\
\hline 26 & p & $\mathrm{N}$ & Ea25-50\% & $\mathrm{N}$ & $\mathrm{N}$ & $\mathrm{N}$ & $\mathrm{N}$ & $25 \%$ \\
\hline 27 & $p$ & $\mathrm{~N}$ & Ea25-50\% & $\mathrm{N}$ & $\mathrm{N}$ & $\mathrm{N}$ & $\mathrm{N}$ & $25-50 \%$ \\
\hline 28 & $\mathrm{p}$ & $\mathrm{N}$ & Ea25-50\% & $\mathrm{N}$ & - & - & - & $50-75 \%$ \\
\hline 29 & $p$ & $\mathrm{~N}$ & Da25-50\% & DE-50-75\% & $\mathrm{N}$ & - & $\mathrm{N}$ & - \\
\hline 30 & $\mathrm{p}$ & Shl & Dap50-75\% & DE-50-75\%/25\% & $\mathrm{N}$ & - & $\mathrm{N}$ & - \\
\hline
\end{tabular}

PAC: paciente, MUC: mucosa nasal, SEC: secreção nasal, DESV SEP: desvio septal, HIPER CONC INF: hipertrofia da concha inferior, ADEN: adenóide, CONC INF VIS: cauda da concha inferior visível, SEC NF: secreção nasofaringe, VC: resposta ao vasoconstritor.

S: sim, N: não, -: informação não disponível, D: direito, E: esquerdo, p: pálida, n: normal, h: hiperêmica, hl: hialina, m: mucóide, pr: purulenta, a: anterior, p: posterior, ca: cabeça, co: corpo, cau: cauda. 

Anexo 7

Tabelas A, B e C com os valores médios individuais 

ANEXO 7 - TABELAS A, B e C

Tabela A - Valores médios individuais acompanhados do desvio-padrão das áreas secionais nasais $\left(\mathrm{AST}_{1}, \mathrm{AST}_{2}\right.$ e $\mathrm{AST}_{3}$ ), obtidos em 60 cavidades nasais (direita e esquerda) de 30 indivíduos com obstrução nasal por desvio de septo e/ou hipertrofia de conchas nasais inferiores, por rinometria acústica, expressos em $\mathrm{cm}^{2}$, antes e após a vasoconstrição nasal.

\begin{tabular}{|c|c|c|c|c|c|c|c|c|c|c|c|c|c|c|}
\hline \multirow[b]{2}{*}{ Sujeito } & \multirow[b]{2}{*}{ Gênero } & \multirow[b]{2}{*}{ Lado } & \multicolumn{6}{|c|}{ ANTES VC } & \multicolumn{6}{|c|}{ APÓs VC } \\
\hline & & & AST1 & DP & AST2 & $\mathrm{DP}$ & AST3 & DP & AST1 & DP & AST2 & DP & AST3 & DP \\
\hline \multirow[t]{2}{*}{1} & M & D & 0,45 & 0,01 & 0,57 & 0,01 & 1,08 & 0,01 & 0,55 & 0,00 & 1,25 & 0,01 & 1,96 & 0,03 \\
\hline & & $E$ & 0,31 & 0,01 & 1,40 & 0,01 & 2,25 & 0,02 & 0,35 & 0,01 & 1,55 & 0,04 & 2,41 & 0,06 \\
\hline \multirow[t]{2}{*}{2} & M & D & 0,10 & 0,01 & 0,10 & 0,01 & 0,17 & 0,01 & 0,13 & 0,01 & 0,11 & 0,01 & 0,28 & 0,02 \\
\hline & & $E$ & 0,35 & 0,03 & 0,84 & 0,09 & 1,16 & 0,14 & 0,38 & 0,02 & 1,25 & 0,02 & 1,47 & 0,03 \\
\hline \multirow[t]{2}{*}{3} & M & D & 0,22 & 0,02 & 0,74 & 0,03 & 0,99 & 0,05 & 0,26 & 0,01 & 1,26 & 0,02 & 1,48 & 0,01 \\
\hline & & $E$ & 0,66 & 0,04 & 1,04 & 0,05 & 1,26 & 0,05 & 0,99 & 0,03 & 3,03 & 0,06 & 3,01 & 0,08 \\
\hline \multirow[t]{2}{*}{4} & $M$ & $\mathrm{D}$ & 0,44 & 0,02 & 0,62 & 0,02 & 0,88 & 0,02 & 0,46 & 0,02 & 1,03 & 0,05 & 1,45 & 0,05 \\
\hline & & $E$ & 0,59 & 0,01 & 1,54 & 0,03 & 2,58 & 0,03 & 0,57 & 0,03 & 1,67 & 0,07 & 2,60 & 0,03 \\
\hline \multirow[t]{2}{*}{5} & M & $\mathrm{D}$ & 0,69 & 0,04 & 1,10 & 0,02 & 1,67 & 0,06 & 0,69 & 0,04 & 1,33 & 0,01 & 2,10 & 0,06 \\
\hline & & $E$ & 0,13 & 0,01 & 0,18 & 0,01 & 0,49 & 0,02 & 0,3 & 0,01 & 0,96 & 0,08 & 1,58 & 0,06 \\
\hline \multirow[t]{2}{*}{6} & M & $D$ & 1,05 & 0,02 & 1,10 & 0,04 & 2,09 & 0,07 & 1,09 & 0,05 & 1,42 & 0,06 & 2,72 & 0,09 \\
\hline & & $E$ & 0,30 & 0,01 & 1,21 & 0,06 & 1,43 & 0,08 & 0,33 & 0,01 & 1,46 & 0,03 & 1,96 & 0,04 \\
\hline \multirow[t]{2}{*}{7} & $M$ & $D$ & 0,55 & 0,02 & 0,71 & 0,02 & 1,02 & 0,02 & 0,51 & 0,02 & 0,82 & 0,03 & 1,44 & 0,03 \\
\hline & & $E$ & 0,57 & 0,03 & 1,43 & 0,03 & 2,21 & 0,05 & 0,58 & 0,01 & 1,37 & 0,02 & 2,34 & 0,04 \\
\hline \multirow[t]{2}{*}{8} & $M$ & $D$ & 0,23 & 0,01 & 0,12 & 0,00 & 0,2 & 0,01 & 0,57 & 0,13 & 0,94 & 0,03 & 0,76 & 0,01 \\
\hline & & $E$ & 0,14 & 0,02 & 0,23 & 0,02 & 0,35 & 0,01 & 0,28 & 0,02 & 1,07 & 0,03 & 1,55 & 0,06 \\
\hline \multirow[t]{2}{*}{9} & $\mathrm{M}$ & $D$ & 0,54 & 0,01 & 0,54 & 0,01 & 0,66 & 0,01 & 0,73 & 0,01 & 1,28 & 0,03 & 2,04 & 0,05 \\
\hline & & $E$ & 0,27 & 0,01 & 0,57 & 0,01 & 0,89 & 0,02 & 0,52 & 0,01 & 1,57 & 0,05 & 2,38 & 0,09 \\
\hline \multirow[t]{2}{*}{10} & $M$ & $D$ & 0,52 & 0,01 & 1,18 & 0,05 & 1,33 & 0,07 & 0,56 & 0,04 & 1,50 & 0,02 & 2,06 & 0,04 \\
\hline & & $E$ & 0,15 & 0,01 & 0,30 & 0,01 & 0,61 & 0,02 & 0,33 & 0,00 & 1,82 & 0,06 & 2,38 & 0,02 \\
\hline \multirow[t]{2}{*}{11} & $M$ & $D$ & 0,71 & 0,02 & 0,73 & 0,02 & 1,50 & 0,04 & 0,73 & 0,01 & 1,24 & 0,02 & 1,88 & 0,02 \\
\hline & & $E$ & 0,63 & 0,02 & 1,34 & 0,02 & 1,35 & 0,04 & 0,60 & 0,01 & 1,48 & 0,05 & 1,69 & 0,04 \\
\hline \multirow[t]{2}{*}{12} & $M$ & $D$ & 0,35 & 0,01 & 0,91 & 0,01 & 1,23 & 0,02 & 0,44 & 0,02 & 1,27 & 0,02 & 1,58 & 0,07 \\
\hline & & $E$ & 0,43 & 0,03 & 0,78 & 0,00 & 1,11 & 0,01 & 0,47 & 0,02 & 1,62 & 0,03 & 1,74 & 0,06 \\
\hline \multirow[t]{2}{*}{13} & $M$ & $D$ & 0,46 & 0,02 & 0,83 & 0,02 & 0,82 & 0,02 & 0,64 & 0,04 & 1,55 & 0,07 & 1,86 & 0,07 \\
\hline & & $E$ & 0,22 & 0,02 & 0,53 & 0,03 & 0,87 & 0,05 & 0,47 & 0,01 & 2,11 & 0,06 & 2,35 & 0,09 \\
\hline \multirow[t]{2}{*}{14} & $M$ & D & 0,35 & 0,01 & 0,90 & 0,05 & 1,95 & 0,07 & 0,38 & 0,01 & 1,18 & 0,03 & 2,24 & 0,05 \\
\hline & & $E$ & 0,45 & 0,02 & 1,35 & 0,03 & 1,08 & 0,04 & 0,48 & 0,03 & 1,78 & 0,03 & 2,14 & 0,07 \\
\hline \multirow[t]{2}{*}{15} & $F$ & $D$ & 0,22 & 0,02 & 0,98 & 0,07 & 1,42 & 0,09 & 0,29 & 0,03 & 0,95 & 0,05 & 1,59 & 0,05 \\
\hline & & $E$ & 0,38 & 0,03 & 0,74 & 0,02 & 1,23 & 0,05 & 0,51 & 0,03 & 1,34 & 0,07 & 1,76 & 0,02 \\
\hline 16 & $F$ & $D$ & 0,64 & 0,01 & 1,57 & 0,05 & 1,82 & 0,06 & 0,69 & 0,03 & 1,68 & 0,03 & 1,86 & 0,02 \\
\hline & & $E$ & 0,56 & 0,03 & 0,99 & 0,03 & 1,53 & 0,02 & 0,57 & 0,05 & 1,75 & 0,1 & 2,43 & 0,08 \\
\hline 17 & $F$ & $D$ & 0,44 & 0,01 & 0,96 & 0,02 & 1,20 & 0,03 & 0,51 & 0,01 & 1,20 & 0,01 & 1,54 & 0,01 \\
\hline & & $E$ & 0,56 & 0,02 & 1,37 & 0,02 & 1,50 & 0,01 & 0,61 & 0,02 & 1,53 & 0,04 & 1,74 & 0,04 \\
\hline 18 & $F$ & $D$ & 0,37 & 0,01 & 0,87 & 0,04 & 1,46 & 0,04 & 0,37 & 0,01 & 1,18 & 0,03 & 1,86 & 0,02 \\
\hline & & $E$ & 0,42 & 0,01 & 0,90 & 0,02 & 1,36 & 0,04 & 0,44 & 0,01 & 1,31 & 0,02 & 1,94 & 0,03 \\
\hline 19 & $\mathrm{~F}$ & $D$ & 0,22 & 0,01 & 0,51 & 0,01 & 0,54 & 0,02 & 0,27 & 0,00 & 0,81 & 0,02 & 0,70 & 0,02 \\
\hline & & E & 0,57 & 0,05 & 0,44 & 0,01 & 0,78 & 0,03 & 0,61 & 0,02 & 0,94 & 0,01 & 1,47 & 0,02 \\
\hline 20 & $F$ & $D$ & 0,24 & 0,01 & 0,54 & 0,02 & 1,15 & 0,04 & 0,29 & 0,01 & 1,00 & 0,02 & 1,95 & 0,03 \\
\hline & & $E$ & 0,27 & 0,01 & 0,57 & 0,01 & 1,02 & 0,01 & 0,44 & 0,01 & 1,39 & 0,07 & 2,40 & 0,07 \\
\hline 21 & $\mathrm{~F}$ & D & 0,51 & 0,03 & 0,76 & 0,02 & 0,96 & 0,02 & 0,55 & 0,01 & 0,97 & 0,02 & 1,31 & 0,03 \\
\hline & & E & 0,28 & 0,02 & 0,56 & 0,01 & 0,88 & 0,01 & 0,37 & 0,01 & 1,14 & 0,04 & 1,48 & 0,04 \\
\hline
\end{tabular}


Tabela A - Continuação

\begin{tabular}{|c|c|c|c|c|c|c|c|c|c|c|c|c|c|c|}
\hline \multirow[b]{2}{*}{ Sujeito } & \multirow[b]{2}{*}{ Gênero } & \multirow[b]{2}{*}{ Lado } & \multicolumn{6}{|c|}{ ANTES VC } & \multicolumn{6}{|c|}{ APÓS VC } \\
\hline & & & AST1 & DP & AST2 & $\mathrm{DP}$ & AST3 & $\mathrm{DP}$ & AST1 & $\mathrm{DP}$ & AST2 & $\mathrm{DP}$ & AST3 & $\mathrm{DP}$ \\
\hline \multirow[t]{2}{*}{22} & $\mathrm{~F}$ & D & 0,37 & 0,01 & 0,99 & 0,03 & 1,39 & 0,03 & 0,36 & 0,01 & 0,97 & 0,01 & 1,45 & 0,02 \\
\hline & & E & 0,36 & 0,01 & 0,90 & 0,01 & 1,34 & 0,02 & 0,37 & 0,01 & 1,15 & 0,02 & 1,73 & 0,04 \\
\hline \multirow[t]{2}{*}{23} & $F$ & D & 0,63 & 0,03 & 1,69 & 0,10 & 2,07 & 0,07 & 0,71 & 0,03 & 1,89 & 0,07 & 2,43 & 0,07 \\
\hline & & E & 0,40 & 0,01 & 0,89 & 0,02 & 1,14 & 0,02 & 0,42 & 0,02 & 1,30 & 0,02 & 1,77 & 0,02 \\
\hline \multirow[t]{2}{*}{24} & $\mathrm{~F}$ & D & 0,57 & 0,02 & 1,17 & 0,03 & 1,34 & 0,04 & 0,59 & 0,01 & 1,81 & 0,09 & 2,10 & 0,11 \\
\hline & & E & 0,25 & 0,02 & 0,52 & 0,05 & 0,91 & 0,09 & 0,28 & 0,01 & 1,00 & 0,01 & 1,41 & 0,05 \\
\hline \multirow[t]{2}{*}{25} & $\mathrm{~F}$ & D & 0,60 & 0,02 & 0,66 & 0,02 & 0,37 & 0,01 & 0,70 & 0,03 & 1,36 & 0,02 & 1,72 & 0,06 \\
\hline & & E & 0,19 & 0,01 & 0,44 & 0,01 & 0,61 & 0,03 & 0,27 & 0,05 & 0,85 & 0,09 & 1,43 & 0,16 \\
\hline \multirow[t]{2}{*}{26} & $\mathrm{~F}$ & D & 0,52 & 0,01 & 0,58 & 0,02 & 1,06 & 0,04 & 0,58 & 0,03 & 1,20 & 0,03 & 2,42 & 0,10 \\
\hline & & E & 0,26 & 0,01 & 1,29 & 0,03 & 1,82 & 0,05 & 0,21 & 0,01 & 1,15 & 0,08 & 1,67 & 0,13 \\
\hline \multirow[t]{2}{*}{27} & $F$ & D & 0,44 & 0,01 & 1,08 & 0,03 & 1,47 & 0,06 & 0,55 & 0,02 & 1,57 & 0,00 & 2,03 & 0,03 \\
\hline & & E & 0,29 & 0,01 & 0,62 & 0,02 & 1,08 & 0,01 & 0,33 & 0,00 & 1,10 & 0,04 & 1,86 & 0,08 \\
\hline \multirow[t]{2}{*}{28} & $F$ & D & 0,41 & 0,01 & 0,71 & 0,02 & 1,15 & 0,03 & 0,47 & 0,02 & 1,25 & 0,07 & 1,89 & 0,04 \\
\hline & & E & 0,36 & 0,01 & 0,54 & 0,02 & 0,91 & 0,04 & 0,44 & 0,01 & 1,14 & 0,03 & 1,61 & 0,02 \\
\hline \multirow[t]{2}{*}{29} & $F$ & D & 0,28 & 0,01 & 0,23 & 0,00 & 0,18 & 0,01 & 0,55 & 0,01 & 1,23 & 0,03 & 0,91 & 0,02 \\
\hline & & E & 0,41 & 0,02 & 1,42 & 0,04 & 1,58 & 0,03 & 0,38 & 0,01 & 1,39 & 0,06 & 1,59 & 0,05 \\
\hline \multirow[t]{2}{*}{30} & $F$ & D & 0,49 & 0,03 & 0,48 & 0,00 & 0,79 & 0,02 & 0,57 & 0,02 & 0,94 & 0,02 & 1,78 & 0,04 \\
\hline & & $E$ & 0,47 & 0,03 & 1,03 & 0,07 & 1,38 & 0,09 & 0,53 & 0,01 & 1,34 & 0,04 & 1,96 & 0,09 \\
\hline
\end{tabular}


Tabela B - Valores médios individuais acompanhados do desvio-padrão das distâncias das áreas secionais nasais (dAST $1, \mathrm{dAST}_{2}$ e dAST $\mathrm{d}_{3}$ ), com relação às narinas, obtidos em 60 cavidades nasais (direita e esquerda) de 30 indivíduos com obstrução nasal por desvio de septo e/ou hipertrofia de conchas nasais inferiores, por rinometria acústica, expressos em cm, antes e após a vasoconstrição nasal.

\begin{tabular}{|c|c|c|c|c|c|c|c|c|c|c|c|c|c|c|}
\hline \multirow[b]{2}{*}{ Sujeito } & \multirow[b]{2}{*}{ Gênero } & \multirow[b]{2}{*}{ Lado } & \multicolumn{6}{|c|}{ ANTES VC } & \multicolumn{6}{|c|}{ APÓS VC } \\
\hline & & & dAST1 & DP & dAST2 & $\mathrm{DP}$ & dAST3 & DP & dAST1 & $\mathrm{DP}$ & dAST2 & $\mathrm{DP}$ & dAST3 & DP \\
\hline \multirow[t]{2}{*}{1} & $M$ & D & 2,34 & 0,00 & 4,02 & 0,00 & 5,71 & 0,00 & 2,10 & 0,00 & 4,02 & 0,00 & 5,95 & 0,00 \\
\hline & & $E$ & 2,10 & 0,00 & 4,26 & 0,00 & 6,19 & 0,00 & 2,18 & 0,14 & 4,26 & 0,00 & 6,19 & 0,00 \\
\hline \multirow[t]{2}{*}{2} & $M$ & D & 2,58 & 0,00 & 4,26 & 0,00 & 5,71 & 0,00 & 3,54 & 0,00 & 5,23 & 0,00 & 7,39 & 0,00 \\
\hline & & $E$ & 2,34 & 0,00 & 4,18 & 0,14 & 6,18 & 0,00 & 2,34 & 0,00 & 4,50 & 0,00 & 6,59 & 0,14 \\
\hline \multirow[t]{2}{*}{3} & $M$ & D & 1,86 & 0,00 & 3,78 & 0,00 & 5,95 & 0,00 & 1,86 & 0,00 & 4,10 & 0,14 & 5,95 & 0,00 \\
\hline & & $E$ & 2,34 & 0,00 & 4,50 & 0,00 & 5,71 & 0,00 & 1,86 & 0,00 & 4,02 & 0,00 & 6,19 & 0,00 \\
\hline \multirow[t]{2}{*}{4} & M & D & 2,10 & 0,00 & 3,62 & 0,14 & 5,31 & 0,14 & 2,02 & 0,14 & 3,70 & 0,14 & 5,47 & 0,00 \\
\hline & & $E$ & 2,10 & 0,00 & 4,02 & 0,00 & 5,23 & 0,00 & 2,10 & 0,00 & 4,18 & 0,14 & 5,23 & 0,00 \\
\hline \multirow[t]{2}{*}{5} & $M$ & D & 2,34 & 0,00 & 3,70 & 0,14 & 5,79 & 0,14 & 2,34 & 0,00 & 3,78 & 0,00 & 5,95 & 0,00 \\
\hline & & $E$ & 3,06 & 0,00 & 4,50 & 0,00 & 6,43 & 0,00 & 2,26 & 0,14 & 4,02 & 0,24 & 5,95 & 0,00 \\
\hline \multirow[t]{2}{*}{6} & $M$ & D & 2,10 & 0,00 & 3,78 & 0,00 & 5,47 & 0,00 & 2,10 & 0,00 & 3,78 & 0,00 & 5,47 & 0,00 \\
\hline & & $E$ & 2,10 & 0,00 & 4,50 & 0,00 & 6,43 & 0,00 & 2,26 & 0,14 & 4,67 & 0,14 & 6,75 & 0,14 \\
\hline \multirow[t]{2}{*}{7} & $M$ & $D$ & 2,26 & 0,14 & 3,54 & 0,00 & 4,83 & 0,14 & 2,34 & 0,00 & 3,70 & 0,14 & 5,71 & 0,00 \\
\hline & & $E$ & 2,10 & 0,00 & 4,02 & 0,00 & 5,63 & 0,14 & 2,10 & 0,00 & 3,62 & 0,14 & 5,71 & 0,00 \\
\hline \multirow[t]{2}{*}{8} & $M$ & $D$ & 2,10 & 0,00 & 3,94 & 0,14 & 5,95 & 0,00 & 2,42 & 0,28 & 4,10 & 0,14 & 5,79 & 0,14 \\
\hline & & $E$ & 2,58 & 0,00 & 4,02 & 0,00 & 5,71 & 0,00 & 2,10 & 0,00 & 3,94 & 0,14 & 5,95 & 0,00 \\
\hline \multirow[t]{2}{*}{9} & $M$ & $D$ & 2,34 & 0,00 & 4,02 & 0,00 & 5,55 & 0,14 & 2,10 & 0,00 & 3,78 & 0,00 & 5,47 & 0,00 \\
\hline & & $E$ & 2,34 & 0,00 & 4,02 & 0,00 & 5,71 & 0,00 & 2,34 & 0,00 & 4,18 & 0,14 & 5,95 & 0,00 \\
\hline \multirow[t]{2}{*}{10} & $M$ & $D$ & 2,34 & 0,00 & 4,50 & 0,00 & 5,95 & 0,00 & 2,34 & 0,00 & 4,58 & 0,14 & 6,39 & 0,35 \\
\hline & & E & 2,58 & 0,00 & 4,26 & 0,00 & 6,11 & 0,14 & 2,34 & 0,00 & 4,26 & 0,00 & 6,67 & 0,00 \\
\hline \multirow[t]{2}{*}{11} & $M$ & D & 1,86 & 0,00 & 3,62 & 0,14 & 5,95 & 0,00 & 1,86 & 0,00 & 3,54 & 0,00 & 5,23 & 0,00 \\
\hline & & $E$ & 2,26 & 0,14 & 3,78 & 0,00 & 5,47 & 0,00 & 2,10 & 0,00 & 3,94 & 0,14 & 5,23 & 0,00 \\
\hline \multirow[t]{2}{*}{12} & $M$ & $D$ & 2,18 & 0,14 & 4,67 & 0,14 & 5,95 & 0,00 & 2,10 & 0,00 & 4,50 & 0,00 & 5,95 & 0,00 \\
\hline & & E & 2,10 & 0,00 & 4,02 & 0,00 & 5,87 & 0,14 & 1,94 & 0,14 & 4,02 & 0,00 & 5,95 & 0,00 \\
\hline \multirow[t]{2}{*}{13} & $M$ & D & 2,10 & 0,00 & 4,18 & 0,14 & 6,43 & 0,00 & 1,62 & 0,00 & 4,26 & 0,00 & 6,51 & 0,28 \\
\hline & & E & 2,10 & 0,00 & 4,18 & 0,14 & 6,11 & 0,14 & 1,62 & 0,00 & 4,26 & 0,00 & 6,43 & 0,00 \\
\hline \multirow[t]{2}{*}{14} & $M$ & D & 2,18 & 0,14 & 3,86 & 0,14 & 5,95 & 0,00 & 2,34 & 0,00 & 4,26 & 0,00 & 5,95 & 0,00 \\
\hline & & $E$ & 2,10 & 0,00 & 4,26 & 0,00 & 5,71 & 0,00 & 2,10 & 0,00 & 4,42 & 0,14 & 5,95 & 0,01 \\
\hline \multirow[t]{2}{*}{15} & $\mathrm{~F}$ & $D$ & 2,10 & 0,00 & 3,78 & 0,00 & 5,87 & 0,14 & 2,02 & 0,14 & 3,30 & 0,00 & 5,23 & 0,00 \\
\hline & & E & 2,10 & 0,00 & 4,02 & 0,00 & 5,71 & 0,00 & 1,86 & 0,00 & 4,02 & 0,00 & 5,23 & 0,00 \\
\hline 16 & $F$ & D & 1,86 & 0,00 & 4,02 & 0,00 & 5,95 & 0,00 & 1,86 & 0,00 & 4,02 & 0,00 & 5,95 & 0,00 \\
\hline & & $E$ & 2,10 & 0,00 & 4,02 & 0,00 & 5,95 & 0,00 & 1,86 & 0,00 & 4,02 & 0,00 & 6,43 & 0,00 \\
\hline 17 & $\mathrm{~F}$ & D & 2,26 & 0,14 & 4,18 & 0,14 & 5,95 & 0,00 & 2,18 & 0,14 & 4,26 & 0,00 & 5,95 & 0,00 \\
\hline & & $E$ & 2,10 & 0,00 & 3,78 & 0,00 & 5,78 & 0,14 & 2,10 & 0,00 & 4,02 & 0,00 & 5,95 & 0,00 \\
\hline 18 & $F$ & D & 2,10 & 0,00 & 4,02 & 0,00 & 5,71 & 0,00 & 2,10 & 0,00 & 4,18 & 0,14 & 6,27 & 0,14 \\
\hline & & $E$ & 2,10 & 0,00 & 4,02 & 0,00 & 5,71 & 0,00 & 2,10 & 0,00 & 4,02 & 0,00 & 5,71 & 0,00 \\
\hline 19 & $\mathrm{~F}$ & D & 2,10 & 0,00 & 4,02 & 0,00 & 6,11 & 0,14 & 2,10 & 0,00 & 3,86 & 0,14 & 6,11 & 0,14 \\
\hline & & $E$ & 2,10 & 0,00 & 3,06 & 0,00 & 4,99 & 0,00 & 2,10 & 0,00 & 3,06 & 0,00 & 4,75 & 0,00 \\
\hline 20 & $\mathrm{~F}$ & D & 2,34 & 0,00 & 3,78 & 0,00 & 6,19 & 0,00 & 2,10 & 0,00 & 3,70 & 0,14 & 6,19 & 0,00 \\
\hline & & $E$ & 2,34 & 0,00 & 3,54 & 0,00 & 5,47 & 0,00 & 2,10 & 0,00 & 3,54 & 0,00 & 5,47 & 0,00 \\
\hline 21 & $F$ & $D$ & 2,10 & 0,00 & 3,54 & 0,00 & 5,23 & 0,00 & 2,10 & 0,00 & 3,54 & 0,00 & 5,23 & 0,00 \\
\hline & & $E$ & 2,34 & 0,00 & 4,02 & 0,00 & 5,71 & 0,00 & 2,10 & 0,00 & 3,94 & 0,14 & 5,95 & 0,00 \\
\hline
\end{tabular}


Tabela B - Continuação

\begin{tabular}{|c|c|c|c|c|c|c|c|c|c|c|c|c|c|c|}
\hline \multirow[b]{2}{*}{ Sujeito } & \multirow[b]{2}{*}{ Gênero } & \multirow[b]{2}{*}{ Lado } & \multicolumn{6}{|c|}{ ANTES VC } & \multicolumn{6}{|c|}{ APÓS VC } \\
\hline & & & dAST1 & DP & dAST2 & DP & dAST3 & DP & dAST1 & DP & dAST2 & DP & dAST3 & DP \\
\hline \multirow[t]{2}{*}{22} & $\mathrm{~F}$ & $\mathrm{D}$ & 2,10 & 0,00 & 3,78 & 0,00 & 5,55 & 0,14 & 2,10 & 0,00 & 4,02 & 0,00 & 5,71 & 0,00 \\
\hline & & E & 2,10 & 0,00 & 4,10 & 0,14 & 5,95 & 0,00 & 2,10 & 0,00 & 4,26 & 0,00 & 6,19 & 0,00 \\
\hline \multirow[t]{2}{*}{23} & $\mathrm{~F}$ & D & 2,10 & 0,00 & 3,94 & 0,14 & 5,71 & 0,00 & 2,10 & 0,00 & 3,78 & 0,00 & 5,47 & 0,00 \\
\hline & & E & 2,34 & 0,00 & 4,02 & 0,00 & 5,95 & 0,00 & 2,34 & 0,00 & 4,26 & 0,00 & 6,19 & 0,00 \\
\hline \multirow[t]{2}{*}{24} & $F$ & D & 1,94 & 0,14 & 4,50 & 0,00 & 6,43 & 0,00 & 1,62 & 0,00 & 4,26 & 0,00 & 6,19 & 0,00 \\
\hline & & $E$ & 2,10 & 0,00 & 4,02 & 0,00 & 6,43 & 0,00 & 2,10 & 0,00 & 4,02 & 0,00 &, 03 & 0,14 \\
\hline \multirow[t]{2}{*}{25} & $\mathrm{~F}$ & D & 2,10 & 0,00 & 4,75 & 0,00 & 6,43 & 0,00 & 1,86 & 0,00 & 4,91 & 0,14 & 7,15 & 0,00 \\
\hline & & E & 2,42 & 0,14 & 4,02 & 0,00 & 6,43 & 0,00 & 2,26 & 0,14 & 4,02 & 0,00 & 6,27 & 0,14 \\
\hline \multirow[t]{2}{*}{26} & $F$ & D & 2,10 & 0,00 & 4,02 & 0,00 & 5,71 & 0,00 & 2,10 & 0,00 & 4,02 & 0,00 & 6,19 & 0,00 \\
\hline & & $E$ & 2,50 & 0,14 & 4,50 & 0,00 & 6,35 & 0,14 & 2,42 & 0,14 & 4,26 & 0,00 & 6,35 & 0,14 \\
\hline \multirow[t]{2}{*}{27} & $F$ & D & 1,86 & 0,00 & 4,26 & 0,00 & 6,35 & 0,14 & 1,78 & 0,14 & 3,54 & 0,00 & 6,43 & 0,00 \\
\hline & & E & 1,86 & 0,00 & 3,62 & 0,14 & 5,95 & 0,00 & 1,86 & 0,00 & 3,46 & 0,14 & 6,67 & 0,00 \\
\hline \multirow[t]{2}{*}{28} & $F$ & D & 2,10 & 0,00 & 3,78 & 0,00 & 5,71 & 0,00 & 1,86 & 0,00 & 3,86 & 0,14 & 5,71 & 0,00 \\
\hline & & $E$ & 2,26 & 0,14 & 3,78 & 0,00 & 5,63 & 0,14 & 2,10 & 0,00 & 3,79 & 0,01 & 5,95 & 0,00 \\
\hline \multirow[t]{2}{*}{29} & $F$ & D & 2,18 & 0,14 & 4,50 & 0,00 & 5,95 & 0,00 & 2,10 & 0,00 & 3,78 & 0,00 & 5,63 & 0,14 \\
\hline & & $E$ & 2,26 & 0,14 & 4,50 & 0,00 & 6,43 & 0,00 & 2,10 & 0,00 & 4,34 & 0,14 & 6,27 & 0,14 \\
\hline \multirow[t]{2}{*}{30} & $F$ & $D$ & 2,10 & 0,00 & 3,78 & 0,00 & 5,47 & 0,00 & 1,94 & 0,14 & 3,70 & 0,14 & 5,47 & 0,00 \\
\hline & & $E$ & 2,10 & 0,00 & 3,70 & 0,14 & 5,55 & 0,14 & 2,02 & 0,14 & 3,94 & 0,14 & 5,63 & 0,14 \\
\hline
\end{tabular}


Tabela C - Valores médios individuais acompanhados do desvio-padrão dos volumes nasais $\left(V_{1}, V_{2}\right.$ e $\left.V_{3}\right)$, obtidos em 60 cavidades nasais (direita e esquerda) de 30 indivíduos com obstrução nasal por desvio de septo e/ou hipertrofia de conchas nasais inferiores, por rinometria acústica, expressos em $\mathrm{cm}^{3}$, antes e após a vasoconstrição nasal.

\begin{tabular}{|c|c|c|c|c|c|c|c|c|c|c|c|c|c|c|}
\hline \multirow[b]{2}{*}{ Sujeito } & \multirow[b]{2}{*}{ Gênero } & \multirow[b]{2}{*}{ Lado } & \multicolumn{6}{|c|}{ ANTES VC } & \multicolumn{6}{|c|}{ APÓS VC } \\
\hline & & & V1 & $\mathrm{DP}$ & V2 & DP & V3 & DP & V1 & DP & V2 & DP & V3 & DP \\
\hline \multirow[t]{2}{*}{1} & $M$ & D & 1,42 & 0,01 & 2,62 & 0,02 & 14,69 & 0,36 & 1,63 & 0,03 & 5,06 & 0,06 & 21,45 & 0,58 \\
\hline & & $E$ & 1,17 & 0,01 & 5,70 & 0,03 & 20,17 & 0,44 & 1,23 & 0,02 & 6,28 & 0,10 & 21,41 & 0,67 \\
\hline \multirow[t]{2}{*}{2} & $\mathrm{M}$ & D & 1,21 & 0,05 & 0,43 & 0,02 & 2,03 & 0,14 & 1,61 & 0,02 & 0,45 & 0,01 & 2,48 & 0,22 \\
\hline & & E & 1,53 & 0,07 & 3,12 & 0,25 & 7,90 & 0,57 & 1,66 & 0,11 & 4,76 & 0,08 & 17,30 & 0,35 \\
\hline \multirow[t]{2}{*}{3} & M & D & 0,86 & 0,07 & 3,16 & 0,17 & 11,12 & 0,59 & 1,07 & 0,03 & 4,73 & 0,07 & 15,38 & 0,40 \\
\hline & & E & 1,92 & 0,06 & 3,34 & 0,14 & 12,77 & 0,70 & 2,93 & 0,07 & 9,27 & 0,17 & 21,87 & 0,39 \\
\hline \multirow[t]{2}{*}{4} & $M$ & D & 1,41 & 0,02 & 2,76 & 0,02 & 14,00 & 0,32 & 1,53 & 0,01 & 4,27 & 0,08 & 18,54 & 0,40 \\
\hline & & E & 2,06 & 0,01 & 6,68 & 0,06 & 24,42 & 0,86 & 1,98 & 0,02 & 6,85 & 0,18 & 29,23 & 1,00 \\
\hline \multirow[t]{2}{*}{5} & M & D & 2,12 & 0,05 & 4,82 & 0,17 & 14,87 & 0,80 & 2,12 & 0,08 & 5,79 & 0,20 & 18,65 & 1,05 \\
\hline & & E & 0,77 & 0,03 & 0,94 & 0,05 & 3,58 & 0,36 & 0,92 & 0,03 & 3,70 & 0,14 & 14,33 & 0,78 \\
\hline \multirow[t]{2}{*}{6} & M & D & 2,88 & 0,02 & 5,52 & 0,16 & 16,82 & 0,40 & 3,01 & 0,10 & 7,06 & 0,27 & 16,26 & 1,93 \\
\hline & & E & 1,13 & 0,03 & 3,92 & 0,13 & 12,25 & 0,45 & 1,27 & 0,02 & 4,64 & 0,19 & 16,60 & 0,49 \\
\hline \multirow[t]{2}{*}{7} & M & D & 1,63 & 0,05 & 3,29 & 0,06 & 18,96 & 0,57 & 1,59 & 0,04 & 3,53 & 0,04 & 21,36 & 0,39 \\
\hline & & $E$ & 1,86 & 0,09 & 5,85 & 0,18 & 25,45 & 0,71 & 1,93 & 0,03 & 5,93 & 0,09 & 26,19 & 0,46 \\
\hline \multirow[t]{2}{*}{8} & $\mathrm{M}$ & D & 1,00 & 0,03 & 0,46 & 0,01 & 2,16 & 0,06 & 1,61 & 0,01 & 2,87 & 0,10 & 9,98 & 0,27 \\
\hline & & E & 0,98 & 0,05 & 0,89 & 0,04 & 3,89 & 0,32 & 1,23 & 0,08 & 4,34 & 0,15 & 14,85 & 0,6 \\
\hline \multirow[t]{2}{*}{9} & M & D & 1,63 & 0,01 & 1,98 & 0,01 & 8,08 & 0,14 & 2,2 & 0,03 & 5,59 & 0,08 & 16,05 & 0,51 \\
\hline & & $E$ & 1,32 & 0,04 & 2,28 & 0,04 & 6,68 & 0,04 & 1,73 & 0,02 & 6,11 & 0,14 & 20,55 & 0,61 \\
\hline \multirow[t]{2}{*}{10} & $\mathrm{M}$ & D & 1,87 & 0,01 & 3,91 & 0,18 & 14,49 & 0,70 & 1,88 & 0,10 & 5,18 & 0,09 & 19,75 & 0,32 \\
\hline & & $E$ & 0,88 & 0,02 & 1,37 & 0,02 & 4,97 & 0,06 & 1,88 & 0,10 & 5,18 & 0,09 & 18,77 & 0,63 \\
\hline \multirow[t]{2}{*}{11} & $M$ & D & 1,71 & 0,05 & 3,23 & 0,07 & 15,72 & 0,36 & 1,93 & 0,02 & 5,60 & 0,00 & 19,11 & 0,30 \\
\hline & & $E$ & 1,82 & 0,05 & 4,49 & 0,08 & 14,30 & 0,46 & 1,86 & 0,03 & 5,27 & 0,12 & 15,19 & 0,28 \\
\hline \multirow[t]{2}{*}{12} & $\mathrm{M}$ & D & 1,05 & 0,02 & 3,13 & 0,04 & 15,90 & 0,58 & 1,40 & 0,08 & 4,70 & 0,19 & 22,00 & 0,36 \\
\hline & & E & 1,63 & 0,10 & 3,06 & 0,02 & 15,23 & 0,30 & 1,82 & 0,04 & 5,59 & 0,09 & 22,11 & 0,81 \\
\hline \multirow[t]{2}{*}{13} & $\mathrm{M}$ & D & 1,37 & 0,01 & 2,89 & 0,04 & 11,80 & 0,40 & 1,89 & 0,05 & 5,62 & 0,15 & 19,02 & 0,21 \\
\hline & & $E$ & 0,79 & 0,03 & 2,24 & 0,10 & 10,02 & 0,65 & 1,82 & 0,02 & 6,82 & 0,10 & 20,51 & 0,32 \\
\hline \multirow[t]{2}{*}{14} & $\mathrm{M}$ & D & 1,44 & 0,02 & 4,40 & 0,16 & 17,47 & 0,61 & 1,43 & 0,02 & 5,04 & 0,13 & 21,36 & 0,72 \\
\hline & & E & 1,54 & 0,04 & 4,04 & 0,11 & 15,22 & 0,62 & 1,69 & 0,08 & 6,03 & 0,11 & 21,27 & 0,38 \\
\hline \multirow[t]{2}{*}{15} & $F$ & D & 0,94 & 0,05 & 4,08 & 0,2 & 14,68 & 0,41 & 1,14 & 0,05 & 4,73 & 0,25 & 17,01 & 0,83 \\
\hline & & E & 1,31 & 0,03 & 3,26 & 0,07 & 16,32 & 0,4 & 1,68 & 0,04 & 5,23 & 0,12 & 20,05 & 0,65 \\
\hline 16 & $F$ & D & 1,62 & 0,04 & 5,29 & 0,13 & 18,55 & 0,34 & 1,74 & 0,01 & 5,72 & 0,07 & 20,88 & 0,37 \\
\hline & & $E$ & 1,51 & 0,02 & 3,61 & 0,08 & 13,53 & 0,44 & 1,85 & 0,10 & 6,36 & 0,27 & 19,15 & 0,65 \\
\hline 17 & $\mathrm{~F}$ & D & 1,62 & 0,06 & 3,46 & 0,05 & 13,67 & 0,30 & 1,78 & 0,05 & 4,50 & 0,02 & 15,68 & 0,08 \\
\hline & & $E$ & 2,00 & 0,03 & 5,01 & 0,04 & 13,49 & 0,11 & 2,12 & 0,03 & 5,55 & 0,11 & 15,77 & 0,36 \\
\hline 18 & $F$ & D & 1,26 & 0,02 & 3,66 & 0,03 & 17,95 & 0,06 & 1,27 & 0,05 & 4,77 & 0,03 & 23,08 & 1,05 \\
\hline & & E & 1,34 & 0,05 & 3,63 & 0,09 & 17,65 & 0,11 & 1,50 & 0,03 & 5,14 & 0,09 & 21,97 & 0,82 \\
\hline 19 & $\mathrm{~F}$ & D & 0,97 & 0,03 & 1,68 & 0,02 & 6,45 & 0,28 & 1,11 & 0,04 & 2,51 & 0,04 & 10,34 & 0,23 \\
\hline & & $E$ & 1,49 & 0,05 & 2,4 & 0,06 & 11,43 & 0,23 & 1,72 & 0,02 & 4,58 & 0,07 & 19,68 & 0,88 \\
\hline 20 & $\mathrm{~F}$ & D & 1,18 & 0,01 & 2,52 & 0,12 & 10,31 & 0,48 & 1,31 & 0,02 & 4,91 & 0,12 & 18,48 & 0,79 \\
\hline & & $E$ & 1,03 & 0,02 & 2,65 & 0,02 & 10,64 & 0,19 & 1,48 & 0,02 & 6,62 & 0,09 & 21,24 & 0,76 \\
\hline 21 & $F$ & D & 1,46 & 0,06 & 2,91 & 0,02 & 15,47 & 0,55 & 1,55 & 0,02 & 3,85 & 0,05 & 20,15 & 0,61 \\
\hline & & $E$ & 1,00 & 0,01 & 2,24 & 0,01 & 11,35 & 0,27 & 1,26 & 0,02 & 4,17 & 0,09 & 20,21 & 0,31 \\
\hline
\end{tabular}


TABELA C - Continuação

\begin{tabular}{|c|c|c|c|c|c|c|c|c|c|c|c|c|c|c|}
\hline \multirow[b]{2}{*}{ Sujeito } & \multirow[b]{2}{*}{ Gênero } & \multirow[b]{2}{*}{ Lado } & \multicolumn{6}{|c|}{ ANTES VC } & \multicolumn{6}{|c|}{ APÓS VC } \\
\hline & & & V1 & DP & V2 & DP & V3 & DP & V1 & DP & V2 & DP & V3 & $\mathrm{DP}$ \\
\hline \multirow[t]{2}{*}{22} & $F$ & D & 1,39 & 0,02 & 3,95 & 0,09 & 20,26 & 0,86 & 1,38 & 0,01 & 3,94 & 0,03 & 20,94 & 0,51 \\
\hline & & $E$ & 1,21 & 0,04 & 3,51 & 0,02 & 16,7 & 0,23 & 1,26 & 0,04 & 4,37 & 0,11 & 20,87 & 0,70 \\
\hline \multirow[t]{2}{*}{23} & $F$ & D & 2,03 & 0,06 & 6,37 & 0,30 & 28,61 & 2,09 & 2,2 & 0,05 & 7,29 & 0,19 & 33,93 & 0,83 \\
\hline & & E & 1,38 & 0,04 & 3,5 & 0,07 & 17,38 & 0,51 & 1,49 & 0,49 & 5,06 & 0,09 & 27,87 & 0,68 \\
\hline \multirow[t]{2}{*}{24} & $F$ & D & 1,39 & 0,02 & 3,77 & 0,09 & 11,31 & 1,5 & 1,84 & 0,08 & 5,92 & 0,28 & 15,65 & 1,24 \\
\hline & & $E$ & 0,84 & 0,03 & 2,16 & 0,03 & 7,62 & 0,35 & 0,97 & 0,04 & 3,80 & 0,04 & 13,41 & 0,31 \\
\hline \multirow[t]{2}{*}{25} & $F$ & D & 1,56 & 0,03 & 2,21 & 0,04 & 4,95 & 0,38 & 2,00 & 0,07 & 4,90 & 0,08 & 14,70 & 2,89 \\
\hline & & E & 0,85 & 0,01 & 1,72 & 0,06 & 6,02 & 0,61 & 0,94 & 0,10 & 3,44 & 0,43 & 13,72 & 0,86 \\
\hline \multirow[t]{2}{*}{26} & $F$ & D & 1,55 & 0,01 & 2,72 & 0,06 & 15,41 & 0,28 & 1,78 & 0,09 & 5,42 & 0,18 & 18,66 & 1,26 \\
\hline & & $E$ & 1,04 & 0,02 & 4,48 & 0,1 & 14,93 & 1,15 & 0,92 & 0,05 & 4,33 & 0,28 & 14,38 & 0,81 \\
\hline \multirow[t]{2}{*}{27} & $F$ & D & 1,20 & 0,05 & 3,79 & 0,11 & 12,31 & 0,63 & 1,73 & 0,03 & 6,31 & 0,03 & 16,87 & 0,43 \\
\hline & & E & 1,00 & 0,02 & 2,62 & 0,04 & 12,5 & 0,10 & 1,26 & 0,02 & 4,99 & 0,08 & 15,17 & 0,73 \\
\hline \multirow[t]{2}{*}{28} & $F$ & D & 1,29 & 0,05 & 3,13 & 0,09 & 15,45 & 0,6 & 1,62 & 0,04 & 5,37 & 0,16 & 20,70 & 0,42 \\
\hline & & $E$ & 1,09 & 0,02 & 2,42 & 0,05 & 12,38 & 0,25 & 1,41 & 0,04 & 4,75 & 0,07 & 17,94 & 0,62 \\
\hline \multirow[t]{2}{*}{29} & $F$ & D & 1,17 & 0,03 & 0,79 & 0,01 & 2,85 & 0,06 & 1,8 & 0,05 & 3,70 & 0,06 & 6,91 & 0,14 \\
\hline & & E & 1,39 & 0,02 & 5,36 & 0,04 & 11,76 & 0,46 & 1,31 & 0,02 & 5,12 & 0,16 & 10,82 & 0,42 \\
\hline \multirow[t]{2}{*}{30} & $F$ & D & 1,56 & 0,02 & 2,15 & 0,02 & 9,47 & 0,14 & 1,78 & 0,03 & 4,56 & 0,07 & 12,13 & 0,36 \\
\hline & & $\mathrm{E}$ & 1,56 & 0,04 & 4,13 & 0,26 & 13,75 & 0,35 & 1,75 & 0,07 & 5,39 & 0,12 & 17,30 & 0,52 \\
\hline
\end{tabular}


Anexo 8 Rinogramas representativos dos pacientes com obstrução nasal analisados

São destacados com asterisco os casos com AST alterada em um ou mais dos segmentos analisados. Os traçados em verde e vermelho foram obtidos do lado direito e esquerdo, respectivamente, antes da vasoconstrição. Os traçados em azul claro e roxo foram obtidos do lado direito e esquerdo, respectivamente, após a vasoconstrição. 

ANEXO 8 - RINOGRAMAS REPRESENTATIVOS DOS PACIENTES COM OBSTRUÇÃO NASAL ANALISADOS
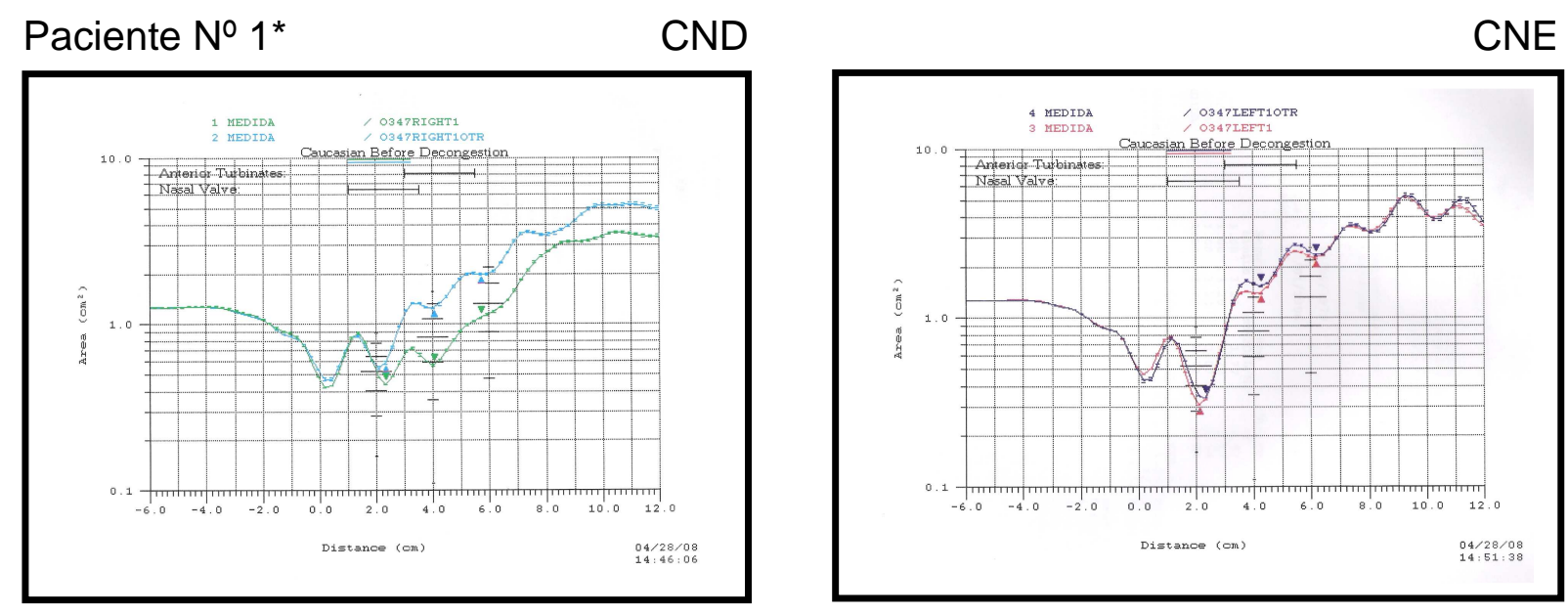

Paciente № $2^{*}$

CND

CNE
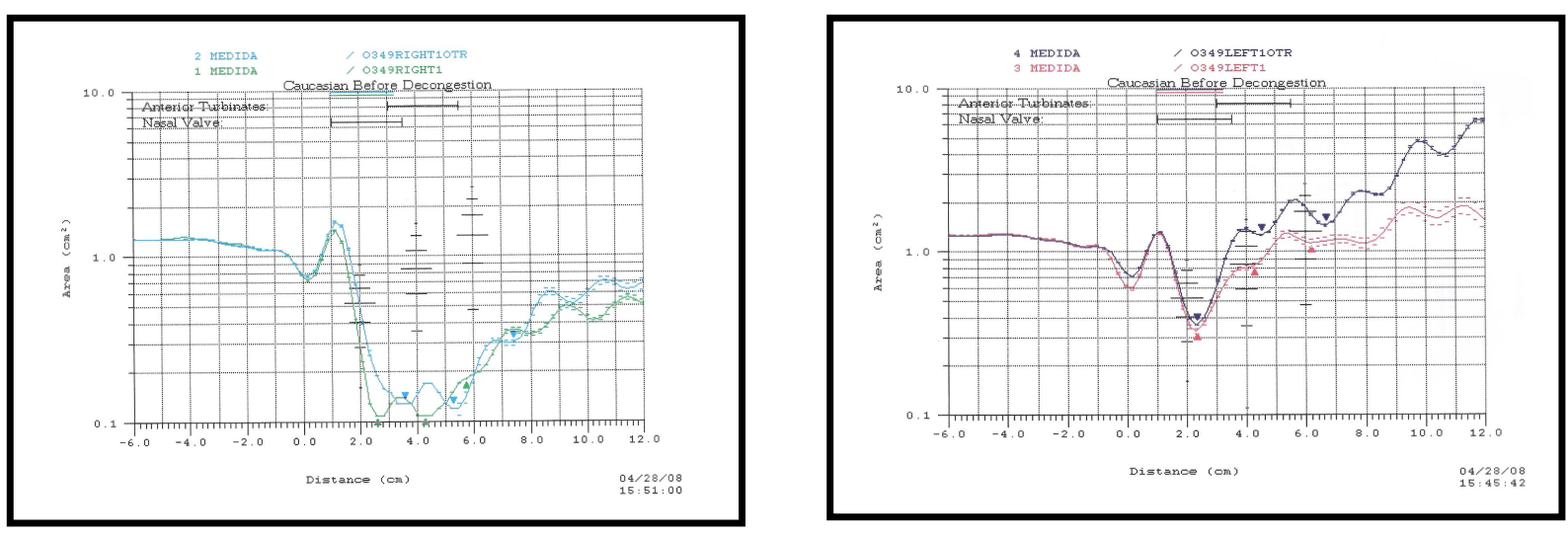

Paciente № 3 *

CND

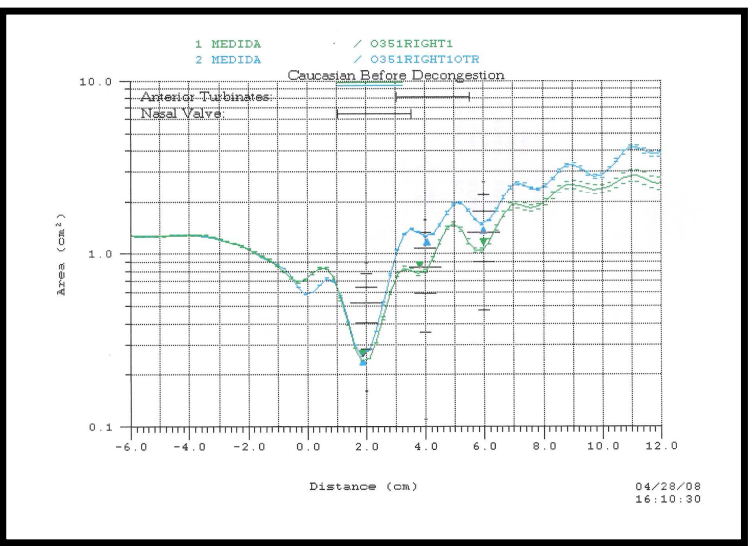

CNE

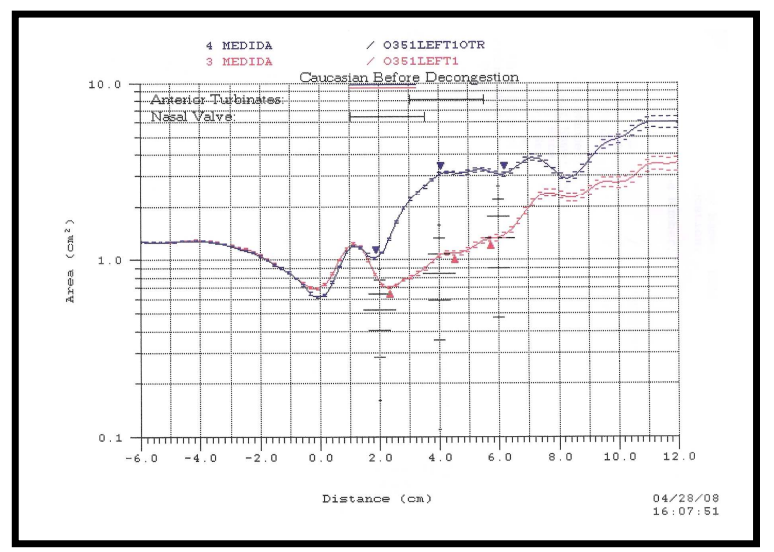

Antes da vasoconstrição nasal

Após a vasoconstrição nasal 

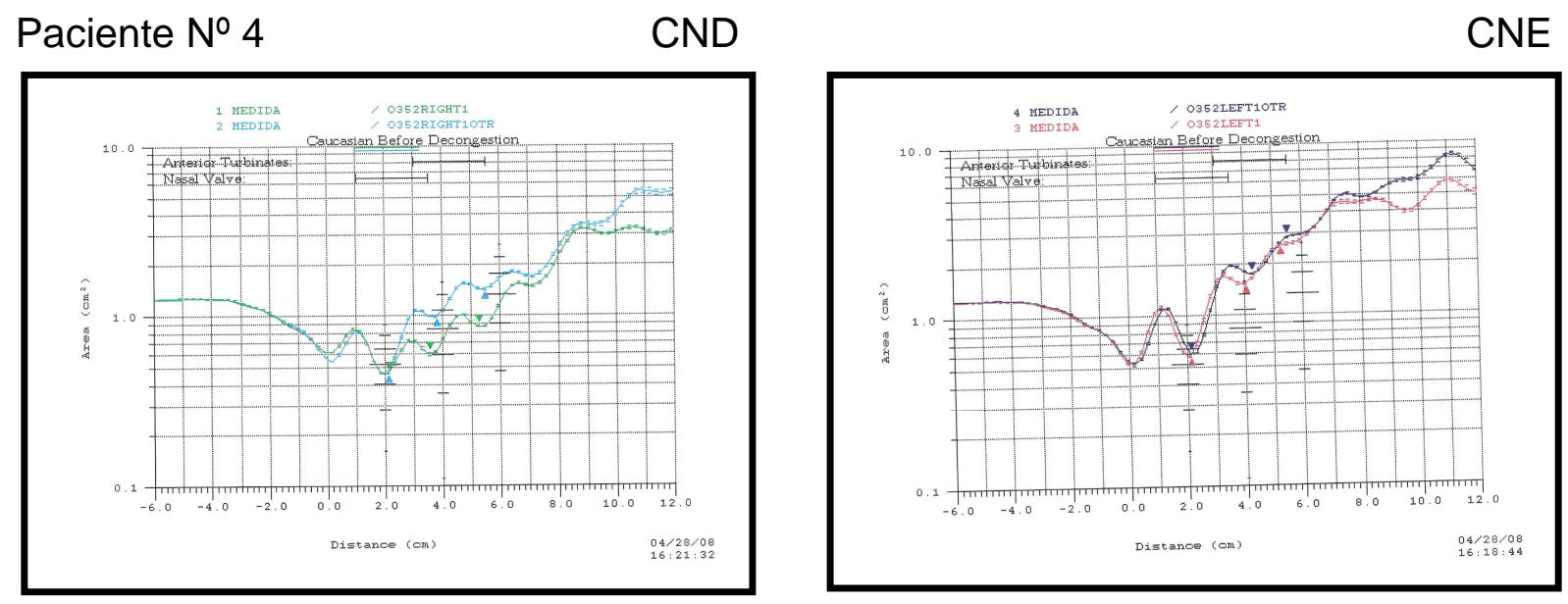

Paciente № $5^{\star}$

CND

CNE
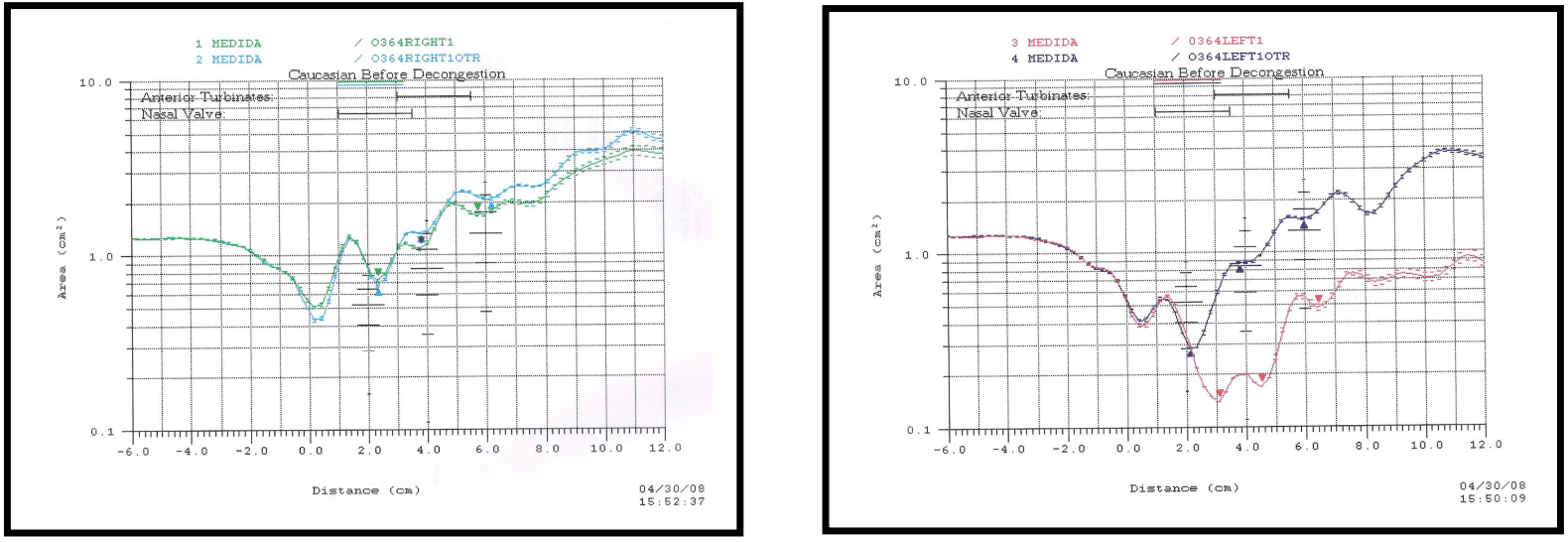

Paciente № $6^{*}$

CND
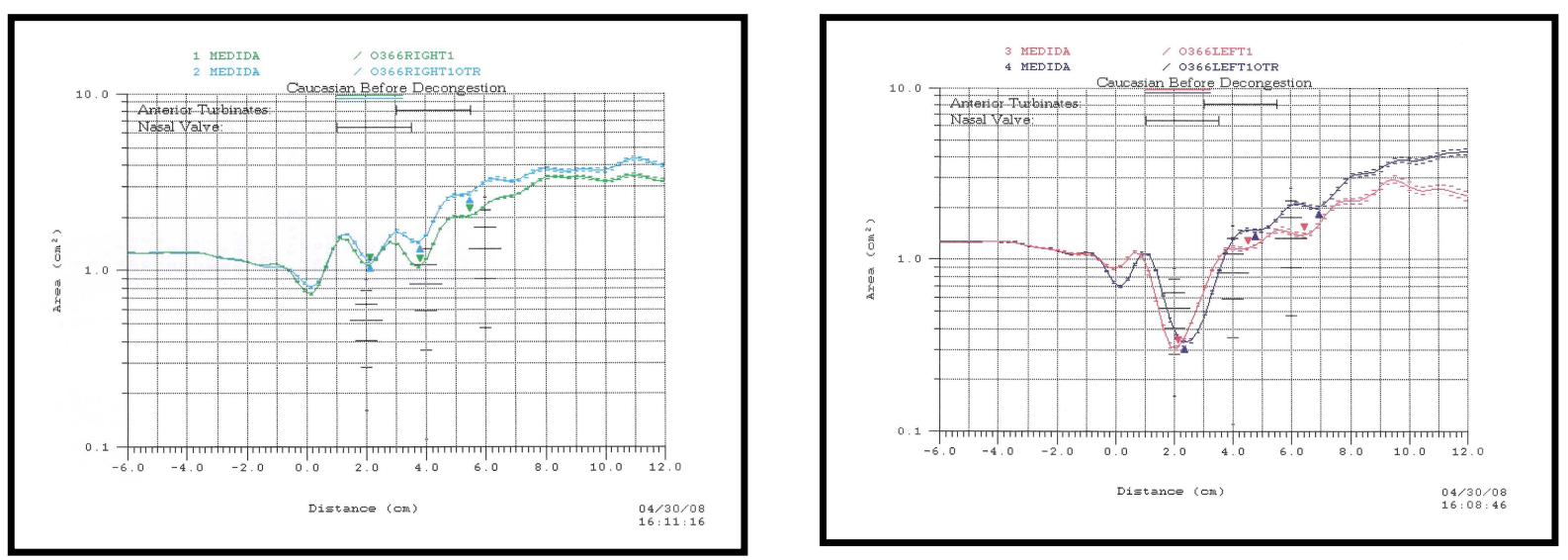

Antes da vasoconstrição nasal

Após a vasoconstrição nasal 

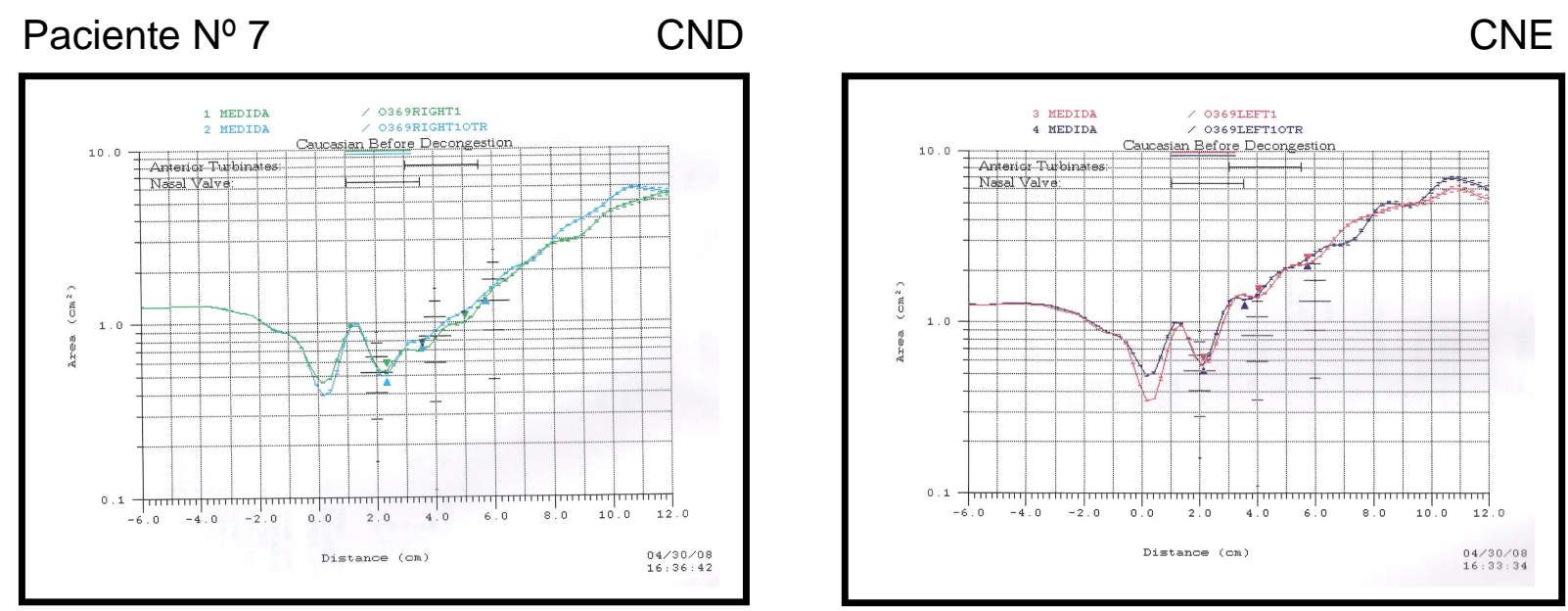

Paciente № $8^{*}$ CND

CNE
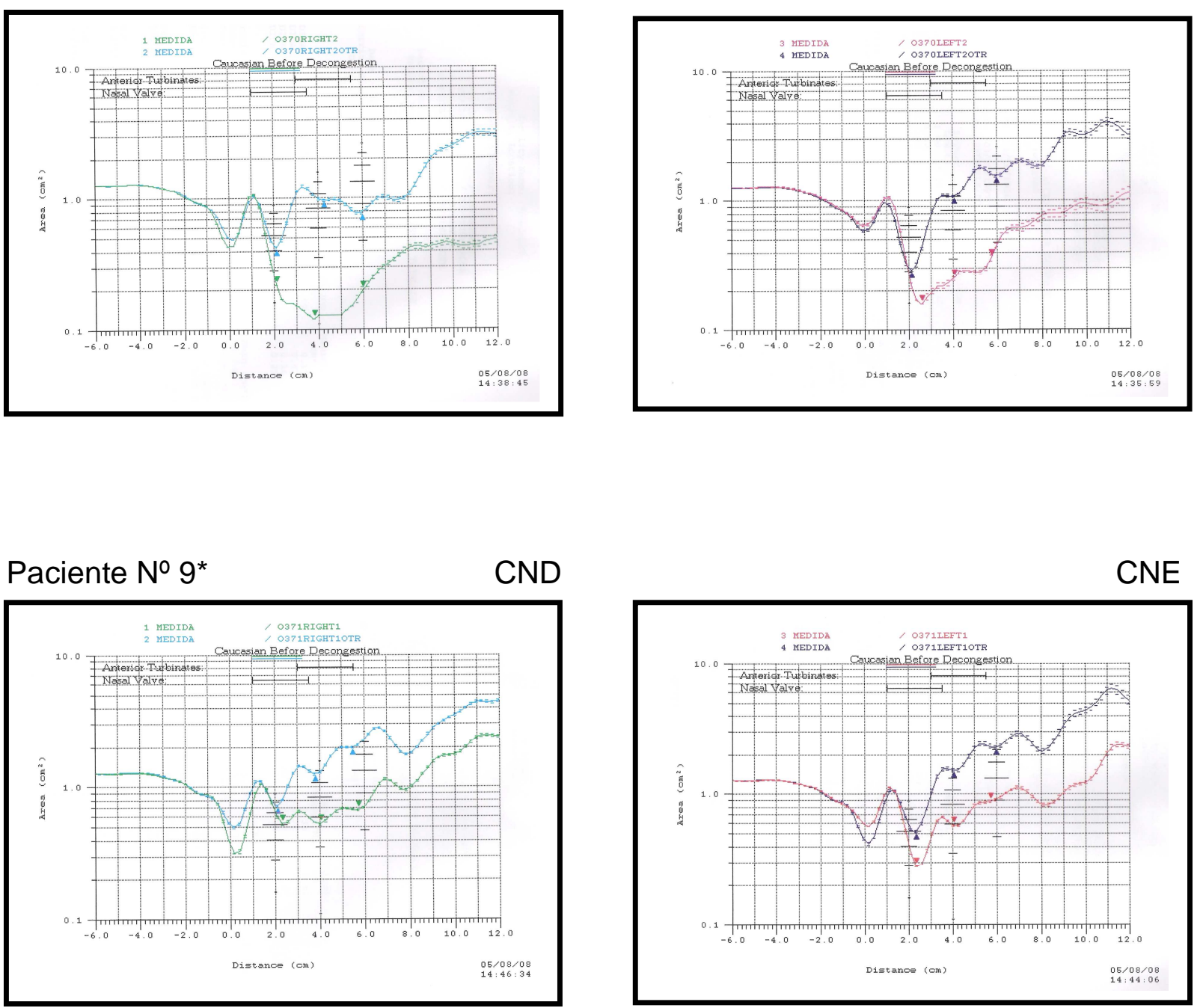

Antes da vasoconstrição nasal

Após a vasoconstrição nasal 

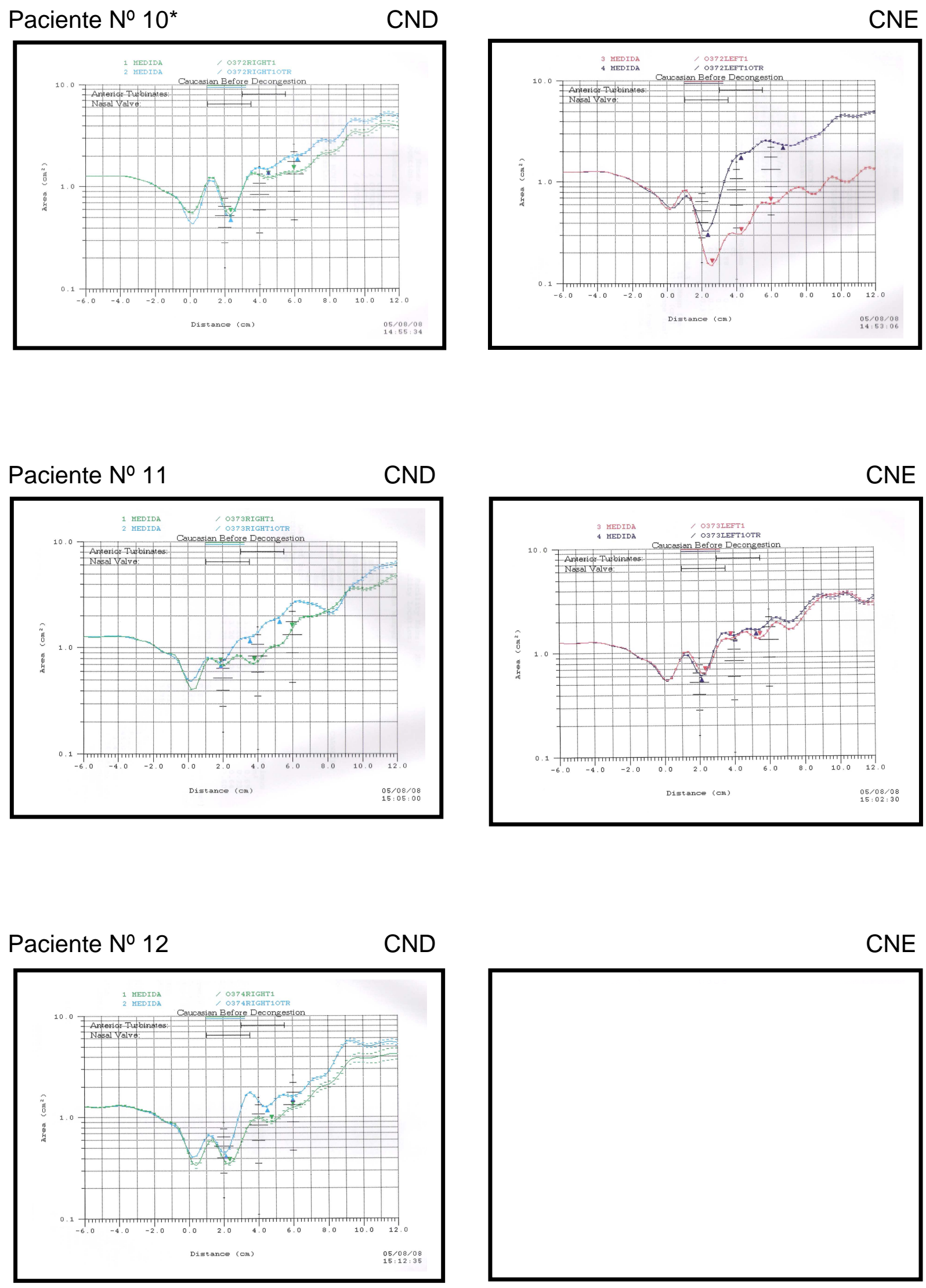

CNE

Antes da vasoconstrição nasal Após a vasoconstrição nasal 
ERROR: ioerror

OFFENDING COMMAND: image

STACK : 